\title{
Current state of Alzheimer's fluid biomarkers
}

\author{
José Luis Molinuevo ${ }^{1,2} \cdot$ Scott Ayton ${ }^{3} \cdot$ Richard Batrla $^{4} \cdot$ Martin M. Bednar $^{5} \cdot$ Tobias Bittner $^{6} \cdot$ Jeffrey Cummings $^{7}$. \\ Anne M. Fagan ${ }^{8} \cdot$ Harald Hampel $^{9,10,11,12} \cdot$ Michelle M. Mielke $^{13} \cdot$ Alvydas Mikulskis $^{14} \cdot$ Sid O' $^{\prime}$ Bryant $^{15}$. \\ Philip Scheltens ${ }^{16}$. Jeffrey Sevigny ${ }^{17}$. Leslie M. Shaw ${ }^{18}$. Holly D. Soares ${ }^{19}$. Gary Tong ${ }^{20}$. John Q. Trojanowski ${ }^{21}$. \\ Henrik Zetterberg $22,23,24,25 \cdot$ Kaj Blennow ${ }^{22,23}$
}

Received: 17 September 2018 / Revised: 5 November 2018 / Accepted: 7 November 2018 / Published online: 28 November 2018 (c) The Author(s) 2018

\begin{abstract}
Alzheimer's disease (AD) is a progressive neurodegenerative disease with a complex and heterogeneous pathophysiology. The number of people living with $\mathrm{AD}$ is predicted to increase; however, there are no disease-modifying therapies currently available and none have been successful in late-stage clinical trials. Fluid biomarkers measured in cerebrospinal fluid (CSF) or blood hold promise for enabling more effective drug development and establishing a more personalized medicine approach for $\mathrm{AD}$ diagnosis and treatment. Biomarkers used in drug development programmes should be qualified for a specific context of use (COU). These COUs include, but are not limited to, subject/patient selection, assessment of disease state and/or prognosis, assessment of mechanism of action, dose optimization, drug response monitoring, efficacy maximization, and toxicity/ adverse reactions identification and minimization. The core AD CSF biomarkers A $\beta 42$, $t$-tau, and $\mathrm{p}$-tau are recognized by research guidelines for their diagnostic utility and are being considered for qualification for subject selection in clinical trials. However, there is a need to better understand their potential for other COUs, as well as identify additional fluid biomarkers reflecting other aspects of AD pathophysiology. Several novel fluid biomarkers have been proposed, but their role in AD pathology and their use as AD biomarkers have yet to be validated. In this review, we summarize some of the pathological mechanisms implicated in the sporadic $\mathrm{AD}$ and highlight the data for several established and novel fluid biomarkers (including BACE1, TREM2, YKL-40, IP-10, neurogranin, SNAP-25, synaptotagmin, $\alpha$-synuclein, TDP-43, ferritin, VILIP-1, and NF-L) associated with each mechanism. We discuss the potential COUs for each biomarker.
\end{abstract}

Keywords Alzheimer's disease $\cdot$ Amyloid $\cdot$ Biomarker $\cdot$ Blood $\cdot$ Cerebrospinal fluid $\cdot$ Tau

\section{Introduction}

Worldwide, approximately 50 million people are living with dementia, with Alzheimer's disease (AD) comprising $60-70 \%$ of cases [391]. AD is a progressive, neurodegenerative disease characterized clinically by cognitive decline and behavioural disturbances and pathologically by the accumulation of amyloid beta $(\mathrm{A} \beta)$ plaques and neurofibrillary tangles formed by tau fibrils, together with degeneration of neurons and their synapses, glial activation, and neuroinflammation [37, 149, 314]. The incidence of AD increases with age, and the prevalence is growing as a result of the ageing of the population [6]. To date, no disease-modifying

Kaj Blennow

kaj.blennow@neuro.gu.se

Extended author information available on the last page of the article therapy (DMT) has been successful [18]. This lack of success may be partly explained by AD having a complex aetiology and considerable heterogeneity in its pathophysiology, and by limitations in past clinical trial designs, which have generally enrolled participants later in the course of the disease (e.g. mild-to-moderate AD), and which did not enrich for $\mathrm{A} \beta$-positive individuals, resulting in substantial misclassification (i.e. inclusion of participants without $A \beta$ pathology) [12, 241, 317].

Biomarkers hold promise for enabling more effective drug development in AD and establishing a more personalized medicine approach [126, 127, 314]; they may soon become essential in staging, tracking, and providing a more quantitative categorization of the disease, as well as for documenting the effect of potential therapeutics. These points are underscored in the 2018 draft guidance documents issued by both the US Food and Drug Administration (FDA) (Early 
Alzheimer's disease: developing drugs for treatment; draft guidance for industry) [96] and the European Medicines Agency's (EMA) Committee for Medicinal Products for Human Use (CHMP) (Guideline on the clinical investigation of medicines for the treatment of Alzheimer's disease) [78]. Fluid biomarkers have the potential to be easy to implement in clinical trials, and several biomarkers reflecting different pathophysiological mechanisms can be analyzed in the same sample. Furthermore, cerebrospinal fluid (CSF) or blood may provide a window for detection of some biomarkers that cannot be identified via brain imaging [125].

CSF represents a logical source for developing viable biomarkers in $\mathrm{AD}$ given its direct interaction with the extracellular space in the brain, thus potentially reflecting the associated pathophysiological alterations [32]. The overall safety record of lumbar puncture is strongly supported by extensive meta-analyses [76, 262]. However, fluid biomarkers are unable to reflect brain regional pathogeographies, which may be particularly important during early $\mathrm{AD}[47,281]$. Other limitations of CSF include the relative invasiveness of CSF collection by lumbar puncture, limited access and acceptability in some countries, the inability to collect samples from large populations especially if serial measures are needed, concerns over slowing for subject recruitment into clinical trials, educational gaps on the safety of lumbar puncture, development and validation of CSF assays, and clinical utility. Some of the limitations of CSF have prompted research efforts into the development and validation of diagnostic or prognostic AD biomarkers in blood [215, 216]. Indeed, the Biofluid Based Biomarkers Professional Interest Area [of the Alzheimer's Association International Society to Advance Alzheimer's Research and Treatment (ISTAART)], an international working group of leading AD scientists, has been established to scrutinize potential blood-based biomarkers and to provide standards for the collection of biofluids [128, $140,268,269]$.

The ideal fluid biomarker for $\mathrm{AD}$ would be reliable, reproducible, non-invasive, simple to measure, and inexpensive [360], as well as easy to implement into large populations such as clinical trials and the primary care setting. Importantly, biomarkers used in drug-development programmes should be qualified for a specific context of use (COU); these include (but are not limited to) patient/clinical trial diagnosis and subject selection, assessment of disease state and/or prognosis, assessment of mechanism of action, dose optimization, drug-response monitoring, efficacy maximization, and toxicity/adverse reaction identification and minimization [95]. For successful AD drug development, it is critical to ensure that subjects enrolled into clinical trials are those who have $\mathrm{AD}$ pathology and are most likely to progress along the disease continuum. Fluid biomarkers could have an important role in clinical trial subject selection (including subject enrichment or stratification) [123, 126, 127], and could be useful for measuring target engagement of the drug and the impact of the drug on the pathogenic mechanisms [184, 279]. Additionally, fluid biomarkers, especially blood biomarkers, could be used in early screening in primary care to identify potential clinical trial subjects and patients at risk of $\mathrm{AD}$, thereby improving early diagnosis and enabling longitudinal tracking of various disease indicators over extended periods of time [22, 128].

Currently, three core AD CSF biomarkers are included in research guidelines for $\mathrm{AD}$ and are being increasingly used in clinical trials as inclusion criteria and/or outcome measures: CSF amyloid beta 42 (A $\beta 42)$, total tau (t-tau), and tau phosphorylated at threonine 181 (p-tau) [75, 214, $217,247,298]$. These biomarkers have been validated as core CSF biomarkers of AD pathophysiology [33, 99, 122, 124]. Qualification opinions have also been published for CSF A $\beta 42$ and t-tau by the EMA, supporting their use as patient-selection tools [153]. Although these core biomarkers are now recognized for their diagnostic utility, there is a need to identify additional fluid biomarkers for other COUs such as subject enrichment, risk stratification, prognosis, and (eventually) drug-response monitoring, and to better understand the complex heterogeneity of AD pathology [78, 96]. Several novel biomarkers have been proposed; some have been extensively investigated, but they have yet to be validated and integrated into guidelines for use in clinical practice and drug development $[99,206]$.

This review summarizes some of the pathological mechanisms implicated in sporadic AD (Fig. 1) and highlights several established and novel fluid biomarkers associated with each mechanism. For each biomarker, a summary of published studies, the stage of assay development (Table 1), and the potential COU (Table 2) are discussed. Most of the fluid biomarkers examined in this review are CSF biomarkers, owing to the limited number of published studies on bloodbased biomarkers. It should be noted that unselected biomarker combinations ("panels") identified through "omics" technologies are not included; this topic has been recently reviewed elsewhere [46, 219, 222, 260].

\section{Alzheimer's disease pathological mechanisms}

Extracellular plaque deposits of $\mathrm{A} \beta$ peptides and intraneuronal tau-containing neurofibrillary tangles (NFTs) and neuropil threads (NTs), are the defining neuropathological features of $\mathrm{AD}$ brains [238, 314]. A $\beta$-plaque deposition is an insidious process that occurs over decades, well before symptoms emerge [156, 379]. Approximately one-third of people over the age of 65 years who are cognitively normal have $A \beta$-plaque deposition equivalent to that of someone 


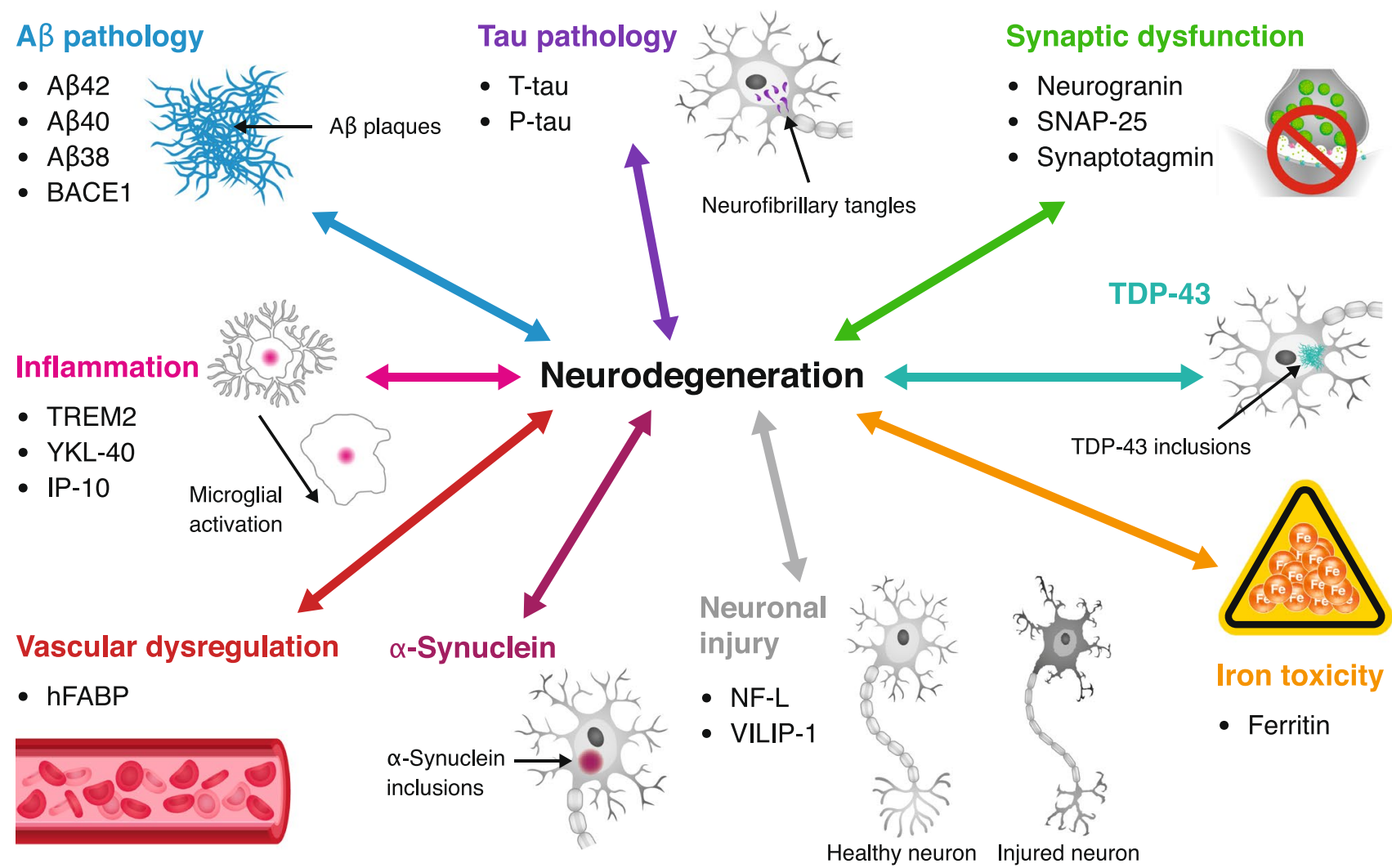

Fig. 1 Pathological mechanisms implicated in $\mathrm{AD}$ and associated fluid biomarkers. In this figure, the arrows reflect hypothetical relationships, not direct causal links between the pathological mechanisms and neurodegeneration. Only select pathological mechanisms (and associated biomarkers) of $\mathrm{AD}$ are represented. $A \beta 38$ amyloid beta 38, A 340 amyloid beta $40, A \beta 42$ amyloid beta $42, A D$ Alzheimer's disease, BACE1 $\beta$-site amyloid precursor protein cleav-

with AD [305]; the significance of this finding is a topic of intensive evaluation.

In $\mathrm{AD}$, comorbid pathology is often present and contributes to the clinical symptoms. For example, there is an increasing burden of cerebrovascular pathology as a function of age, and approximately $30 \%$ of $\mathrm{AD}$ patients have concomitant cerebrovascular disease [365]. In addition to plaques and tangles, more than half of $\mathrm{AD}$ patients also show widespread cortical Lewy bodies (LBs) and Lewy neurites formed by misfolded $\alpha$-synuclein like those found in patients with Parkinson's disease dementia (PDD) or dementia with Lewy bodies (DLB) [121, 207]. Conversely, approximately $40 \%$ of DLB patients have AD pathology as determined by their CSF-biomarker profile [199]. Furthermore, up to half of $\mathrm{AD}$ patients harbour transactive response DNA-binding protein 43 (TDP-43) inclusions that are characteristic of frontotemporal lobar degeneration (FTLD) and sporadic amyotrophic lateral sclerosis (ALS) [7, 50, 159]. Amylin deposits, which are found in the pancreas of most patients with type 2 diabetes mellitus, have also been found

ing enzyme $1, h F A B P$ heart-type fatty acid-binding protein, $I P-10$ interferon- $\gamma$-induced protein $10, N F-L$ neurofilament light, $P$-tau phosphorylated tau, SNAP-25 synaptosome-associated protein 25 , TDP-43 transactive response DNA-binding protein 43 , TREM2 triggering receptor expressed on myeloid cells 2, T-tau total tau, VILIP-1 visinin-like protein 1

in $\mathrm{AD}$ (and type 2 diabetes) brains [157]. Thus, although $\mathrm{AD}$ is typically characterized by $\mathrm{A} \beta$ plaques and NFTs, most $\mathrm{AD}$ patients have multiple pathologies and different types of brain proteinopathies [21]. In the Center for Neurodegenerative Disease Research (CNDR) Brain Bank at the University of Pennsylvania, only $35 \%$ of 247 autopsy-confirmed AD brains examined for the presence of tau, $\mathrm{A} \beta, \alpha$-synuclein, and TDP-43 deposits had only plaques and tangles as the underlying cause of dementia, while $22 \%$ had all four of these pathologies [300]. This finding emphasizes the urgent need for biomarkers that can indicate the presence of multiple pathologies in AD patients, with the methodological attributes of being reliable, accessible, and cost-efficient.

\section{$A \beta$ pathology}

The "amyloid cascade hypothesis", initially proposed in 1992 [134], but essentially embedded in the reports of the initial discovery of the partial $A \beta$ sequence in cerebral 


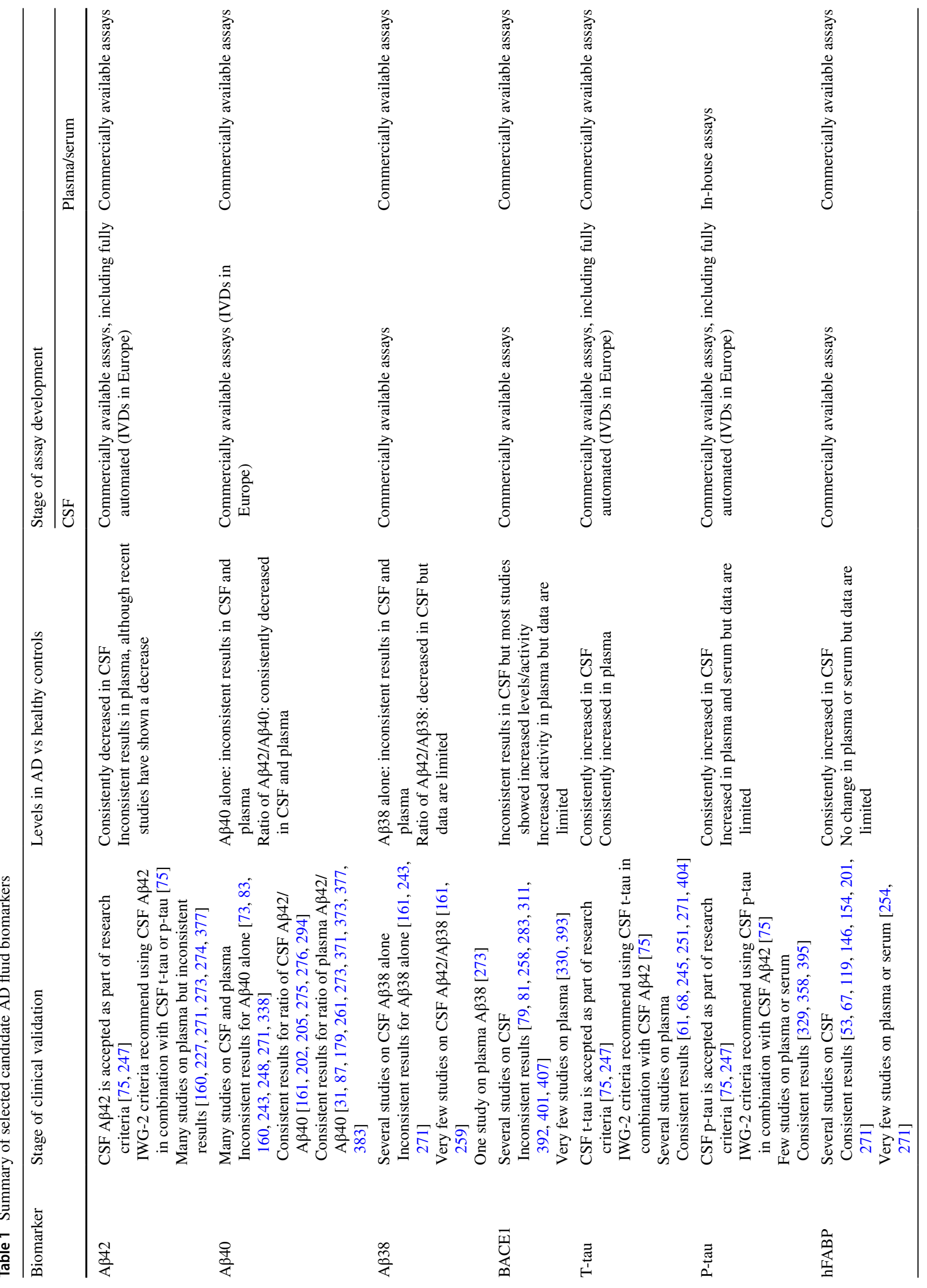




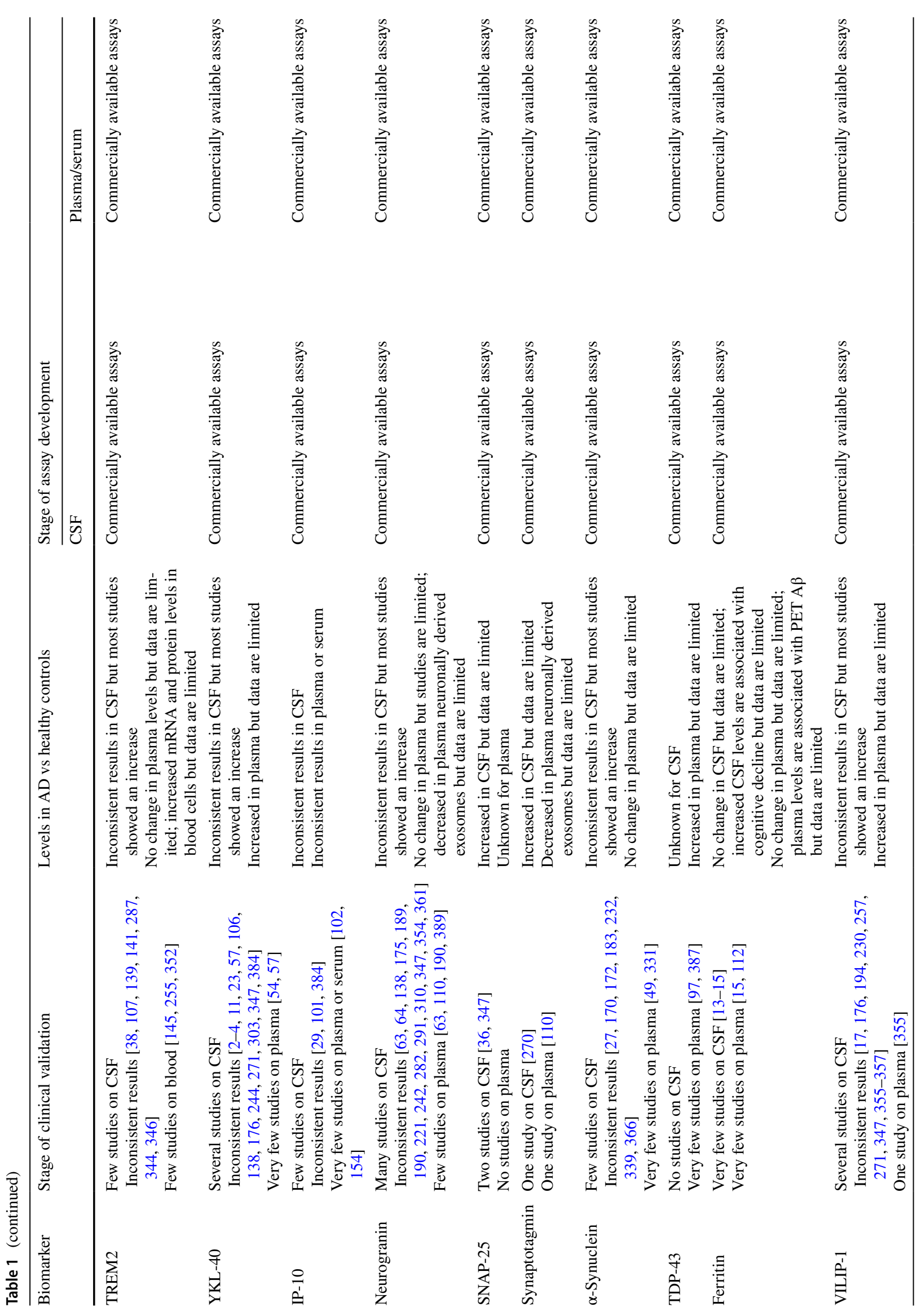


vessels $[108,109]$ and the whole $4 \mathrm{kDa} \mathrm{A} \beta$ peptide in plaques [239], is supported by genetic and biochemical data, and has been the dominant model of $\mathrm{AD}$ pathogenesis. The model is based on the gradual deposition of fibrillar $A \beta$ as diffuse plaques, which triggers an inflammatory response, altered ion homeostasis, oxidative stress, and altered kinase/ phosphatase activity, leading to the formation of NFTs and to widespread synaptic dysfunction and neuronal loss [320]. Notably, recent experimental evidence suggests that the $A \beta$ plaque environment can accelerate the templated spread of tau pathology [136].

Genetic data strongly implicate $A \beta$ in $A D$ pathogenesis $[315,390]$. Whether monomeric or aggregated forms are more relevant to the neurodegenerative process remains unknown. Recent reports indicate that soluble $A \beta$ oligomers may be more toxic than $A \beta$ neuritic plaques [320, 321], suggesting that other forms of $A \beta$ may be more relevant to measure. Phase 3 clinical studies of solanezumab, a monoclonal antibody $(\mathrm{mAb})$ that targets monomeric $\mathrm{A} \beta$, resulted in very modest slowing of clinical decline [72], whereas a Phase $1 \mathrm{~b}$ study of aducanumab, a mAb that targets soluble and insoluble forms of aggregated $A \beta$, demonstrated robust plaque reduction and a slowing of clinical decline $[42,323]$.

Fluid biomarkers of $A \beta$ metabolism and aggregation

\section{$A \beta$ peptides}

$\mathrm{A} \beta$ is generated as the result of the sequential cleavage of amyloid precursor protein (APP) by $\beta$-site amyloid precursor protein cleaving enzyme 1 (BACE1) and $\gamma$-secretase [45, 394]. The cleavage position of the $\gamma$-secretase in the transmembrane domain of APP is imprecise, resulting in the production of $A \beta$ peptides of variable length [166, 289]. Changes in some of these $A \beta$ species have been associated with $\mathrm{AD}$, as discussed below, but little is known about the changes over time in relation to clinical presentation.

\section{$A \beta 42$}

The 42-amino acid form of $A \beta, A \beta 42$, is a minor component of A $\beta$ peptides in the CSF [290] and plasma [277], but in $\mathrm{AD}$ brains, $\mathrm{A} \beta 42$ is the principal $\mathrm{A} \beta$ peptide in plaques $[113,155]$. Decreases in CSF A $\beta 42$ levels in AD patients were first reported by Motter et al. [256]. Several subsequent studies have consistently shown that CSF levels of A $\beta 42$ correlate inversely with plaque load as observed in autopsies and in vivo with positron emission tomography (PET) [82, $114,158,343,353]$. CSF A $\beta 43$ is also reported to decrease in $\mathrm{AD}$, but it has similar diagnostic accuracy to CSF $\mathrm{A} \beta 42$ $[39,193]$ so research has focused on the latter.

CSF A $\beta 42$, together with t-tau and p-tau, are biomarkers accepted as supportive of an AD diagnosis [75, 247] 
Table 2 Potential uses for selected candidate AD fluid biomarkers

\begin{tabular}{|c|c|c|c|c|}
\hline Biomarker & $\begin{array}{l}\text { Patient/clinical trial } \\
\text { subject selection }\end{array}$ & $\begin{array}{l}\text { Assessment of disease } \\
\text { state and/or prognosis }\end{array}$ & Target engagement & Other \\
\hline $\mathrm{A} \beta 42$ & $\checkmark^{*}$ & o* & $\circ$ & \\
\hline $\mathrm{A} \beta 40$ & of & of & $\circ$ & \\
\hline $\mathrm{A} \beta 38$ & of & o† & $\circ$ & \\
\hline BACE1 & $\circ$ & $\circ$ & & \\
\hline T-tau & $\sqrt{ } \pm$ & $\circ \pm$ & & $\square \Delta$ \\
\hline P-tau & $\sqrt{ } \pm$ & $\circ \pm$ & & $\square$ \\
\hline hFABP & o & $\circ$ & & \\
\hline TREM2 & o & & & \\
\hline YKL-40 & $\circ$ & $\circ$ & & \\
\hline IP-10 & o & & & \\
\hline Neurogranin & $\circ$ & $\circ$ & & $\square \Delta$ \\
\hline SNAP-25 & $\circ$ & & & $\Delta$ \\
\hline Synaptotagmin & $\circ$ & & & $\Delta$ \\
\hline$\alpha$-Synuclein & $\circ$ & & & \\
\hline TDP-43 & $\circ$ & $\circ$ & & \\
\hline Ferritin & $\circ$ & $\circ$ & & \\
\hline VILIP-1 & o & $\circ$ & & $\Delta$ \\
\hline NF-L & $\circ$ & $\circ$ & & $\square \Delta$ \\
\hline
\end{tabular}

$A \beta 38$ amyloid beta $38, A \beta 40$ amyloid beta $40, A \beta 42$ amyloid beta $42, A D$ Alzheimer's disease, $B A C E 1 \beta$-site amyloid precursor protein cleaving enzyme $1, h F A B P$ heart-type fatty acid-binding protein, $I P$ - 10 interferon- $\gamma$-induced protein $10, N F-L$ neurofilament light, $P$-tau phosphorylated tau, SNAP-25 synaptosome-associated protein 25, TDP-43 transactive response DNA-binding protein 43, TREM2 triggering receptor expressed on myeloid cells 2, T-tau total tau, VILIP-1 visinin-like protein 1

$\checkmark$ Accepted (validated) use

OPotential use, supportive data available

$\square_{\text {Speculative use for drug response monitoring, no supportive data available }}$

${ }^{\Delta}$ Speculative use for toxicity/adverse reactions minimization, no supportive data available

*Alone or when measured as a ratio with tau

${ }^{\dagger}$ When measured as a ratio with $\mathrm{A} \beta 42$

${ }^{ \pm}$Alone or when measured as a ratio with $\mathrm{A} \beta 42$

(Table 2), and evidence suggests they may be prognostic of disease progression in both cognitively normal individuals $[84,209]$ and those with mild cognitive impairment (MCI) $[5,9,91,133]$. CSF A $\beta 42$ has the potential to discriminate AD from FTLD but shows significant overlap with other non-AD dementias [80].

The development of automated assays to measure CSF A $\beta 42$ will reduce variability among samples and laboratories and make it easier to interpret results and implement this biomarker into routine clinical practice [295]. However, several unresolved issues remain when using CSF A $\beta 42$ in clinical trials. First, there needs to be a better understanding of how to interpret changes in CSF A $\beta 42$ levels in $\mathrm{AD}$ in response to DMTs, since this is likely to vary with the mechanism of action of the DMT and with the duration of treatment. It seems logical to measure $A \beta 42$ to help determine target engagement of drugs designed to reduce $\mathrm{A} \beta$ pathology $[88,208]$; however, some trials have reported changes in CSF A 442 but no improvement in clinical endpoints [298]. Furthermore, truncated, post-translationally modified fragments of $A \beta$ (e.g. pyroglutamate $A \beta 42$ ) may be more prone to pathogenic aggregation [25, 117], and consideration needs to be given to what forms of $A \beta 42$ are being measured. In addition, CSF A 442 remains relatively stable over time in patients with $\mathrm{AD}$ dementia and may have limited utility for monitoring disease progression in this group [34, 41, 367, 402]. Finally, CSF A $\beta 42$ measures are influenced by preanalytical factors such as the type of collection tube and number of freeze/thaw cycles [198, 284, 368], so it is essential to develop harmonized standard operating procedures for sample collection and handling, as established for biomarker studies in the Alzheimer's Disease Neuroimaging Initiative (ADNI) [326, 327].

There has been great interest in developing new techniques to measure $A \beta 42$ in blood. Although most studies have failed to show an association between plasma $A \beta 42$ alone and risk of $\mathrm{AD}$ or association with PET $\mathrm{A} \beta[227,271]$, recent studies using ultrasensitive analytical assays as well as fully automated immunoassays suggest that plasma $A \beta$ could be a useful screening biomarker. Using an ultrasensitive immunoassay technique (Simoa platform), levels of $A \beta 42$ and the ratio of $A \beta 42 / A \beta 40$ in plasma were shown to correlate with CSF levels and with $A \beta$ deposition measured by PET [160, 377], and plasma A $\beta 42 / A \beta 40$ associated with risk of progression to $\mathrm{MCI}$ or dementia in cognitively normal individuals with subjective cognitive decline [377]. 
Ovod et al. used mass spectrometry to demonstrate lower levels of plasma $A \beta 42$ and $A \beta 42 / A \beta 40$ in subjects with an $A \beta$-positive PET [273]. In addition to the use of novel technologies, plasma samples could be chemically treated to reduce degradation of $A \beta$ and improve the accuracy of plasma A $\beta$ measurements [278]. Recently, a fully automated immunoassay has been shown to detect plasma $A \beta 42$ and $\mathrm{A} \beta 40$ and accurately predict $\mathrm{A} \beta$-positivity (using the CSF $\mathrm{A} \beta 42 / 40$ ratio as reference standard) in cognitively normal, subjective cognitive decline, MCI and AD dementia patients [274].

In summary, CSF A $\beta 42$ is widely accepted and used as an $\mathrm{AD}$ biomarker, and both $\mathrm{CSF}$ and plasma $\mathrm{A} \beta 42$ continue to be intensively studied (Tables 1 and 2). CSF A $\beta 42$ is recognized as a core biomarker for AD diagnosis and is currently being considered by the FDA for qualification for subject selection in clinical trials (Table 2). It shows great promise as a biomarker for prognosis and has the potential to be used during drug trials to help assess target engagement. Plasma A $\beta 42$ may prove to be useful for subject/patient selection (screening) and research is ongoing. There are several commercially available assays, and for CSF A $\beta 42$, there are in vitro diagnostic (IVD) assays in Europe and fully automated assays.

\section{$A \beta 40$}

$\mathrm{A} \beta 40$ is the predominant form of $\mathrm{A} \beta$ peptide in the brain [322, 348, 349], CSF [290, 322], and plasma [277], but it does not appear to be as pathogenic as A $\beta 42$ [246]. A $\beta 40$ may have protective effects against $A \beta$ plaque formation [180] but it is the relative amount of $A \beta 40$ to $A \beta 42$ that may be more important than the absolute amounts of either peptide [188].

Research on CSF A $\beta 40$ and its correlation with AD dementia has shown inconsistent results [73, 248, 338], and a meta-analysis by Olsson et al. (data from 25 AD cohorts and 24 control cohorts) found only a minor association [271]. One study demonstrated an association between PET $\mathrm{A} \beta$ and CSF A $\beta 40$ levels (as well as CSF A $\beta 38$ and a combination of $\mathrm{A} \beta 40$ and $\mathrm{A} \beta 38$ ), although the association was stronger in individuals who were not carriers of the apolipoprotein-E $(A P O E) \varepsilon 4$ allele (a major genetic risk factor for AD) compared with $A P O E$ \&4-positive individuals [243]. CSF A $\beta 40$ may be useful (together with other biomarkers) in assessing target engagement of drugs such as BACE1 inhibitors, which selectively decrease $\mathrm{A} \beta 40$ and $\mathrm{A} \beta 42$ [173].

Although CSF A $\beta 40$ shows no consistent change in $\mathrm{AD}$ across studies, the ratio of CSF $\mathrm{A} \beta 42 / \mathrm{A} \beta 40$ has been shown to be a better predictor of $\mathrm{A} \beta$-positive PET than CSF $A \beta 42$ alone $[161,202,205,276]$, and comparable to the ratios of $\mathrm{t}-\mathrm{tau} / \mathrm{A} \beta 42$ and $\mathrm{p}-\mathrm{tau} / \mathrm{A} \beta 42$ [275, 294]. The $\mathrm{A} \beta 42 /$ $\mathrm{A} \beta 40$ ratio also appears to be better than CSF $\mathrm{A} \beta 42$ alone at distinguishing $\mathrm{AD}$ from non-AD dementias [73, 161]. Assessment of the CSF $\mathrm{A} \beta 42 / \mathrm{A} \beta 40$ ratio (together with $\mathrm{CSF}$ tau levels), instead of absolute levels of A $\beta 42$, may reduce misdiagnosis of cognitively normal individuals who are low $\mathrm{A} \beta$ producers and $\mathrm{AD}$ patients who are high $\mathrm{A} \beta$ producers [388], and to correct for inter-individual differences in CSF dynamics. The use of the $A \beta 42 / A \beta 40$ ratio can also help to reduce the impact of pre-analytical factors affecting $\mathrm{A} \beta 42$ (and A $\beta 40$ ) levels [104].

Studies on plasma $A \beta 40$ have had mixed results [160, 248], but the meta-analysis by Olsson et al. (data from 21 $\mathrm{AD}$ cohorts and 19 control cohorts) found no difference between $\mathrm{AD}$ and controls [271]. In a separate study, plasma $\mathrm{A} \beta 40$ did not correlate with $\mathrm{A} \beta$-positive PET in cognitively normal elderly individuals [83]. However, as with CSF, the ratio of $A \beta 42 / A \beta 40$ in plasma may be more useful than A $\beta 40$ alone; plasma $A \beta 42 / A \beta 40$ appears to be associated with an increased risk of progression to $\mathrm{AD}$ dementia [373, 377], and has shown promise in detecting A $\beta$-positivity [87, $261,273,274,371,377]$ and supporting the diagnosis of $\mathrm{AD}$ [31, 179, 383].

Overall, the data suggest that CSF or plasma $\mathrm{A} \beta 40$ alone has limited utility as a biomarker for AD diagnosis but could be used to confirm target engagement of certain drugs (Tables 1 and 2). The ratio of A $\beta 42 / \mathrm{A} \beta 40$ in CSF and plasma appears to be useful for subject/patient selection and may be superior to A $\beta 42$ alone (Table 2). Additionally, fluidbased $A \beta 42 / A \beta 40$ may be useful for prognosis but the data are limited. Commercial assays are available for fluid-based $\mathrm{A} \beta 40$ (and A $\beta 42$ ), and IVD assays are available for CSF $\mathrm{A} \beta 40$ (and $\mathrm{A} \beta 42$ ) in Europe. Ongoing research may lead to the availability of validated assays for blood-based $A \beta$ peptides in the future.

\section{Shorter $A \beta$ peptides}

A $\beta$ peptides shorter than 40 residues have been evaluated for potential utility as AD biomarkers. CSF A $\beta 38$ was included in the meta-analysis by Olsson et al. (eight studies were analyzed) but there was no difference between $\mathrm{AD}$ patients and control subjects [271]. However, CSF A $\beta 38$ has been found to correlate with PET A $\beta$ [243] and the ratio of CSF A $\beta 42 /$ $\mathrm{A} \beta 38$ is better at predicting $\mathrm{A} \beta$-positive PET than CSF A $\beta 42$ alone (and comparable to CSF A $\beta 42 / A \beta 40$ ) [161]. Furthermore, CSF A $\beta 42 / A \beta 38$ may be useful for differentiating between AD and DLB [259] and other non-AD dementias [161].

Another possible use for shorter $A \beta$ peptides is to demonstrate target engagement of drugs designed to affect $A \beta$ processing. For example, treatment with $\gamma$-secretase modulators is associated with a selective decrease in CSF A $\beta 42$ and $A \beta 40$ and an increase in $A \beta 38$ and $A \beta 37$ [272], so these 
biomarkers can be used to monitor patients receiving these drugs [341].

In summary, the evidence is limited for fluid-based $A \beta$ peptides $<40$ residues (Table 1 ) but commercial assays are available for CSF A $\beta 38$ and this biomarker has the potential to be used for subject/patient selection (in combination with $\mathrm{A} \beta 42$ ) and to help demonstrate target engagement of $\gamma$-secretase modulators (Table 2).

\section{$A \beta$ oligomers}

$\mathrm{A} \beta$ oligomers may play a key role in $\mathrm{AD}$ pathogenesis so the accurate detection and quantification of these species in CSF or blood could prove useful. Different technologies have been investigated and some have shown promise; examples include ELISA-based methods in CSF [143, 312, 396] and in plasma [381], single-molecule fluorescence microscopy in CSF [144], and a protein misfolding cyclic amplification assay method in CSF [308]. However, the overall findings have been inconsistent or unsatisfactory (reviewed by Schuster and Funke [318]). A number of methodological issues complicate measurement of $\mathrm{A} \beta$ oligomers, including the fact that the oligomeric state of these proteins varies and is affected by numerous factors.

\section{BACE1}

BACE1 has been shown to have several physiological functions in addition to APP processing [376, 394]. It is believed to be a major protease for cell surface proteolysis, contributing to $\sim 19 \%$ of identified shed proteins [186], including neuregulin, which has important functions in myelination [94]. Therefore, monitoring of BACE1 activity may be helpful in subjects receiving investigational BACE1 inhibitors.

CSF BACE1 activity and/or protein levels have been reported to be higher in subjects with MCI compared with $\mathrm{AD}$ patients or controls [407], and higher in $\mathrm{AD}$ patients versus controls [79, 258, 401]. Furthermore, the APOE $\varepsilon 4$ allele has been associated with increased CSF BACE1 activity in both AD and MCI subjects [81]. CSF BACE1 activity has also been shown to be higher in subjects with MCI who progressed to AD compared with those with stable MCI [401]. However, some studies have found no differences in BACE1 activity among AD, MCI, and control groups [283, 311], and one study found a decline in age-adjusted CSF BACE1 activity in AD patients compared with controls [392]. A recent study of elderly healthy subjects, who received chronic treatment with a BACE1 inhibitor, reported no change in CSF BACE1 levels after BACE1 inhibition, but did find strong correlations between levels of CSF BACE1 and its downstream markers including CSF A $\beta 42$ [362].

Plasma BACE1 has also been studied and has been shown to differentiate AD patients from controls [330, 393]. In addition, plasma BACE1 activity was found to be higher in subjects with $\mathrm{MCI}$ who progressed to $\mathrm{AD}$ compared with those with stable MCI or AD [330].

Overall, studies of BACE1 have given mixed results, and the association between BACE1 and AD remains unclear (Table 1). Recent research on BACE1 activity in plasma shows potential for subject/patient selection and prognosis (Table 2) but further studies are needed to validate the initial findings. Commercial assays are available to measure both BACE1 protein levels and BACE1 activity.

\section{Tau pathology}

Tau is a microtubule-associated protein comprised of six human isoforms predominantly located in the axon of neurons [177]. Neuronal and/or glial inclusions of tau can be detected in several neurodegenerative diseases, or "tauopathies", including AD [152], which may be characterized, to some extent, by their tau isoform profile [252]. The NFTs characteristic of $\mathrm{AD}$ are composed primarily of hyperphosphorylated tau $[19,196]$.

The abnormal phosphorylation of tau in $\mathrm{AD}$ has been hypothesized to be driven by A $\beta$ pathology $[19,177]$, although transgenic mice genetically engineered to develop A $\beta$ plaques do not develop tau tangles [197], except after intracerebral injections of AD brain-derived tau [136].

Hyperphosphorylation of tau has several pathogenic effects. It reduces tau's affinity for microtubules, and increases its likelihood to aggregate and fibrillize [309]. This leads to destabilization of microtubules with subsequent axonal transport failure and neurodegeneration, which can be offset or corrected by microtubule-stabilizing drugs [24, 40, 405]. Hyperphosphorylation of tau is thought to cause its mislocalization to somatodendritic compartments, where it interacts with $A \beta$ to cause synaptotoxicity through the excessive activation of the $N$-methyl-D-aspartate (NMDA) receptors [177]. In addition, hyperphosphorylation of tau is implicated in A $\beta$-induced cell death [200], possibly via a toxic gain of function mechanism [89].

Studies have shown that the density of neocortical NFTs has a stronger correlation than $\mathrm{A} \beta$ plaques with ante-mortem cognitive status (reviewed by Nelson et al.) [263]. This finding, together with the involvement of tau in neurodegenerative processes, has led to increasing interest in tau as a therapeutic target for $\mathrm{AD}$, with several compounds now in the early stages of clinical development $[19,60]$.

\section{Fluid biomarkers of tau pathology}

\section{T-tau and p-tau}

CSF t-tau and p-tau (tau phosphorylated at threonine 181), together with CSF A $\beta 42$, are considered core biomarkers to 
support AD diagnosis [75, 247] (Table 2). Both CSF t-tau and p-tau differentiate $\mathrm{AD}$ from controls, and given that CSF p-tau levels are normal in most other dementias, this biomarker is also important for differential diagnosis [33]. In Creutzfeldt-Jakob disease (CJD), CSF t-tau levels are very high (around 20 times higher than in AD), whereas p-tau is close to normal [297, 336]. As with CSF A 442, CSF tau has the potential to predict disease progression in cognitively unimpaired individuals [301] and in those with MCI [91, 285]. CSF t-tau has been shown to predict more aggressive disease progression in patients with $\mathrm{MCI}$ due to $\mathrm{AD}$ or in mild-to-moderate $\mathrm{AD}$ [65].

Although CSF t-tau and p-tau are well-established AD biomarkers, their utility for diagnosis of AD is markedly improved when measured in combination with $A \beta 42$ [75]. Hulstaert et al. found that the combination of CSF tau and A $\beta 42$ was better than the individual biomarkers at discriminating $\mathrm{AD}$ patients from controls or subjects with other neurological disorders [148]. In the initial CSF study of the ADNI cohort, a logistic regression model combining A $\beta 42$, $\mathrm{t}$-tau, and the APOE $\varepsilon 4$ allele count showed a stronger association with mild $\mathrm{AD}$ than $\mathrm{A} \beta 42, \mathrm{t}$-tau, $\mathrm{p}$-tau, or tau/A $\beta 42$ alone [326]. Both CSF t-tau/A $\beta 42$ and $p$-tau/A $\beta 42$ ratios have been shown to outperform any of the individual biomarkers for distinguishing individuals with an $\mathrm{A} \beta$-positive PET [85]. In a study of the Oxford Project to Investigate Memory and Ageing (OPTIMA) cohort, CSF t-tau/A $\beta 40$ and $\mathrm{p}$-tau/A $\beta 42$ were the best discriminators of autopsy-confirmed AD from controls [319]. The combination of CSF tau and $\mathrm{A} \beta 42$, in particular, $\mathrm{p}$-tau/A $\beta 42$, has also shown promise for differentiating AD from other dementias [299, 319].

The combination of tau and $\mathrm{A} \beta$ markers has also demonstrated their utility for predicting disease progression. CSF $\mathrm{t}$-tau/A $\beta 42$ and $\mathrm{p}$-tau/A $\beta 42$ have been shown to predict cognitive decline in cognitively normal individuals [84], and the combination or ratios of tau ( $\mathrm{t}$-tau or $\mathrm{p}$-tau) and $\mathrm{A} \beta 42$ have been shown to be better at predicting progression from $\mathrm{MCI}$ to AD than the individual biomarkers [91, 374]. Furthermore, the EMA approved CSF A $\beta 42 / \mathrm{t}$-tau for use as an enrichment biomarker in a study of a $\gamma$-secretase inhibitor [77]. More recently, the synergistic interaction between CSF p-tau and $A \beta$ imaging was found to be associated with the progression from MCI to AD dementia [280].

CSF t-tau and p-tau are frequently measured in clinical trials but, as with CSF A $\beta 42$, the relationship between clinical endpoints or therapeutic drug (interventional) response and these biomarkers is unclear [298], owing to their small longitudinal variation $[34,41]$ and the lack of DMTs that precludes testing their performance. Other challenges include variability in measured values due to pre-analytical and analytical factors, and the lack of consensus on cut-off values [98]. However, it is feasible that CSF tau could be used to assess target engagement of tau-targeted drugs [174, 363].

In addition to the CSF tau biomarkers, plasma tau has also been evaluated and has shown potential for clinical utility. The meta-analysis by Olsson et al. (data from six AD cohorts and five control cohorts) found an association between plasma t-tau and $\mathrm{AD}$ [271]; however, no significant difference in plasma t-tau has been reported between MCI subjects and controls [61, 245, 404]. Elevated plasma t-tau is associated with lower grey matter density but the brain atrophy pattern associated with plasma t-tau is different from that of CSF t-tau [68]. Longitudinally, higher levels of plasma t-tau have been associated with greater cognitive decline and risk of MCI [245, 251]. Notably, the relationship between plasma t-tau and cognition was independent of elevated brain A $\beta$ [251]. These findings suggest that plasma $\mathrm{t}$-tau could be useful as a screening tool or a prognostic marker for non-specific cognitive decline in cases where acute central nervous system (CNS) injury has been ruled out. Blood-based p-tau has also been measured in a few recent studies and found to be elevated in $\mathrm{AD}$ patients [329, $358,395]$ and MCI subjects [329, 395] compared with controls. In addition, platelet-derived tau has been explored, and preliminary studies suggest that the ratio of high molecular weight to low molecular weight tau is higher in $\mathrm{AD}$ than in controls [264, 337]. However, the role of platelet-derived tau is not clear; it could either be a confounder or help to clarify the relationship between central and peripheral compartment tau measurements.

Although most tau biomarker research has focused on $\mathrm{t}$-tau and p-tau, studies suggest that a variety of other tau peptides and fragments can be detected in CSF [250] and in serum [150], and some may have potential as AD biomarkers. For example, one study found that 11 (of 47) different tau phosphopeptides were upregulated in $\mathrm{AD}$ patients relative to controls [306], while another study found that non-phosphorylated tau also has potential as a diagnostic biomarker [204]. These initial studies may lead to further research into novel tau biomarkers, which may be especially helpful in the development of tau-directed therapies.

In summary, CSF t-tau and p-tau are widely accepted and used in $\mathrm{AD}$ research (Tables 1 and 2). They are recognized as core biomarkers to support the diagnosis of $\mathrm{AD}$ and are currently being considered for qualification by the FDA for subject selection in clinical trials (Table 2). CSF tau also shows promise as a biomarker for prognosis and target engagement. Commercial assays are available for both CSF $\mathrm{t}$-tau and p-tau, including IVD assays in Europe and fully automated assays. There has been recent renewed interest in plasma t-tau, which shows potential for subject/patient selection (screening) and for prognosis (Table 2). In addition, research into other tau biomarkers (blood-based p-tau, 
platelet-derived tau, tau peptides/fragments) is ongoing but is still in its early stages.

\section{Vascular dysregulation}

Concurrent cerebrovascular disease is more common in $\mathrm{AD}$ than in most other neurodegenerative disorders [365] and vascular dysregulation as a contributing factor to $\mathrm{AD}$ has been a long-standing hypothesis for AD pathogenesis [296, 340]. The time sequence of the impact of vascular dysregulation has been debated, but recent work supports the possibility that these changes may be an early pathological event that precedes $A \beta$ pathology. The spatiotemporal changes in various neuroimaging, plasma, and CSF biomarkers from the ADNI cohort, suggest that vascular dysregulation is the earliest and strongest pathological factor associated with late-onset $\mathrm{AD}$, followed by $\mathrm{A} \beta$ deposition, glucose metabolism dysregulation, functional impairment, and grey matter atrophy [154].

Vascular dysregulation reduces oxygen and nutrient supply to the brain, causing cell damage and dysfunction of the blood-brain barrier, which lead in turn to neurotoxic effects such as oxidative stress and inflammation [69]. The hypoxic conditions are thought to increase the accumulation of $\mathrm{A} \beta$ peptides through the activation of BACE1 and $\gamma$-secretase [307]. Additionally, disruption of the blood-brain barrier has been suggested to impair clearance of $A \beta$ peptides from the brain [48].

\section{Fluid biomarkers associated with the vascular system}

\section{hFABP}

Heart-type fatty acid-binding protein (hFABP), which has been proposed as a biomarker of myocardial infarction [1], was the CSF analyte with the highest degree of abnormalities in the spatiotemporal analysis of the ADNI cohort [154]. It was also identified as a potential AD biomarker in an independent cohort [146]. FABP showed associations with CSF A $\beta 42$ levels but not with cognitive impairment [201]. In the meta-analysis by Olsson et al., CSF hFABP had a moderate association with $\mathrm{AD}$ (data from five $\mathrm{AD}$ and control cohorts), with a lower degree of change in $\mathrm{AD}$ versus controls than seen for t-tau [271]. CSF hFABP has also been shown to predict progression from $\mathrm{MCI}$ to $\mathrm{AD}$ [119], correlate with brain atrophy among individuals with low CSF A $\beta 42$ [67], differentiate AD and DLB from Parkinson's disease (PD) and other neurological diseases [53], and correlate with cognitive impairment in a cohort of patients with different neurodegenerative diseases [53]. The source of hFABP in CSF is uncertain but it is highly expressed in the brain where hFABP levels are second only to levels in muscle tissues (https://www.proteinatlas.org/ENSG000001 21769-FABP3/tissue).

Serum hFABP was included in the meta-analysis by Olsson et al. and showed no association with AD (data from two $\mathrm{AD}$ and control cohorts) [271]; one study suggested it may be useful for differentiating between AD and DLB when measured as a ratio with CSF tau [254].

In summary, recent data for hFABP suggest that it may play a more important role in $\mathrm{AD}$ than previously thought (Table 1). CSF hFABP could be useful for both subject/ patient selection and prognosis (Table 2) but further studies are needed to confirm these hypotheses. Commercial assays are available for CSF and serum hFABP.

\section{Inflammation/glial activation}

Inflammation has been proposed as a contributor to $\mathrm{AD}$ pathogenesis [37, 44]. A $\beta$ plaques and NFTs induce an immune response in the brain, which is characterized by activated glial cells [37]. Microglia and astrocytes are the two main types of glial cells implicated in the pathogenesis of AD [37]. Microglia, the resident immune effector cells of the CNS, are important for brain homeostasis as well as immune responses [52]. Astrocytes are the most abundant type of glial cell in the CNS. They have important roles in homeostasis, synaptogenesis, signal transmission, and synaptic plasticity, and provide trophic and metabolic support to neurons [342].

The activation of glial cells serves to protect the brain; however, uncontrolled and prolonged activation can lead to detrimental effects that override the beneficial effects [37]. In this condition, glial cells lose some of their homeostatic functions and acquire a pro-inflammatory phenotype. The release of pro-inflammatory molecules, reactive oxygen species, and nitric oxide contribute to neuronal cell death. In addition, pro-inflammatory molecules increase $\mathrm{A} \beta$ synthesis as well as tau hyperphosphorylation [37].

\section{Fluid biomarkers of inflammation/glial activation}

\section{TREM2}

Triggering receptor expressed on myeloid cells 2 (TREM2) is expressed by many cells of the myeloid lineage, including microglial cells in the CNS, and has several physiological functions including the regulation of myeloid cell number, phagocytosis, and inflammation [162]. TREM2 expression is upregulated in $\mathrm{AD}$ brains, where it may have a protective effect in the early stages, through the phagocytic clearance of $A \beta$, but a pathogenic effect in the later stages, through activation of the inflammatory response [162]. Rare TREM2 
gene variants have been associated with an increased risk of developing AD [59, 116, 304, 332]. TREM2 haplodeficiency in mice and humans has been associated with increased axonal dystrophy and $\mathrm{p}$-tau accumulation around $\mathrm{A} \beta$ plaques [400].

A soluble variant, sTREM2, can be detected in CSF and has the potential to be used as a biomarker for AD. One study found that CSF sTREM2 levels were increased in autosomal dominant AD mutation carriers 5 years before expected symptom onset but after initial $\mathrm{A} \beta$ deposition (as measured by PET) and changes in CSF A $\beta 42$ and t-tau [344]. Some studies have found slightly higher CSF sTREM2 levels in $\mathrm{AD}[38,141,287,346]$ and MCI groups [38] compared with controls, and in subjects with MCI due to AD compared with other $\mathrm{AD}$ groups (preclinical $\mathrm{AD}$ or $\mathrm{AD}$ dementia) [346]. However, one study found no difference between patients with $\mathrm{AD}$ or MCI and cognitively normal controls [139]. In patients with MCI, elevated CSF sTREM2 levels correlated with increased grey matter volume and reduced diffusivity, suggesting a role for TREM2 in the regulation of the neuroinflammatory response in early AD [107].

Levels of TREM2 mRNA in peripheral blood mononuclear cells and TREM2 protein expression on monocytes have been reported to be higher in patients with AD than in controls, and inversely correlated with cognitive performance [145]. In the same study, there was also a trend for upregulation of TREM2 protein on granulocytes and in plasma but this was not statistically significant [145]. Subsequent studies by other groups also found increased peripheral TREM 2 mRNA expression in AD compared with controls [255, 352].

In summary, a few studies have observed increased levels of CSF sTREM2 and peripheral TREM2 expression in AD (Table 1), suggesting possible use in subject/patient selection (Table 2) but additional research is required to validate these findings. Commercial assays are available for the measurement of TREM2 protein.

\section{YKL-40}

YKL-40 (or chitinase-3-like protein 1) is upregulated in a variety of inflammatory conditions and cancers, and may have a role in promoting inflammation and angiogenesis [211]. In AD, YKL-40 is expressed in astrocytes near $A \beta$ plaques [57] and correlates positively with tau pathology [293], suggesting a role for YKL-40 in the inflammatory response in $\mathrm{AD}$ and other tauopathies.

Several studies have shown that CSF YKL-40 levels are higher in $\mathrm{AD}$ patients compared with controls $[4,11,23,57$, $176,303,384]$, and in the late preclinical AD stages compared with early preclinical stages [2]. The meta-analysis by Olsson et al. found that the degree of increase is modest (data from six AD cohorts and five control cohorts) compared with the change in neuronal proteins such as t-tau and neurofilament light (NF-L) [271]. However, a recent study of the ADNI cohort found no significant difference between the $\mathrm{AD}$ and cognitively normal groups, although levels were higher in AD versus MCI A $\beta$-negative (based on CSF A 342 ) subjects [347]. Longitudinally, all groups showed an increase in CSF YKL-40 over time, but the change was statistically significant only in the MCI A $\beta$-positive group (mean follow-up was 4 years) [347]. CSF YKL-40 levels have been shown to correlate with neuroimaging parameters, including cortical thickness in AD-vulnerable areas in subjects who were A 342 -positive (by CSF) [3] and grey matter volume in $A P O E$ \& 4 carriers [106].

Higher levels of CSF YKL-40 and YKL-40/A $\beta 42$ ratio have been associated with increased risk of progression from normal cognition to MCI [57]. Levels of CSF YKL40 have been found to predict progression from MCI to AD and increase longitudinally in MCI and AD patients but not in cognitively normal individuals [176]. CSF YKL-40 has also been shown to differentiate AD from DLB, PD [384], FTLD [23], and non-AD MCI [138], although one early study found no differences among diagnostic groups [244].

Plasma YKL-40 has also been assessed as an AD biomarker, and elevated levels have been reported in patients with mild AD [57] and early AD [54] compared with controls. However, plasma YKL-40 did not demonstrate utility for predicting cognitive decline [57].

In summary, the available evidence supports a role for CSF YKL-40 as a biomarker of neuroinflammation or astrogliosis in $\mathrm{AD}$ and other neurodegenerative diseases (reviewed by Baldacci et al. [20]), with the potential to aid subject/patient selection and prognosis (Tables 1 and 2). Plasma YKL-40 could also be useful for subject/patient selection, but further studies are needed. Commercial assays are available.

\section{Other inflammatory markers}

Interferon- $\gamma$-induced protein 10 (IP-10), which has roles in angiogenesis as well as inflammation and is secreted by a variety of cells [10, 223], has been reported to be increased in the CSF of patients with MCI and mild AD but not in severe AD [101]. However, in another study, IP-10 levels were not increased in the AD group [384]. In a recent study in asymptomatic older adults, increased levels of CSF IP-10 were associated with increased levels of CSF t-tau and p-tau [29].

IP-10 was the plasma analyte with the highest degree of abnormalities in a spatiotemporal analysis of biomarkers from the ADNI cohort [154]. However, a previous study found no association between serum IP-10 and AD [102].

Overall, very few studies have investigated IP-10 in AD and the results have been mixed (Table 1). Potentially, CSF 
or blood-based IP-10 could support subject/patient selection (Table 2), but further research is warranted to clarify the role of IP-10 in AD. Commercial assays are available.

Many other inflammatory markers have been investigated for their potential use as biomarkers for $\mathrm{AD}$, but results have been inconsistent [142, 350]. In a meta-analysis of 40 studies on blood and 14 on CSF, AD patients had higher levels of interleukin (IL)-6, tumour necrosis factor (TNF)- $\alpha$, IL- $1 \beta$, transforming growth factor- $\beta$ (TGF- $\beta$ ), IL- 12 , and IL-18 in blood, and higher levels of TGF- $\beta$ in CSF, compared with controls [350]. In a more recent meta-analysis of 175 studies on blood, increased IL-1 $\beta$, IL-2, IL-6, IL-18, interferon- $\gamma$, homocysteine, high-sensitivity $\mathrm{C}$ reactive protein, $\mathrm{C}-\mathrm{X}-\mathrm{C}$ motif chemokine-10, epidermal growth factor, vascular cell adhesion molecule- 1 , TNF- $\alpha$ converting enzyme, soluble TNF receptors 1 and 2, $\alpha 1$-antichymotrypsin and decreased IL-1 receptor antagonist and leptin were found in patients with AD compared with controls [191]. These findings strengthen the evidence that $\mathrm{AD}$ is accompanied by inflammatory responses, although the effects of age and sex and the precise roles of different inflammatory mediators are still to be established. A more systematic, within- and betweensubject, rigorous longitudinal evaluation may improve the utility of inflammatory markers in AD and other neurodegenerative diseases.

\section{Synaptic dysfunction}

Synaptic dysfunction and synapse loss are early events in AD pathogenesis [167, 218, 359]. Notably, hippocampal synapse loss and impaired synaptic function were detected in 3-month-old tau transgenic mice, when pathological tau was detectable biochemically but before microscopically visible neurofibrillary tau tangles emerged [397]. The level of synaptic loss in post-mortem brains has been found to correlate with pre-mortem cognitive function in individuals with MCI or early AD $[62,313]$. The synaptic pathology in $\mathrm{AD}$ is found throughout the neuropil, without any clear accentuation in relation to plaques [30, 235]. Importantly, the synaptic loss in $\mathrm{AD}$ is more severe than the neuronal loss in the same cortical region [137, 237]. A PET tracer has recently been developed that binds to synaptic vesicle glycoprotein $2 \mathrm{~A}$ (SV2A) and can be used to quantify synaptic density in vivo; this could be used to complement existing $\mathrm{AD}$ imaging tools in the future [93].

Evidence suggests that NMDA receptors are central to the synaptic dysfunction observed in AD. Overstimulation of NMDA receptors triggers an excessive influx of calcium, which in turn can lead to a series of downstream events that culminate in synaptic dysfunction and apoptosis [167, 369]. $\mathrm{A} \beta$ oligomers are thought to contribute to NMDA activation, possibly by causing an aberrant rise in extrasynaptic glutamate levels [369].

\section{Fluid biomarkers of synaptic dysfunction}

\section{Neurogranin}

Neurogranin is predominantly expressed in dendritic spines and is involved in post-synaptic signalling pathways through the regulation of the calcium-binding protein calmodulin [70]. Animal models and genetic studies have linked neurogranin to cognitive function and synaptic plasticity [70]. Notably, CSF neurogranin has been proposed as a marker of synaptic degeneration [361] and, together with other synaptic proteins, holds promise to serve as a novel candidate marker for AD [218].

CSF neurogranin levels are higher in AD [63, 175, 190, $221,242,291,310,347,354,361]$ or MCI patients [291, 347] compared with controls or non-AD dementia patients [354]. Higher levels of CSF neurogranin have been reported in AD compared with MCI [138, 291], although there was no significant difference between $\mathrm{AD}$ and MCI A $\beta$-positive (based on CSF A 442 ) groups in a recent study of the ADNI cohort [347]. Also in the ADNI study, CSF neurogranin levels decreased longitudinally in the $\mathrm{AD}$ group (mean followup was 4 years) but there was no significant longitudinal change in any other group [347]. Neurogranin is processed to a series of C-terminal peptides before release into the CSF [190], but the relevance of the individual peptides is unknown. However, one study that used an assay specific for C-terminally truncated neurogranin observed increased levels in MCI patients but no significant difference between AD patients and controls [64]. CSF neurogranin has been shown to predict disease progression in several studies [175, 189, 291, 354] including future cognitive impairment in cognitively normal controls [354]. In addition, CSF neurogranin levels have been found to correlate with brain atrophy but only in individuals with $A \beta$ pathology [282].

To date, no significant differences have been reported in plasma levels of neurogranin between patients with $\mathrm{AD}$ and controls $[63,190]$. However, levels of neurogranin in neuronally derived exosomes in plasma have been found to be lower in AD patients compared with controls [110, 389], as well as in MCI subjects who progressed to AD compared with stable MCI subjects [389].

Overall, the available data indicate that CSF neurogranin (and potentially, plasma neuronally derived exosomes) could be useful as an $\mathrm{AD}$ biomarker for subject/patient selection and prognosis (Tables 1 and 2), although results may vary depending on the neurogranin fragment being measured (full-length vs C-terminal peptides and C-terminus intact vs truncated). Commercial assays are available. 


\section{SNAP-25 and synaptotagmin}

The exocytosis of synaptic vesicles for neurotransmitter release is a complex process, mediated by several proteins including the SNARE (soluble $N$-ethylmaleimide-sensitive factor attachment protein receptor) complex and the calcium sensor protein synaptotagmin [131]. Post-mortem studies on AD brains have shown altered levels of several synaptic proteins, including synaptosome-associated protein 25 (SNAP-25), a component of the SNARE complex [74], and synaptotagmin [236, 351].

CSF levels of SNAP-25 [36, 347] and synaptotagmin [270] have been assessed and found to be elevated in patients with AD or MCI compared with controls. In a study of the ADNI cohort, baseline CSF SNAP-25 levels were higher in $\mathrm{AD}$ and $\mathrm{MCI} \mathrm{A} \beta$-positive (based on CSF $\mathrm{A} \beta 42$ ) groups than the cognitively normal (A $\beta$-positive or -negative) and $\mathrm{MCI}$ A $\beta$-negative groups [347]. CSF SNAP-25 levels decreased longitudinally in the $\mathrm{AD}$ group (mean follow-up was 4 years) but there was no significant longitudinal change in any other group [347]. No studies have been published to date on blood-based SNAP-25, but synaptotagmin levels in plasma neuronally derived exosomes have been reported to be lower in AD patients than in controls [110]. The data are limited but suggest there could be a role for the synaptic proteins, SNAP-25 and synaptotagmin, as AD biomarkers for subject/ patient selection (Tables 1 and 2). Commercial assays are available for both SNAP-25 and synaptotagmin.

\section{a-Synuclein pathology}

$\alpha$-Synuclein is an abundant neuronal protein, predominantly localized in the presynaptic terminals, and involved in vesicle fusion and neurotransmitter release [181]. Aggregates of $\alpha$-synuclein are the main component of LBs, which are intracellular inclusions characteristic of certain neurodegenerative diseases termed $\alpha$-synucleinopathies [181]. Primary $\alpha$-synucleinopathies include PD, PDD, DLB, and multiple system atrophy [181]; however, $\alpha$-synuclein aggregates are also found in approximately half of sporadic AD brains [121] and Down's syndrome brains with concomitant AD pathology [213], and in almost all cases of familial AD with PSEN 1 mutations [203].

$\alpha$-Synuclein oligomers have been shown to have multiple toxic effects including inflammation, synaptic dysfunction, compromised cell membrane integrity, and impaired intracellular protein degradation $[151,406]$. Furthermore, there is growing evidence that $\alpha$-synuclein may act in a prion-like manner such that misfolded $\alpha$-synuclein can be propagated from cell to cell $[35,118,164,370]$, even in wild-type nontransgenic mice [229]. The relationship between AD pathology and $\alpha$-synuclein is unclear, although studies suggest that $\alpha$-synuclein can act synergistically with both tau [105] and A $\beta$ [234] to promote their aggregation and accumulation.

\section{Fluid biomarkers of a-synuclein pathology}

\section{a-Synuclein}

Although CSF $\alpha$-synuclein was developed as a candidate biomarker for PD, levels of CSF $\alpha$-synuclein have been found to be higher in patients with MCI [183] and AD [183, $232,339]$ compared with controls. However, in one study, no differences were reported between diagnostic groups except for higher levels in rapid progressors (MCI patients who developed $\mathrm{AD}$ during the 2-year study and had a short duration of symptoms before the study) [27]. CSF $\alpha$-synuclein shows a strong correlation with CSF $t$-tau and a weaker correlation with p-tau in $\mathrm{AD}$, but a subset of patients in the ADNI cohort had a mismatch—high p-tau accompanied by low $\alpha$-synuclein levels-it was hypothesized that this CSF signature could represent concomitant LB pathology in AD patients [366].

CSF $\alpha$-synuclein has been assessed as a biomarker in PD and other neurodegenerative diseases $[66,171,253]$ and is a major focus area (together with tau and $A \beta$ ) of the Parkinson's Progression Marker Initiative (PPMI) [168, 169]. $\alpha$-Synuclein in plasma [212], and even in salivary secretions [380], has been investigated in PD.

CSF $\alpha$-synuclein levels have been reported to be slightly lower in PD compared with AD [253] or controls [66, 168, $169,253]$. CSF $\alpha$-synuclein levels were lower in DLB patients compared with AD patients in some studies [172, 253, 339], most often with a large overlap between the diagnostic groups, but the opposite was observed in one study [170]. Importantly, CSF $\alpha$-synuclein levels are many-fold higher in CJD than in PD [171, 253]. Commercial assays are available for total $\alpha$-synuclein and one has been clinically validated for the diagnosis of sporadic CJD [225].

Most currently available assays for $\alpha$-synuclein have been designed to measure total amounts of the protein and not LB-specific fragments, although phosphorylated $\alpha$-synuclein has been detected in CSF of PD patients [382]. There are reports of increased CSF concentrations of $\alpha$-synuclein oligomers in CSF of PD patients [132, 233, 364], and recent publications on sensitive assays that appear to detect the minute amounts of putative seeds of $\alpha$-synuclein oligomers in CSF [86, 325].

Plasma levels of $\alpha$-synuclein have been reported to be elevated in patients with PD compared with controls [195] and correlate with cognitive decline [212]. No differences in plasma have been found between AD and controls [49, 331].

In summary, although fluid-based $\alpha$-synuclein has promise as a diagnostic and prognostic biomarker for PD and CJD, studies in AD have been relatively limited and its 
potential role as a biomarker is unknown (Table 1). Nevertheless, $\alpha$-synuclein may prove to be useful for identifying LB pathology among AD patients, therefore, could support subject/patient selection (Table 2).

\section{TDP-43 pathology}

TDP-43 binds both DNA and RNA and is involved in transcription and splicing. Under pathophysiological conditions, TDP-43 accumulates in the cytoplasm and is hyperphosphorylated and/or ubiquitinated, and this is characteristic of the cytoplasmic inclusions observed in ALS and in many cases of FTLD [51, 265]. TDP-43 pathology is also detected in $20-50 \%$ of $\mathrm{AD}$ patients $[7,50,159]$, and appears to be associated with greater brain atrophy, memory loss, and cognitive impairment $[50,163]$. Studies suggest that TDP-43 pathology can be triggered by $\mathrm{A} \beta$ peptides, and that TDP- 43 contributes to neuroinflammation and may have a role in mitochondrial and neural dysfunction [50].

\section{Fluid biomarkers of TDP-43 pathology}

\section{TDP-43}

A few studies have reported on CSF and plasma TDP-43 in ALS and FTLD [165, 187, 345], but research has been hampered by difficulties with detecting the protein (candidate antibodies have been reviewed by Goossens et al.) [111]. Furthermore, CSF TDP-43 appears to be mainly bloodderived, although it may be possible to enrich for brainspecific fractions of TDP-43 from exosomes in CSF [90].

One study reported elevated plasma TDP-43 in a greater proportion of AD patients compared with controls [97]. Another small study found that plasma levels of diseaserelated TDP-43 variants were increased in the pre-MCI stage in subjects who subsequently progressed to $\mathrm{AD}$ dementia [387].

Overall, research to date suggests that blood-based TDP43 may have a role as an AD biomarker for subject/patient selection and prognosis and could be more useful than CSF TDP-43 (Tables 1 and 2). Commercial assays are available.

\section{Iron toxicity}

Iron is important for normal functioning of the brain, but when present in excess it is known to cause neurodegeneration, for example in the genetic disorders classified as neurodegeneration with brain iron accumulation (NBIA) [135]. Studies have shown elevated iron in AD [55, 226] and MCI [372] brains, which is also replicated in animal models [210]. Iron is a redox-active biometal that has been shown to bind $A \beta$ in vitro and cause its aggregation, while releasing hydrogen peroxide [147]. Intracellular iron can influence APP processing and bind to hyperphosphorylated tau and induce its aggregation [58]. In a recent magnetic resonance imaging study, brain iron measured by quantitative susceptibility mapping was shown to be moderately elevated in people with PET-confirmed A $\beta$, but highly predictive of cognitive decline over 6 years only in subjects with $A \beta$, suggesting that iron accelerates the clinical manifestation of the underlying pathology [16].

\section{Fluid biomarkers associated with iron metabolism}

\section{Ferritin}

Ferritin is the major intracellular iron storage protein in the body and has an important role in brain iron homeostasis [333]. Inherited ferritinopathies are associated with motor and cognitive dysfunction [333], and ferritin levels are increased in $\mathrm{AD}$ brain tissue [58]. CSF levels of ferritin have been shown to be higher in $A P O E \& 4$ carriers than in non-carriers, but there was no difference in levels among subjects with AD or MCI and controls [15]. Increased CSF ferritin levels were associated with cognitive decline and predicted progression from MCI to $\mathrm{AD}$, regardless of $A P O E$ genotype [15]. In a subsequent analysis, CSF ferritin was associated with cognitive decline in cognitively normal subjects, but the association was strongest in APOE \&4 carriers [14]. In the same cohort, high CSF ferritin was associated with accelerated depreciation of CSF A $\beta 42$ in subjects with a high tau/A $\beta 42$ ratio [13]. Plasma ferritin levels showed a modest correlation with CSF levels, but unlike CSF ferritin, there was no difference in plasma ferritin between $A P O E$ \& 4 carriers and non-carriers [15]. In another study, plasma ferritin levels were elevated in cognitively normal subjects with $A \beta$ pathology identified by PET when adjusted for covariates (age, sex, APOE $\varepsilon 4$ status, and levels of C-reactive protein), although ferritin alone had a relatively minor effect compared with the base model (derived from logistic regression of the same covariates) [112].

In summary, the data are limited but a small number of studies suggest that both CSF and plasma ferritin may be useful as AD biomarkers (Table 1). CSF ferritin may have a role as a prognostic biomarker, whereas plasma ferritin could be used for subject/patient selection (screening) to help identify preclinical AD (Table 2); however, further studies by independent groups are needed to validate the initial findings. Commercial assays are available. 


\section{Other neuronal proteins}

\section{VILIP-1}

Visinin-like protein 1 (VILIP-1, or VLP-1) is a neuronal calcium sensor protein involved in signalling pathways related to synaptic plasticity [115]. CSF VILIP-1 was identified through mouse gene array analyses as being abundantly produced in the brain [192]. It was subsequently associated with AD and found to correlate with CSF t-tau and p-tau [194], supporting its use as a neurodegeneration marker.

CSF VILIP-1 levels have been shown to be higher in patients with AD compared with controls in several studies [194, 230, 257, 347, 355], although one study found no significant difference [176]. The meta-analysis by Olsson et al. found VILIP-1 to have a moderate association with $\mathrm{AD}$ (data from four AD and control cohorts) with around 50\% higher levels in AD than in controls [271]. AD patients had higher levels than MCI subjects in one study [257] but no difference was noted in a later study [17]. In a recent study of the ADNI cohort, baseline CSF VILIP-1 levels were higher in $A \beta$-positive (based on CSF A $\beta 42$ ) $\mathrm{MCI}$ and $\mathrm{AD}$ subjects compared with both the $\mathrm{A} \beta$-negative MCI and A $\beta$-negative cognitively normal groups [347]. No significant differences were found between any of the $\mathrm{A} \beta$-positive subsets of the cognitively normal, MCI, and AD groups. CSF VILIP-1 levels decreased longitudinally in the $\mathrm{AD}$ group (mean follow-up was 4 years) but there were no significant longitudinal changes in any other group [347]. CSF VILIP-1 may be prognostic of future cognitive decline [355], rates of cognitive decline [357], rates of brain atrophy [356], and progression from MCI to $\mathrm{AD}$ [176]. In addition, studies suggest that CSF VILIP-1 can diagnostically differentiate AD from other dementias $[17,230,355]$.

Data on plasma VILIP-1 are limited; plasma levels were found to be higher in patients with mild AD compared with controls in one study, although the difference was more significant in CSF than in plasma [355].

Overall, the data for VILIP-1 suggest a possible role in subject/patient selection and prognosis (Tables 1 and 2) but study results have varied so further research is warranted. Commercial assays are available.

\section{NF-L}

Neurofilaments are intermediate filaments expressed in neurons and are particularly abundant in axons [398]. They are composed of four subunits-neurofilament light (NFL), neurofilament middle (NF-M), neurofilament heavy
(NF-H), and $\alpha$-internexin in the CNS, and NF-L, NF-M, $\mathrm{NF}-\mathrm{H}$, and peripherin in the peripheral nervous system [398]. Neurofilaments are essential for the radial growth of axons during development, structural support, and the transmission of electrical impulses [398]. Recent research suggests that they are also important for normal synaptic function [399]. Abnormal aggregation and other alterations of neurofilaments are evident in several neurological diseases including $\mathrm{AD}[378,398,399]$ and in the LBs of PD [316].

CSF levels of the NF-L subunit are known to be increased in several neurodegenerative diseases, supporting its role as a marker of axonal injury $[231,286,334]$. CSF NF-L levels have been shown to be higher in $\mathrm{AD}[4,220,288$, 334, 403] and MCI patients [403] compared with controls, and correlate with cognitive impairment and short survival time in patients with dementia [335]. The meta-analysis by Olsson et al. found CSF NF-L to have a large effect size for differentiating between AD patients and controls (data from nine AD cohorts and eight control cohorts) [271]. CSF NF-L correlates with brain atrophy [282, 403], but appears not to be specific for AD since levels are elevated in other neurodegenerative diseases, likely reflecting non-specific axonal injury [28, 103, 282]. In multiple sclerosis (MS), CSF NF-L has been shown to correlate with clinical and radiological outcomes, making it potentially useful for monitoring response to therapy [182, 249, 266, 267].

Recently, there has been great interest in the potential utility of NF-L in blood as a biomarker for several neurodegenerative diseases including AD, MS, progressive supranuclear palsy (PSP), ALS, and Huntington's disease [43, 71, $228,240,302,385,408]$, as well as a marker of traumatic brain injury [224, 324]. In AD, plasma or serum levels of NF-L have been shown to be elevated compared with controls in presymptomatic individuals known to be carriers of AD-causing gene mutations [385] and subjects with MCI or AD [240, 408]. Furthermore, blood-based NF-L appears to correlate with poor cognition and brain atrophy [240, 385]. In MS, serum NF-L has demonstrated potential as a biomarker for monitoring response to DMTs and predicting relapse [71], and in PSP, plasma NF-L has been shown to predict disease progression [302].

Taken together, these findings indicate that both CSF and plasma NF-L are promising biomarkers, although the specific $\mathrm{COU}$ has not been determined given that changes are observed in various neurodegenerative diseases, not just $\mathrm{AD}$ (Tables 1 and 2). Potentially, CSF NF-L could be useful as a non-specific marker of axonal injury and for prognosis, and recent research gives hope that plasma NF-L could be used as a non-invasive biomarker for subject/patient selection (screening) and prognosis (Table 2). Commercial assays are available and IVD assays are available for CSF NF-L in Europe. 


\section{Discussion}

In addition to the established core CSF biomarkers, $A \beta 42$, $\mathrm{t}$-tau, and p-tau, several candidate fluid biomarkers show potential for clinical use in $\mathrm{AD}$, particularly to support diagnosis (and clinical trial subject selection) and prognosis (or assessment of disease state) (Table 2). Of all the biomarkers reviewed, CSF A $\beta 42$, $t$-tau, $p$-tau, and the ratio of tau/A $\beta 42$ are already accepted for use as diagnostic biomarkers, while several other biomarkers hold promise for future use (Table 1). Further studies are needed for the validation and regulatory qualification of all these biomarkers. In addition, the relationship between the biomarkers and clinical presentation (i.e. cognitive measures), as well as the effects of patient variables (e.g. sex, $A P O E$ $\varepsilon 4$ status) on biomarker changes need to be investigated.

It should be noted that only a selection of promising biomarkers has been included in this review, and many other candidates are being studied at present. As well as other protein/peptide markers and panels [206], nonprotein analytes such as lipids [8], amino acids [56], and microRNAs [120, 328] are being explored. Advances in technologies such as mass spectrometry enable the precise measurement of analytes, helping to identify new candidate biomarkers [26] as well as supporting harmonization efforts for the core biomarkers [292].

Of all the possible biomarker COUs, there appears to be an unmet need for validated fluid biomarkers for drug development, especially for monitoring response to therapy and adverse reactions (Table 2). This is not surprising given the current absence of approved DMTs but highlights the need for fluid-based surrogate biomarkers of drug efficacy and safety. The important role of biomarkers in AD drug development has been highlighted in the FDA draft guidance for industry [96].

Further development of candidate biomarkers, as well as identification of new ones, would benefit greatly from a unified and coordinated approach [100, 124, 178, 269]. There is a need to reach a consensus on the areas that require the most focus and to implement effective strategies to advance the field. This effort requires collaboration among academia, industry, laboratory managers, and clinicians, at an international level.

An ever-increasing number of biomarkers are being researched, and studies have a considerable degree of heterogeneity (biomarker collection/methodology, disease diagnosis/stage of disease, and characterization of comorbid CNS diseases, especially neurodegenerative diseases), making it difficult to interpret results and establish how the biomarkers fit within the stages of AD pathogenesis. Publication bias may be a barrier in this step, as "negative" studies may be under-published. To fast-track data dissemination, a centralized database would be useful to share individual patient-level biomarker data. The Coalition Against Major Diseases (CAMD), one of 12 consortia of the Critical Path Institute (C-Path), aims to include CSF biomarker data in a central repository as part of their ongoing initiative to advance regulatory drug development tools [12].

Once the data gaps are identified, studies can be designed to address the specific unmet needs. Careful planning of study design, subjects, and methodology is critical, to ensure that data gaps are appropriately addressed and that outcomes are reliable and representative of a wider population. The COU should be decided from the outset, and this will influence the subject inclusion criteria and study design. For example, studies on biomarkers for preclinical AD should enroll cognitively normal subjects with evidence of AD pathology and include longitudinal follow-ups and biomarker measurements over 5 years or more.

For studies to provide meaningful and comparable data, a concerted effort needs to be made to reduce heterogeneity in study methodologies. The development and/or update of consensus recommendations and guidelines should help in this regard, for example, by standardizing diagnostic criteria for different stages of the AD continuum, pre-analytical variables, assays, threshold values, and study designs and populations used for any given COU. The National Institute on Aging-Alzheimer's Association (NIA-AA) is currently updating a research framework for $\mathrm{AD}$, which will help to harmonize subject selection and disease staging in future studies. There have been longstanding efforts to better understand and control for pre-analytical sources of variability in CSF AD biomarkers, and consensus conferences have defined these [375]. A CSF pre-analytics consortium, sponsored by the Alzheimer's Association is working to develop a consensus regarding remaining pre-analytical factors such as tube plastic type and other collection parameters that can be implemented into routine clinical practice. Factors that had been recognized but incompletely understood, such as the effect of tube type and CSF volume involved in transfer steps, were recently described and will help to clarify the potential impact of such factors on CSF AD biomarker measurements [386]. The International Federation of Clinical Chemistry Working Group for CSF proteins (IFCC WG-CSF) is an international joint effort to develop reference measurement procedures (RMP) and certified reference materials (CRM) with the aim of standardizing CSF biomarkers and harmonizing read-outs between assay formats [185]. To date, two Joint Committee for Traceability in Laboratory Medicine (JCTLM) -approved RMPs and three CRMs for CSF A $\beta 42$ are available, and work on $A \beta 40$ and tau proteins is ongoing. In parallel with the recent drive to standardize CSF pre-analytics, guidelines have also been proposed by the Biofluid Based Biomarkers Professional 
Interest Area (of ISTAART) for the pre-analytical processing of blood-based AD biomarkers [268]. Furthermore, "Appropriate use criteria for CSF in clinical practice" are also being developed by the Alzheimer's Association, which will help define the use of AD CSF biomarkers by clinicians for assessment of cognitive decline and impairment.

Although biomarkers are routinely included in drug studies for understanding target engagement and for patient enrichment, the hurdles are high for biomarker adoption to inform standard of care in daily clinical practice. Health agencies have recognized the importance of biomarkers, and both the FDA and EMA have developed pathways to accelerate biomarker qualification for clinical trials [12]. To achieve biomarker qualification, evidence is needed that the biomarker can reliably support a specified manner of interpretation and application in drug development for a specifically stated COU [12]. Therefore, the aforementioned hurdles, such as data sharing and standardization of study methods, are important to address at the earliest stages of biomarker research. Once a biomarker has been shown to be useful for a specific COU in the clinical trial setting, measures can be taken to further develop it as a companion biomarker useful to practitioners.

The ultimate goal in AD is to follow the approach developed in the more advanced research field of oncology and deliver precision medicine to all patients, in such a way that diagnosis, treatment, and prevention are "tailored" to the characteristics of the individual according to the precision medicine paradigm $[46,92,126,127,129,130]$. In this context, the precision medicine strategy enables a paradigm shift from the traditional "one treatment fits all" approach in drug discovery towards biomarker-guided "tailored" therapies, i.e. targeted interventions adapted to the biological profile of the individual patient. In this regard, the US Precision Medicine Initiative (PMI) (https://obamawhitehouse.archi ves.gov/precision-medicine) and the US All of Us Research Program (https://allofus.nih.gov/)—formerly known as and evolved from the US PMI Cohort Program (PMI-CP)—have been inaugurated recently. As is the case in most fields of medicine, important progress in detecting, treating, and preventing $\mathrm{AD}$ is anticipated from the implementation of a systematic precision medicine strategy. Therefore, after more than a decade of failed therapy trials and one of the lowest success rates in drug development in medicine, the time has come to launch an international Alzheimer PMI (APMI) and associate it with the US PMI and other related worldwide initiatives $[92,126,127,129,130]$.

Acknowledgements The development of this review manuscript was financially supported by Roche Diagnostics International. Medical writing was provided by Papia Das of Elements Communications Ltd and funded by Roche Diagnostics International. HH is supported by the AXA Research Fund, the "Fondation partenariale Sorbonne Université" and the "Fondation pour la Recherche sur Alzheimer", Paris,
France. Ce travail a bénéficié d'une aide de l'Etat "Investissements d'avenir" ANR-10-IAIHU-06. The research leading to these results has received funding from the program "Investissements d'avenir" ANR10-IAIHU-06 (Agence Nationale de la Recherche-10-IA Agence Institut Hospitalo-Universitaire-6).

\section{Compliance with ethical standards}

Conflict of interest JLM is Principal Investigator of trials funded by Roche, Merck, Novartis, and Janssen and has received speaker or consultant fees from Roche, Roche Diagnostics, Biogen, Merck, Novartis, Oryzon, IBL, Axovant, Lundbeck, and Lilly. SA receives current research support from the National Health and Medical Research Council, Australia (GNT1147442, GNT1123625, GNT1124356, GNT1100441, GNT1101533, GNT1100458) and several non-profit organizations. SA is a co-inventor on biomarker patents related to ferritin. RB is a full-time employee of Roche Diagnostics International. MMB is a full-time employee of Takeda Pharmaceuticals International Co. TB is a full-time employee of Genentech, a member of the Roche Group. JC has provided consultation to Acadia, Accera, Actinogen, ADAMAS, Alkahest, Allergan, Alzheon, Avanir, Axovant, Axsome, BiOasis Technologies, Biogen, Boehinger-Ingelheim, Eisai, Genentech, Grifols, Kyowa, Lilly, Lundbeck, Merck, Nutricia, Otsuka, QR Pharma, Resverlogix, Roche, Samus, Servier, Suven, Takeda, Toyoma, and United Neuroscience companies. JC receives support from Keep Memory Alize (KMA), COBRE grant \#P20GM109025; TRC-PAD \#R01AG053798; DIAGNOSE CTE \#U01NS093334. AMF has served as a consultant or on advisory boards for AbbVie, Araclon/Grifols, DiamiR LLC, Eli Lilly, Genentech, IBL International, and Roche Diagnostics, and has received research support from Biogen, Fujirebio, and Roche Diagnostics. HH serves as Senior Associate Editor for the Journal Alzheimer's and Dementia; he received lecture fees from Biogen and Roche, research grants from Pfizer, Avid, and MSD Avenir (paid to the institution), travel funding from Functional Neuromodulation, Axovant, Eli Lilly and company, Takeda and Zinfandel, GE-Healthcare and Oryzon Genomics, consultancy fees from Jung Diagnostics, Cytox Ltd., Axovant, Anavex, Takeda and Zinfandel, GE Healthcare Oryzon Genomics, and Functional Neuromodulation, and participated in scientific advisory boards of Functional Neuromodulation, Axovant, Eli Lilly and company, Cytox Ltd., GE Healthcare, Takeda and Zinfandel, Oryzon Genomics and Roche Diagnostics. HH is co-inventor in the following patents as a scientific expert and has received no royalties: (1) In Vitro Multiparameter Determination Method for The Diagnosis and Early Diagnosis of Neurodegenerative Disorders Patent Number: 8916388. (2) In Vitro Procedure for Diagnosis and Early Diagnosis of Neurodegenerative Diseases Patent Number: 8298784. (3) Neurodegenerative Markers for Psychiatric Conditions Publication Number: 20120196300. (4) In Vitro Multiparameter Determination Method for The Diagnosis and Early Diagnosis of Neurodegenerative Disorders Publication Number: 20100062463. (5) In Vitro Method for The Diagnosis and Early Diagnosis of Neurodegenerative Disorders Publication Number: 20100035286. (6) In Vitro Procedure for Diagnosis and Early Diagnosis of Neurodegenerative Diseases Publication Number: 20090263822. (7) In Vitro Method for The Diagnosis of Neurodegenerative Diseases Patent Number: 7547553. (8) CSF Diagnostic in Vitro Method for Diagnosis of Dementias and Neuroinflammatory Diseases Publication Number: 20080206797. (9) In Vitro Method for The Diagnosis of Neurodegenerative Diseases Publication Number: 20080199966. (10) Neurodegenerative Markers for Psychiatric Conditions Publication Number: 20080131921. MMM served as a consultant to Eli Lilly and Lysosomal Therapeutics, Inc., and receives research support from the National Institutes of Health (R01 AG49704, P50 AG44170, U01 AG06786 RF1 AG55151), Department of Defense (W81XWH-15-1), and unrestricted research grants from Biogen, Roche, and Lundbeck. AM was an employee of Biogen 
when this manuscript was started. SO has served as a consultant to Roche Diagnostics and has multiple patents on blood biomarkers related to neurodegenerative disease. He is a founder of $\mathrm{Cx}$ Precision Medicine and owns stock. He receives research support for the NIH (R01AG058252, R01AG051848, R01AG054073) and the opinions discussed here do not reflect those of the NIA. PS has acquired grant support (for the institution) from Danone Research, Piramal and Merck. In the past 2 years he has received consultancy/speaker fees (paid to the institution) from Lilly, GE Healthcare, Novartis, Sanofi, Probiodrug, Biogen, Roche and EIP Pharma. JS was an employee of Roche when this manuscript was started. LMS receives research support from the National Institutes of Health (U19 AG024904, P30 AG-10124 for Biomarker Core), Eli Lilly, Hoffman LaRoche, MJFox Foundation for Parkinson's Research for Biofind study and has served as consultant and/or advisory boards for Roche Diagnostics and Eli Lilly. HS is a full-time employee of AbbVie Inc. GT is a full-time employee of Lundbeck Pharmaceuticals LLC. JQT receives research support from the National Institutes of Health (P30 AG-10124-27, P01 AG-17586-18 and P50 NS-053488-11), Eli Lilly, Janssen, Biogen, and several nonprofit organizations. JQT has received revenue from the sale of Avid to Eli Lily as co-inventor on imaging related patents submitted by the University of Pennsylvania, and may accrue revenue in the future on patents submitted by the University of Pennsylvania wherein he is coInventor. HZ has served at advisory boards for Roche Diagnostics and Eli Lilly and has received travel support from Teva. KB has served as a consultant or at advisory boards for Alzheon, BioArctic, Biogen, Eli Lilly, Fujirebio Europe, IBL International, Merck, Novartis, Pfizer, and Roche Diagnostics.

Open Access This article is distributed under the terms of the Creative Commons Attribution 4.0 International License (http://creativeco mmons.org/licenses/by/4.0/), which permits unrestricted use, distribution, and reproduction in any medium, provided you give appropriate credit to the original author(s) and the source, provide a link to the Creative Commons license, and indicate if changes were made.

\section{References}

1. Agnello L, Bivona G, Novo G, Scazzone C, Muratore R, Levantino $\mathrm{P}$ et al (2017) Heart-type fatty acid binding protein is a sensitive biomarker for early AMI detection in troponin negative patients: a pilot study. Scand J Clin Lab Invest 77:428-432. https ://doi.org/10.1080/00365513.2017.1335880

2. Alcolea D, Martínez-Lage P, Sánchez-Juan P, Olazáran J, Antúnez C, Izagirre A et al (2015) Amyloid precursor protein metabolism and inflammation markers in preclinical Alzheimer disease. Neurology 85:626-633. https://doi.org/10.1212/ wnl.0000000000001859

3. Alcolea D, Vilaplana E, Pegueroles J, Montal V, Sánchez-Juan P, González-Suárez A et al (2015) Relationship between cortical thickness and cerebrospinal fluid YKL-40 in predementia stages of Alzheimer's disease. Neurobiol Aging 36:2018-2023. https:// doi.org/10.1016/j.neurobiolaging.2015.03.001

4. Alcolea D, Vilaplana E, Suárez-Calvet M, Illán-Gala I, Blesa R, Clarimón J et al (2017) CSF sAPP $\beta$, YKL-40, and neurofilament light in frontotemporal lobar degeneration. Neurology 89:178-188. https://doi.org/10.1212/WNL.0000000000004088

5. Alexopoulos P, Werle L, Roesler J, Thierjung N, Gleixner LS, Yakushev I et al (2016) Conflicting cerebrospinal fluid biomarkers and progression to dementia due to Alzheimer's disease. Alzheimers Res Ther 8:51. https://doi.org/10.1186/s1319 $5-016-0220-\mathrm{z}$
6. Association Alzheimer's (2016) Alzheimer's disease facts and figures. Alzheimers Dement 12:459-509

7. Amador-Ortiz C, Lin WL, Ahmed Z, Personett D, Davies P, Duara $R$ et al (2007) TDP-43 immunoreactivity in hippocampal sclerosis and Alzheimer's disease. Ann Neurol 61:435-445. https ://doi.org/10.1002/ana.21154

8. Anand S, Barnes JM, Young SA, Garcia DM, Tolley HD, Kauwe JSK et al (2017) Discovery and confirmation of diagnostic serum lipid biomarkers for Alzheimer's disease using direct infusion mass spectrometry. J Alzheimers Dis 59:277-290. https://doi. org/10.3233/JAD-170035

9. Andreasen N, Minthon L, Vanmechelen E, Vanderstichele H, Davidsson P, Winblad B et al (1999) Cerebrospinal fluid tau and A $\beta 42$ as predictors of development of Alzheimer's disease in patients with mild cognitive impairment. Neurosci Lett 273:5-8

10. Angiolillo AL, Sgadari C, Taub DD, Liao F, Farber JM, Maheshwari $S$ et al (1995) Human interferon-inducible protein 10 is a potent inhibitor of angiogenesis in vivo. J Exp Med 182:155-162

11. Antonell A, Mansilla A, Rami L, Lladó A, Iranzo A, Olives J et al (2014) Cerebrospinal fluid level of YKL-40 protein in preclinical and prodromal Alzheimer's disease. J Alzheimers Dis 42:901-908. https://doi.org/10.3233/jad-140624

12. Arnerić SP, Batrla-Utermann R, Beckett L, Bittner T, Blennow K, Carter L et al (2017) Cerebrospinal fluid biomarkers for Alzheimer's disease: a view of the regulatory science qualification landscape from the Coalition Against Major Diseases CSF Biomarker Team. J Alzheimers Dis 55:19-35. https://doi. org/10.3233/JAD-160573

13. Ayton S, Diouf I, Bush AI, Alzheimer's Disease Neuroimaging Initiative (2017) Evidence that iron accelerates Alzheimer's pathology: a CSF biomarker study. J Neurol Neurosurg Psychiatry 89:456-460. https://doi.org/10.1136/jnnp-2017-316551

14. Ayton S, Faux NG, Bush AI (2017) Association of cerebrospinal fluid ferritin level with preclinical cognitive decline in APOE- $\varepsilon 4$ carriers. JAMA Neurol 74:122-125. https://doi.org/10.1001/ jamaneurol.2016.4406

15. Ayton S, Faux NG, Bush AI, Alzheimer's Disease Neuroimaging Initiative (2015) Ferritin levels in the cerebrospinal fluid predict Alzheimer's disease outcomes and are regulated by APOE. Nat Commun 6:6760. https://doi.org/10.1038/ncomms7760

16. Ayton S, Fazlollahi A, Bourgeat P, Raniga P, Ng A, Lim YY et al (2017) Cerebral quantitative susceptibility mapping predicts amyloid-beta-related cognitive decline. Brain 140:2112-2119. https://doi.org/10.1093/brain/awx137

17. Babić Leko M, Borovečki F, Dejanović N, Hof PR, Ŝimić G (2016) Predictive value of cerebrospinal fluid visinin-like protein-1 levels for Alzheimer's disease early detection and differential diagnosis in patients with mild cognitive impairment. J Alzheimers Dis 50:765-778. https://doi.org/10.3233/jad-150705

18. Bachurin SO, Bovina EV, Ustyugov AA (2017) Drugs in clinical trials for Alzheimer's disease: the major trends. Med Res Rev 37:1186-1225. https://doi.org/10.1002/med.21434

19. Bakota L, Brandt R (2016) Tau biology and tau-directed therapies for Alzheimer's disease. Drugs 76:301-313. https://doi. org/10.1007/s40265-015-0529-0

20. Baldacci F, Lista S, Cavedo E, Bonuccelli U, Hampel H (2017) Diagnostic function of the neuroinflammatory biomarker YKL40 in Alzheimer's disease and other neurodegenerative diseases. Expert Rev Proteom 14:285-299. https://doi.org/10.1080/14789 450.2017.1304217

21. Baldacci F, Lista S, Garaci F, Bonuccelli U, Toschi N, Hampel H (2016) Biomarker-guided classification scheme of neurodegenerative diseases. J Sport Health Sci 5:383-387 
22. Baldacci F, Lista S, O'Bryant SE, Ceravolo R, Toschi N, Hampel $\mathrm{H}$ et al (2018) Blood-based biomarker screening with agnostic biological definitions for an accurate diagnosis within the dimensional spectrum of neurodegenerative diseases. Methods Mol Biol 1750:139-155. https://doi. org/10.1007/978-1-4939-7704-8_9

23. Baldacci F, Toschi N, Lista S, Zetterberg H, Blennow K, Kilimann I et al (2017) Two-level diagnostic classification using cerebrospinal fluid YKL-40 in Alzheimer's disease. Alzheimers Dement 13:993-1003. https://doi.org/10.1016/j.jalz.2017.01.021

24. Ballatore C, Brunden KR, Trojanowski JQ, Lee VM, Smith AB 3rd (2017) Non-naturally occurring small molecule microtubulestabilizing agents: a potential tactic for CNS-directed therapies. ACS Chem Neurosci 8:5-7. https://doi.org/10.1021/acschemneu ro.6b00384

25. Bayer TA, Wirths O (2014) Focusing the amyloid cascade hypothesis on $\mathrm{N}$-truncated Abeta peptides as drug targets against Alzheimer's disease. Acta Neuropathol 127:787-801. https://doi. org/10.1007/s00401-014-1287-x

26. Begcevic I, Brinc D, Brown M, Martinez-Morillo E, Goldhardt O, Grimmer T et al (2018) Brain-related proteins as potential CSF biomarkers of Alzheimer's disease: a targeted mass spectrometry approach. J Proteom 182:12-20. https://doi. org/10.1016/j.jprot.2018.04.027

27. Berge G, Sando SB, Albrektsen G, Lauridsen C, Møller I, Grøntvedt GR et al (2016) Alpha-synuclein measured in cerebrospinal fluid from patients with Alzheimer's disease, mild cognitive impairment, or healthy controls: a two year follow-up study. BMC Neurol 16:180. https://doi.org/10.1186/s12883-016-0706-0

28. Bergman J, Dring A, Zetterberg H, Blennow K, Norgren N, Gilthorpe $\mathrm{J}$ et al (2016) Neurofilament light in CSF and serum is a sensitive marker for axonal white matter injury in MS. Neurol Neuroimmunol Neuroinflamm 3:e271. https://doi.org/10.1212/ NXI.0000000000000271

29. Bettcher BM, Johnson SC, Fitch R, Casaletto KB, Heffernan KS, Asthana S et al (2018) Cerebrospinal fluid and plasma levels of inflammation differentially relate to CNS markers of Alzheimer's disease pathology and neuronal damage. J Alzheimers Dis 62:385-397. https://doi.org/10.3233/JAD-170602

30. Blennow K, Bogdanovic N, Alafuzoff I, Ekman R, Davidsson $\mathrm{P}$ (1996) Synaptic pathology in Alzheimer's disease: relation to severity of dementia, but not to senile plaques, neurofibrillary tangles, or the ApoE4 allele. J Neural Transm (Vienna) 103:603618. https://doi.org/10.1007/BF01273157

31. Blennow K, De Meyer G, Hansson O, Minthon L, Wallin A, Zetterberg $\mathrm{H}$ et al (2009) Evolution of Abeta42 and Abeta40 levels and Abeta42/Abeta40 ratio in plasma during progression of Alzheimer's disease: a multicenter assessment. J Nutr Health Aging 13:205-208

32. Blennow K, Dubois B, Fagan AM, Lewczuk P, de Leon MJ, Hampel H (2015) Clinical utility of cerebrospinal fluid biomarkers in the diagnosis of early Alzheimer's disease. Alzheimers Dement 11:58-69. https://doi.org/10.1016/j.jalz.2014.02.004

33. Blennow K, Hampel H, Weiner M, Zetterberg H (2010) Cerebrospinal fluid and plasma biomarkers in Alzheimer disease. Nat Rev Neurol 6:131-144. https://doi.org/10.1038/nrneurol.2010.4

34. Blennow K, Zetterberg H, Minthon L, Lannfelt L, Strid S, Annas P et al (2007) Longitudinal stability of CSF biomarkers in Alzheimer's disease. Neurosci Lett 419:18-22. https://doi. org/10.1016/j.neulet.2007.03.064

35. Brettschneider J, Del Tredici K, Lee VM, Trojanowski JQ (2015) Spreading of pathology in neurodegenerative diseases: a focus on human studies. Nat Rev Neurosci 16:109-120. https://doi. org $/ 10.1038 / \mathrm{nrn} 3887$

36. Brinkmalm A, Brinkmalm G, Honer WG, Frölich L, Hausner L, Minthon L et al (2014) SNAP-25 is a promising novel cerebrospinal fluid biomarker for synapse degeneration in Alzheimer's disease. Mol Neurodegener 9:53. https://doi. org/10.1186/1750-1326-9-53

37. Bronzuoli MR, Iacomino A, Steardo L, Scuderi C (2016) Targeting neuroinflammation in Alzheimer's disease. J Inflamm Res 9:199-208. https://doi.org/10.2147/JIR.S86958

38. Brosseron F, Traschutz A, Widmann CN, Kummer MP, Tacik P, Santarelli F et al (2018) Characterization and clinical use of inflammatory cerebrospinal fluid protein markers in Alzheimer's disease. Alzheimers Res Ther 10:25. https://doi.org/10.1186/ s13195-018-0353-3

39. Bruggink KA, Kuiperij HB, Claassen JA, Verbeek MM (2013) The diagnostic value of CSF amyloid-beta(43) in differentiation of dementia syndromes. Curr Alzheimer Res 10:1034-1040

40. Brunden KR, Zhang B, Carroll J, Yao Y, Potuzak JS, Hogan AM et al (2010) Epothilone D improves microtubule density, axonal integrity, and cognition in a transgenic mouse model of tauopathy. J Neurosci 30:13861-13866. https://doi.org/10.1523/ jneurosci.3059-10.2010

41. Buchhave P, Blennow K, Zetterberg H, Stomrud E, Londos E, Andreasen N, Minthon L et al (2009) Longitudinal study of CSF biomarkers in patients with Alzheimer's disease. PLoS One 4:e6294. https://doi.org/10.1371/journal.pone.0006294

42. Budd Haeberlein S, O'Gorman J, Chiao P, Bussiere T, von Rosenstiel P, Tian Y et al (2017) Clinical development of aducanumab, an anti-Abeta human monoclonal antibody being investigated for the treatment of early Alzheimer's disease. J Prev Alzheimers Dis 4:255-263. https://doi.org/10.14283/jpad.2017.39

43. Byrne LM, Rodrigues FB, Blennow K, Durr A, Leavitt BR, Roos RAC et al (2017) Neurofilament light protein in blood as a potential biomarker of neurodegeneration in Huntington's disease: a retrospective cohort analysis. Lancet Neurol 16:601-609. https ://doi.org/10.1016/s1474-4422(17)30124-2

44. Calsolaro V, Edison P (2016) Neuroinflammation in Alzheimer's disease: current evidence and future directions. Alzheimers Dement 12:719-732. https://doi.org/10.1016/j.jalz.2016.02.010

45. Carroll CM, Li YM (2016) Physiological and pathological roles of the $\gamma$-secretase complex. Brain Res Bull 126:199-206. https ://doi.org/10.1016/j.brainresbull.2016.04.019

46. Castrillo JI, Lista S, Hampel H, Ritchie CW (2018) Systems biology methods for Alzheimer's disease research toward molecular signatures, subtypes, and stages and precision medicine: application in cohort studies and trials. Methods Mol Biol 1750:31-66. https://doi.org/10.1007/978-1-4939-7704-8_3

47. Catafau AM, Bullich S (2017) Non-amyloid PET imaging biomarkers for neurodegeneration: focus on tau, alpha-synuclein and neuroinflammation. Curr Alzheimer Res 14:169-177

48. Chakraborty A, de Wit NM, van der Flier WM, de Vries HE (2017) The blood brain barrier in Alzheimer's disease. Vascul Pharmacol 89:12-18. https://doi.org/10.1016/j.vph.2016.11.008

49. Chang KA, Shin KY, Nam E, Lee YB, Moon C, Suh YH et al (2016) Plasma soluble neuregulin-1 as a diagnostic biomarker for Alzheimer's disease. Neurochem Int 97:1-7. https://doi. org/10.1016/j.neuint.2016.04.012

50. Chang XL, Tan MS, Tan L, Yu JT (2016) The role of TDP-43 in Alzheimer's disease. Mol Neurobiol 53:3349-3359. https://doi. org/10.1007/s12035-015-9264-5

51. Chen-Plotkin AS, Lee VM, Trojanowski JQ (2010) TAR DNAbinding protein 43 in neurodegenerative disease. Nat Rev Neurol 6:211-220. https://doi.org/10.1038/nrneurol.2010.18

52. Chen Z, Trapp BD (2016) Microglia and neuroprotection. J Neurochem 136(Suppl 1):10-17. https://doi.org/10.1111/jnc.13062

53. Chiasserini D, Biscetti L, Eusebi P, Salvadori N, Frattini G, Simoni $S$ et al (2017) Differential role of CSF fatty acid binding protein 3, $\alpha$-synuclein, and Alzheimer's disease core biomarkers 
in Lewy body disorders and Alzheimer's dementia. Alzheimers Res Ther 9:52. https://doi.org/10.1186/s13195-017-0276-4

54. Choi J, Lee HW, Suk K (2011) Plasma level of chitinase 3-like 1 protein increases in patients with early Alzheimer's disease. J Neurol 258:2181-2185. https://doi.org/10.1007/s0041 5-011-6087-9

55. Cornett CR, Markesbery WR, Ehmann WD (1998) Imbalances of trace elements related to oxidative damage in Alzheimer's disease brain. Neurotoxicology 19:339-345

56. Corso G, Cristofano A, Sapere N, la Marca G, Angiolillo A, Vitale $M$ et al (2017) Serum amino acid profiles in normal subjects and in patients with or at risk of Alzheimer dementia. Dement Geriatr Cogn Dis Extra 7:143-159. https://doi. org/10.1159/000466688

57. Craig-Schapiro R, Perrin RJ, Roe CM, Xiong C, Carter D, Cairns $\mathrm{NJ}$ et al (2010) YKL-40: a novel prognostic fluid biomarker for preclinical Alzheimer's disease. Biol Psychiatry 68:903-912. https://doi.org/10.1016/j.biopsych.2010.08.025

58. Cristóvão JS, Santos R, Gomes CM (2016) Metals and neuronal metal binding proteins implicated in Alzheimer's disease. Oxid Med Cell Longev 2016:9812178. https://doi. org/10.1155/2016/9812178

59. Cruchaga C, Kauwe JS, Harari O, Jin SC, Cai Y, Karch CM et al (2013) GWAS of cerebrospinal fluid tau levels identifies risk variants for Alzheimer's disease. Neuron 78:256-268. https:// doi.org/10.1016/j.neuron.2013.02.026

60. Cummings J, Lee G, Mortsdorf T, Ritter A, Zhong K (2017) Alzheimer's disease drug development pipeline: 2017. Alzheimers Dement (N Y) 3:367-384. https://doi.org/10.1016/j. trci.2017.05.002

61. Dage JL, Wennberg AM, Airey DC, Hagen CE, Knopman DS, Machulda MM et al (2016) Levels of tau protein in plasma are associated with neurodegeneration and cognitive function in a population-based elderly cohort. Alzheimers Dement 12:12261234. https://doi.org/10.1016/j.jalz.2016.06.001

62. Davidsson P, Blennow K (1998) Neurochemical dissection of synaptic pathology in Alzheimer's disease. Int Psychogeriatr 10:11-23

63. De Vos A, Jacobs D, Struyfs H, Fransen E, Andersson K, Portelius $\mathrm{E}$ et al (2015) C-terminal neurogranin is increased in cerebrospinal fluid but unchanged in plasma in Alzheimer's disease. Alzheimers Dement 11:1461-1469. https://doi.org/10.1016/j. jalz.2015.05.012

64. De Vos A, Struyfs H, Jacobs D, Fransen E, Klewansky T, De Roeck E et al (2016) The cerebrospinal fluid neurogranin/ BACE1 ratio is a potential correlate of cognitive decline in Alzheimer's disease. J Alzheimers Dis 53:1523-1538. https://doi. org/10.3233/jad-160227

65. Degerman Gunnarsson M, Ingelsson M, Blennow K, Basun H, Lannfelt L, Kilander L (2016) High tau levels in cerebrospinal fluid predict nursing home placement and rapid progression in Alzheimer's disease. Alzheimers Res Ther 8:22. https://doi. org/10.1186/s13195-016-0191-0

66. Delgado-Alvarado M, Gago B, Gorostidi A, Jiménez-Urbieta H, Dacosta-Aguayo R, Navalpotro-Gómez I et al (2017) Tau/ alpha-synuclein ratio and inflammatory proteins in Parkinson's disease: an exploratory study. Mov Disord 32:1066-1073. https ://doi.org/10.1002/mds.27001

67. Desikan RS, Thompson WK, Holland D, Hess CP, Brewer JB, Zetterberg $\mathrm{H}$ et al (2013) Heart fatty acid binding protein and A $\beta$-associated Alzheimer's neurodegeneration. Mol Neurodegener 8:39. https://doi.org/10.1186/1750-1326-8-39

68. Deters KD, Risacher SL, Kim S, Nho K, West JD, Blennow K et al (2017) Plasma tau association with brain atrophy in mild cognitive impairment and Alzheimer's disease. J Alzheimers Dis 58:1245-1254. https://doi.org/10.3233/JAD-161114
69. Di Marco LY, Venneri A, Farkas E, Evans PC, Marzo A, Frangi AF (2015) Vascular dysfunction in the pathogenesis of Alzheimer's disease - a review of endothelium-mediated mechanisms and ensuing vicious circles. Neurobiol Dis 82:593-606. https:// doi.org/10.1016/j.nbd.2015.08.014

70. Díez-Guerra FJ (2010) Neurogranin, a link between calcium/ calmodulin and protein kinase $\mathrm{C}$ signaling in synaptic plasticity. IUBMB Life 62:597-606. https://doi.org/10.1002/iub.357

71. Disanto G, Barro C, Benkert $P$, Naegelin Y, Schädelin S, Giardiello A et al (2017) Serum neurofilament light: a biomarker of neuronal damage in multiple sclerosis. Ann Neurol 81:857870. https://doi.org/10.1002/ana.24954

72. Doody RS, Thomas RG, Farlow M, Iwatsubo T, Vellas B, Joffe S et al (2014) Phase 3 trials of solanezumab for mild-to-moderate Alzheimer's disease. N Engl J Med 370:311-321. https://doi. org/10.1056/NEJMoa1312889

73. Dorey A, Perret-Liaudet A, Tholance Y, Fourier A, Quadrio I (2015) Cerebrospinal fluid A 440 improves the interpretation of A $\beta 42$ concentration for diagnosing Alzheimer's disease. Front Neurol 6:247. https://doi.org/10.3389/fneur.2015.00247

74. Downes EC, Robson J, Grailly E, Abdel-All Z, Xuereb J, Brayne $\mathrm{C}$ et al (2008) Loss of synaptophysin and synaptosomal-associated protein $25-\mathrm{kDa}$ (SNAP-25) in elderly down syndrome individuals. Neuropathol Appl Neurobiol 34:12-22. https://doi.org/ 10.1111/j.1365-2990.2007.00899.x

75. Dubois B, Feldman HH, Jacova C, Hampel H, Molinuevo JL, Blennow $\mathrm{K}$ et al (2014) Advancing research diagnostic criteria for Alzheimer's disease: the IWG-2 criteria. Lancet Neurol 13:614-629. https://doi.org/10.1016/s1474-4422(14)70090-0

76. Engelborghs S, Niemantsverdriet E, Struyfs H, Blennow K, Brouns R, Comabella M et al (2017) Consensus guidelines for lumbar puncture in patients with neurological diseases. Alzheimers Dement (Amst) 8:111-126. https://doi.org/10.1016/j. dadm.2017.04.007

77. European Medicines Agency, Committee for Medicinal Products for Human Use (2011) Qualification opinion of Alzheimer's disease novel methodologies/biomarkers for the use of CSF amyloid beta 1-42 and t-tau signature and/or PET-amyloid imaging (positive/negative) as biomarkers for enrichment, for use in regulatory clinical trials in mild and moderate Alzheimer's disease. http:// www.ema.europa.eu/docs/en_GB/document_library/Regulatory _and_procedural_guideline/2011/12/WC500118365.pdf

78. European Medicines Agency, Committee for Medicinal Products for Human Use (2018) Guideline on the clinical investigation of medicines for the treatment of Alzheimer's disease. http://www. ema.europa.eu/docs/en_GB/document_library/Scientific_guide line/2018/02/WC500244609.pdf

79. Ewers M, Cheng X, Zhong Z, Nural HF, Walsh C, Meindl T et al (2011) Increased CSF-BACE1 activity associated with decreased hippocampus volume in Alzheimer's disease. J Alzheimers Dis 25:373-381. https://doi.org/10.3233/jad-2011-091153

80. Ewers M, Mattsson N, Minthon L, Molinuevo JL, Antonell A, Popp J et al (2015) CSF biomarkers for the differential diagnosis of Alzheimer's disease: a large-scale international multicenter study. Alzheimers Dement 11:1306-1315. https://doi. org/10.1016/j.jalz.2014.12.006

81. Ewers M, Zhong Z, Bürger K, Wallin A, Blennow K, Teipel SJ et al (2008) Increased CSF-BACE 1 activity is associated with ApoE- $\varepsilon 4$ genotype in subjects with mild cognitive impairment and Alzheimer's disease. Brain 131:1252-1258. https://doi. org/10.1093/brain/awn034

82. Fagan AM, Mintun MA, Mach RH, Lee SY, Dence CS, Shah $A R$ et al (2006) Inverse relation between in vivo amyloid imaging load and cerebrospinal fluid A $\beta 42$ in humans. Ann Neurol 59:512-519. https://doi.org/10.1002/ana.20730 
83. Fagan AM, Mintun MA, Shah AR, Aldea P, Roe CM, Mach RH et al (2009) Cerebrospinal fluid tau and ptau(181) increase with cortical amyloid deposition in cognitively normal individuals: implications for future clinical trials of Alzheimer's disease. EMBO Mol Med 1:371-380. https://doi.org/10.1002/ emmm. 200900048

84. Fagan AM, Roe CM, Xiong C, Mintun MA, Morris JC, Holtzman DM (2007) Cerebrospinal fluid tau/ $\beta$-amyloid(42) ratio as a prediction of cognitive decline in nondemented older adults. Arch Neurol 64:343-349. https://doi.org/10.1001/archneur.64.3.noc60 123

85. Fagan AM, Shaw LM, Xiong C, Vanderstichele H, Mintun MA, Trojanowski JQ et al (2011) Comparison of analytical platforms for cerebrospinal fluid measures of $\beta$-amyloid 1-42, total tau, and p-tau 181 for identifying Alzheimer disease amyloid plaque pathology. Arch Neurol 68:1137-1144. https://doi.org/10.1001/ archneurol.2011.105

86. Fairfoul G, McGuire LI, Pal S, Ironside JW, Neumann J, Christie S et al (2016) Alpha-synuclein RT-QuIC in the CSF of patients with alpha-synucleinopathies. Ann Clin Transl Neurol 3:812818. https://doi.org/10.1002/acn3.338

87. Fandos N, Pérez-Grijalba V, Pesini P, Olmos S, Bossa M, Villemagne VL et al (2017) Plasma amyloid $\beta$ 42/40 ratios as biomarkers for amyloid $\beta$ cerebral deposition in cognitively normal individuals. Alzheimers Dement (Amst) 8:179-187. https://doi. org/10.1016/j.dadm.2017.07.004

88. Farlow M, Arnold SE, van Dyck CH, Aisen PS, Snider BJ, Porsteinsson AP et al (2012) Safety and biomarker effects of solanezumab in patients with Alzheimer's disease. Alzheimers Dement 8:261-271. https://doi.org/10.1016/j.jalz.2011.09.224

89. Fath T, Eidenmuller J, Brandt R (2002) Tau-mediated cytotoxicity in a pseudohyperphosphorylation model of Alzheimer's disease. J Neurosci 22:9733-9741

90. Feneberg E, Steinacker P, Lehnert S, Schneider A, Walther P, Thal DR et al (2014) Limited role of free TDP-43 as a diagnostic tool in neurodegenerative diseases. Amyotroph Lateral Scler Frontotemporal Degener 15:351-356. https://doi. org/10.3109/21678421.2014.905606

91. Ferreira D, Rivero-Santana A, Perestelo-Pérez L, Westman E, Wahlund LO, Sarría A et al (2014) Improving CSF biomarkers' performance for predicting progression from mild cognitive impairment to Alzheimer's disease by considering different confounding factors: a meta-analysis. Front Aging Neurosci 6:287. https://doi.org/10.3389/fnagi.2014.00287

92. Ferretti M, Lulita M, Cavedo E, Chiesa P, Schumacher Dimech A, Chadha Santuccione A et al (2018) Sex-specific phenotypes of Alzheimer's disease: the gateway to precision neurology. Nat Rev Neurol 14:457-469. https://doi.org/10.1038/s4158 2-018-0032-9

93. Finnema SJ, Nabulsi NB, Eid T, Detyniecki K, Lin SF, Chen MK et al (2016) Imaging synaptic density in the living human brain. Sci Transl Med 8:348ra396. https://doi.org/10.1126/scitranslm ed.aaf6667

94. Fleck D, van Bebber F, Colombo A, Galante C, Schwenk BM, Rabe L et al (2013) Dual cleavage of neuregulin 1 type III by BACE1 and ADAM17 liberates its EGF-like domain and allows paracrine signaling. J Neurosci 33:7856-7869. https://doi. org/10.1523/JNEUROSCI.3372-12.2013

95. Food and Drug Administration (2011) Guidance for industryE16 biomarkers related to drug or biotechnology product development: context, structure, and format of qualification submissions. https://www.fda.gov/downloads/drugs/guidancecomplia nceregulatoryinformation/guidances/ucm267449.pdf

96. Food and Drug Administration (2018) Early Alzheimer's disease: developing drugs for treatment; draft guidance for industry. https
://www.fda.gov/downloads/Drugs/GuidanceComplianceRegulat oryInformation/Guidances/UCM596728.pdf

97. Foulds P, McAuley E, Gibbons L, Davidson Y, Pickering-Brown SM, Neary D et al (2008) TDP-43 protein in plasma may index TDP-43 brain pathology in Alzheimer's disease and frontotemporal lobar degeneration. Acta Neuropathol 116:141-146. https ://doi.org/10.1007/s00401-008-0389-8

98. Fourier A, Portelius E, Zetterberg H, Blennow K, Quadrio I, Perret-Liaudet A (2015) Pre-analytical and analytical factors influencing Alzheimer's disease cerebrospinal fluid biomarker variability. Clin Chim Acta 449:9-15. https://doi.org/10.1016/j. cca.2015.05.024

99. Frank RA, Galasko D, Hampel H, Hardy J, de Leon MJ, Mehta PD et al (2003) Biological markers for therapeutic trials in Alzheimer's disease. Proceedings of the biological markers working group; NIA initiative on neuroimaging in Alzheimer's disease. Neurobiol Aging 24:521-536

100. Frisoni GB, Boccardi M, Barkhof F, Blennow K, Cappa S, Chiotis K et al (2017) Strategic roadmap for an early diagnosis of Alzheimer's disease based on biomarkers. Lancet Neurol 16:661-676. https://doi.org/10.1016/S1474-4422(17)30159-X

101. Galimberti D, Schoonenboom N, Scheltens P, Fenoglio C, Bouwman F, Venturelli E et al (2006) Intrathecal chemokine synthesis in mild cognitive impairment and Alzheimer disease. Arch Neurol 63:538-543. https://doi.org/10.1001/archneur.63.4.538

102. Galimberti D, Venturelli E, Fenoglio C, Lovati C, Guidi I, Scalabrini D et al (2007) IP-10 serum levels are not increased in mild cognitive impairment and Alzheimer's disease. Eur J Neurol 14:e3-e4. https://doi.org/10.1111/j.1468-1331.2006.01637.x

103. Gendron TF, C9ORF72 Neurofilament Study Group, Daughrity LM, Heckman MG, Diehl NN, Wuu J et al (2017) Phosphorylated neurofilament heavy chain: a biomarker of survival for C9ORF72-associated amyotrophic lateral sclerosis. Ann Neurol 82:139-146. https://doi.org/10.1002/ana.24980

104. Gervaise-Henry C, Watfa G, Albuisson E, Kolodziej A, Dousset B, Olivier JL et al (2017) Cerebrospinal fluid A $\beta$ eta42/A $\beta$ eta40 as a means to limiting tube- and storage-dependent pre-analytical variability in clinical setting. J Alzheimers Dis 57:437-445. https ://doi.org/10.3233/jad-160865

105. Giasson BI, Forman MS, Higuchi M, Golbe LI, Graves CL, Kotzbauer PT et al (2003) Initiation and synergistic fibrillization of tau and alpha-synuclein. Science 300:636-640. https:// doi.org/10.1126/science.1082324

106. Gispert JD, Monte GC, Suárez-Calvet M, Falcon C, Tucholka A, Rojas $S$ et al (2017) The APOE $\varepsilon 4$ genotype modulates CSF YKL-40 levels and their structural brain correlates in the continuum of Alzheimer's disease but not those of sTREM2. Alzheimers Dement (Amst) 6:50-59. https://doi.org/10.1016/j. dadm.2016.12.002

107. Gispert JD, Suárez-Calvet M, Monté GC, Tucholka A, Falcon C, Rojas S et al (2016) Cerebrospinal fluid sTREM2 levels are associated with gray matter volume increases and reduced diffusivity in early Alzheimer's disease. Alzheimers Dement 12:1259-1272. https://doi.org/10.1016/j.jalz.2016.06.005

108. Glenner GG, Wong CW (1984) Alzheimer's disease and Down's syndrome: sharing of a unique cerebrovascular amyloid fibril protein. Biochem Biophys Res Commun 122:1131-1135

109. Glenner GG, Wong CW (1984) Alzheimer's disease: initial report of the purification and characterization of a novel cerebrovascular amyloid protein. Biochem Biophys Res Commun 120:885-890

110. Goetzl EJ, Kapogiannis D, Schwartz JB, Lobach IV, Goetzl L, Abner EL et al (2016) Decreased synaptic proteins in neuronal exosomes of frontotemporal dementia and Alzheimer's disease. FASEB J 30:4141-4148. https://doi.org/10.1096/ff.201600816R 
111. Goossens J, Vanmechelen E, Trojanowski JQ, Lee VM, Van Broeckhoven C, van der Zee J et al (2015) TDP-43 as a possible biomarker for frontotemporal lobar degeneration: a systematic review of existing antibodies. Acta Neuropathol Commun 3:15. https://doi.org/10.1186/s40478-015-0195-1

112. Goozee K, Chatterjee P, James I, Shen K, Sohrabi HR, Asih PR et al (2018) Elevated plasma ferritin in elderly individuals with high neocortical amyloid-beta load. Mol Psychiatry 23:18071812. https://doi.org/10.1038/mp.2017.146

113. Gravina SA, Ho L, Eckman CB, Long KE, Otvos L Jr, Younkin LH et al (1995) Amyloid beta protein (A beta) in Alzheimer's disease brain. Biochemical and immunocytochemical analysis with antibodies specific for forms ending at A beta 40 or A beta 42(43). J Biol Chem 270:7013-7016

114. Grimmer T, Riemenschneider M, Förstl H, Henriksen G, Klunk WE, Mathis CA et al (2009) Beta amyloid in Alzheimer's disease: increased deposition in brain is reflected in reduced concentration in cerebrospinal fluid. Biol Psychiatry 65:927-934. https://doi.org/10.1016/j.biopsych.2009.01.027

115. Groblewska M, Muszynski P, Wojtulewska-Supron A, Kulczynska-Przybik A, Mroczko B (2015) The role of visinin-like protein-1 in the pathophysiology of Alzheimer's disease. J Alzheimers Dis 47:17-32. https://doi.org/10.3233/jad-150060

116. Guerreiro R, Wojtas A, Bras J, Carrasquillo M, Rogaeva E, Majounie E et al (2013) TREM2 variants in Alzheimer's disease. N Engl J Med 368:117-127. https://doi.org/10.1056/NEJMo a1211851

117. Gunn AP, Masters CL, Cherny RA (2010) Pyroglutamate-A $\beta$ : role in the natural history of Alzheimer's disease. Int J Biochem Cell Biol 42:1915-1918. https://doi.org/10.1016/j.bioce 1.2010.08.015

118. Guo JL, Lee VM (2014) Cell-to-cell transmission of pathogenic proteins in neurodegenerative diseases. Nat Med 20:130-138. https://doi.org/10.1038/nm.3457

119. Guo LH, Alexopoulos P, Perneczky R (2013) Heart-type fatty acid binding protein and vascular endothelial growth factor: cerebrospinal fluid biomarker candidates for Alzheimer's disease. Eur Arch Psychiatry Clin Neurosci 263:553-560. https://doi. org/10.1007/s00406-013-0405-4

120. Guo R, Fan G, Zhang J, Wu C, Du Y, Ye H et al (2017) A 9-microRNA signature in serum serves as a noninvasive biomarker in early diagnosis of Alzheimer's disease. J Alzheimers Dis 60:1365-1377. https://doi.org/10.3233/JAD-170343

121. Hamilton RL (2000) Lewy bodies in Alzheimer's disease: a neuropathological review of 145 cases using alpha-synuclein immunohistochemistry. Brain Pathol 10:378-384

122. Hampel H, Bürger K, Teipel SJ, Bokde AL, Zetterberg H, Blennow K (2008) Core candidate neurochemical and imaging biomarkers of Alzheimer's disease. Alzheimers Dement 4:38-48. https://doi.org/10.1016/j.jalz.2007.08.006

123. Hampel H, Frank R, Broich K, Teipel SJ, Katz RG, Hardy J et al (2010) Biomarkers for Alzheimer's disease: academic, industry and regulatory perspectives. Nat Rev Drug Discov 9:560-574. https://doi.org/10.1038/nrd3115

124. Hampel H, Lista S, Khachaturian ZS (2012) Development of biomarkers to chart all Alzheimer's disease stages: the royal road to cutting the therapeutic Gordian Knot. Alzheimers Dement 8:312-336. https://doi.org/10.1016/j.jalz.2012.05.2116

125. Hampel H, Lista S, Teipel SJ, Garaci F, Nisticó R, Blennow K et al (2014) Perspective on future role of biological markers in clinical therapy trials of Alzheimer's disease: a long-range point of view beyond 2020. Biochem Pharmacol 88:426-449. https:// doi.org/10.1016/j.bcp.2013.11.009

126. Hampel H, O'Bryant SE, Castrillo JI, Ritchie C, Rojkova K, Broich K et al (2016) PRECISION MEDICINE-the Golden Gate for detection, treatment and prevention of Alzheimer's disease.
J Prev Alzheimers Dis 3:243-259. https://doi.org/10.14283/ jpad.2016.112

127. Hampel H, O’Bryant SE, Durrleman S, Younesi E, Rojkova K, Escott-Price $\mathrm{V}$ et al (2017) A precision medicine initiative for Alzheimer's disease: the road ahead to biomarker-guided integrative disease modeling. Climacteric 20:107-118. https://doi. org/10.1080/13697137.2017.1287866

128. Hampel H, O’Bryant SE, Molinuevo JL, Zetterberg H, Masters CL, Lista S et al (2018) Blood-based biomarkers for Alzheimer's disease: mapping the road to the clinic. Nat Rev Neurol 14:639-652. https://doi.org/10.1038/s41582-018-0079-7

129. Hampel H, Toschi N, Babiloni C, Baldacci F, Black KL, Bokde ALW et al (2018) Revolution of Alzheimer precision neurology. Passageway of systems biology and neurophysiology. J Alzheimers Dis 64(Suppl 1):S47-S105. https://doi.org/10.3233/JAD179932

130. Hampel H, Vergallo A, Aguilar LF, Benda N, Broich K, Cuello AC et al (2018) Precision pharmacology for Alzheimer's disease. Pharmacol Res 130:331-365. https://doi.org/10.1016/j. phrs.2018.02.014

131. Han J, Pluhackova K, Böckmann RA (2017) The multifaceted role of SNARE proteins in membrane fusion. Front Physiol 8:5. https://doi.org/10.3389/fphys.2017.00005

132. Hansson O, Hall S, Ohrfelt A, Zetterberg H, Blennow K, Minthon L et al (2014) Levels of cerebrospinal fluid $\alpha$-synuclein oligomers are increased in Parkinson's disease with dementia and dementia with Lewy bodies compared to Alzheimer's disease. Alzheimers Res Ther 6:25. https://doi.org/10.1186/alzrt255

133. Hansson O, Zetterberg H, Buchhave P, Londos E, Blennow K, Minthon L (2006) Association between CSF biomarkers and incipient Alzheimer's disease in patients with mild cognitive impairment: a follow-up study. Lancet Neurol 5:228-234. https ://doi.org/10.1016/S1474-4422(06)70355-6

134. Hardy JA, Higgins GA (1992) Alzheimer's disease: the amyloid cascade hypothesis. Science 256:184-185

135. Hare D, Ayton S, Bush A, Lei P (2013) A delicate balance: iron metabolism and diseases of the brain. Front Aging Neurosci 5:34. https://doi.org/10.3389/fnagi.2013.00034

136. He Z, Guo JL, McBride JD, Narasimhan S, Kim H, Changolkar L et al (2018) Amyloid- $\beta$ plaques enhance Alzheimer's brain tau-seeded pathologies by facilitating neuritic plaque tau aggregation. Nat Med 24:29-38. https://doi.org/10.1038/nm.4443

137. Heinonen O, Soininen H, Sorvari H, Kosunen O, Paljärvi L, Koivisto E et al (1995) Loss of synaptophysin-like immunoreactivity in the hippocampal formation is an early phenomenon in Alzheimer's disease. Neuroscience 64:375-384

138. Hellwig K, Kvartsberg H, Portelius E, Andreasson U, Oberstein TJ, Lewczuk P et al (2015) Neurogranin and YKL-40: independent markers of synaptic degeneration and neuroinflammation in Alzheimer's disease. Alzheimers Res Ther 7:74. https://doi. org/10.1186/s13195-015-0161-y

139. Henjum K, Almdahl IS, Årskog V, Minthon L, Hansson O, Fladby $\mathrm{T}$ et al (2016) Cerebrospinal fluid soluble TREM2 in aging and Alzheimer's disease. Alzheimers Res Ther 8:17. https ://doi.org/10.1186/s13195-016-0182-1

140. Henriksen K, O'Bryant SE, Hampel H, Trojanowski JQ, Montine TJ, Jeromin A et al (2014) The future of blood-based biomarkers for Alzheimer's disease. Alzheimers Dement 10:115-131. https ://doi.org/10.1016/j.jalz.2013.01.013

141. Heslegrave A, Heywood W, Paterson R, Magdalinou N, Svensson J, Johansson P et al (2016) Increased cerebrospinal fluid soluble TREM2 concentration in Alzheimer's disease. Mol Neurodegener 11:3. https://doi.org/10.1186/s13024-016-0071-x

142. Hesse R, Wahler A, Gummert P, Kirschmer S, Otto M, Tumani $\mathrm{H}$ et al (2016) Decreased IL-8 levels in CSF and serum of AD 
patients and negative correlation of MMSE and IL-1 $\beta$. BMC Neurol 16:185. https://doi.org/10.1186/s12883-016-0707-z

143. Hölttä M, Hansson O, Andreasson U, Hertze J, Minthon L, Nägga $K$ et al (2013) Evaluating amyloid- $\beta$ oligomers in cerebrospinal fluid as a biomarker for Alzheimer's disease. PLoS One 8:e66381. https://doi.org/10.1371/journal.pone.0066381

144. Horrocks MH, Lee SF, Gandhi S, Magdalinou NK, Chen SW, Devine MJ et al (2016) Single-molecule imaging of individual amyloid protein aggregates in human biofluids. ACS Chem Neurosci 7:399-406. https://doi.org/10.1021/acschemneuro.5b00324

145. Hu N, Tan MS, Yu JT, Sun L, Tan L, Wang YL et al (2014) Increased expression of TREM2 in peripheral blood of Alzheimer's disease patients. J Alzheimers Dis 38:497-501. https://doi. org/10.3233/jad-130854

146. Hu WT, Chen-Plotkin A, Arnold SE, Grossman M, Clark CM, Shaw LM et al (2010) Novel CSF biomarkers for Alzheimer's disease and mild cognitive impairment. Acta Neuropathol 119:669-678. https://doi.org/10.1007/s00401-010-0667-0

147. Huang X, Atwood CS, Hartshorn MA, Multhaup G, Goldstein LE, Scarpa RC et al (1999) The A beta peptide of Alzheimer's disease directly produces hydrogen peroxide through metal ion reduction. Biochemistry 38:7609-7616. https://doi.org/10.1021/ bi990438f

148. Hulstaert F, Blennow K, Ivanoiu A, Schoonderwaldt HC, Riemenschneider M, De Deyn PP et al (1999) Improved discrimination of AD patients using $\beta$-amyloid(1-42) and tau levels in CSF. Neurology 52:1555-1562

149. Huynh RA, Mohan C (2017) Alzheimer's disease: biomarkers in the genome, blood, and cerebrospinal fluid. Front Neurol 8:102. https://doi.org/10.3389/fneur.2017.00102

150. Inekci D, Henriksen K, Linemann T, Karsdal MA, Habib A, Bisgaard C et al (2015) Serum fragments of tau for the differential diagnosis of Alzheimer's disease. Curr Alzheimer Res 12:829-836

151. Ingelsson M (2016) Alpha-synuclein oligomers-neurotoxic molecules in Parkinson's disease and other Lewy body disorders. Front Neurosci 10:408. https://doi.org/10.3389/fnins.2016.00408

152. Irwin DJ (2016) Tauopathies as clinicopathological entities. Parkinsonism Relat Disord 22(Suppl 1):S29-S33. https://doi. org/10.1016/j.parkreldis.2015.09.020

153. Isaac M, Vamvakas S, Abadie E, Jonsson B, Gispen C, Pani L (2011) Qualification opinion of novel methodologies in the predementia stage of Alzheimer's disease: cerebro-spinal-fluid related biomarkers for drugs affecting amyloid burden-regulatory considerations by European Medicines Agency focusing in improving benefit/risk in regulatory trials. Eur Neuropsychopharmacol 21:781-788. https://doi.org/10.1016/j.euron euro.2011.08.003

154. Iturria-Medina Y, Sotero RC, Toussaint PJ, Mateos-Pérez JM, Evans AC, Alzheimer's Disease Neuroimaging Initiative (2016) Early role of vascular dysregulation on late-onset Alzheimer's disease based on multifactorial data-driven analysis. Nat Commun 7:11934. https://doi.org/10.1038/ncomms11934

155. Iwatsubo T, Odaka A, Suzuki N, Mizusawa H, Nukina N, Ihara $\mathrm{Y}$ (1994) Visualization of $\mathrm{A} \beta 42(43)$ and $\mathrm{A} \beta 40$ in senile plaques with end-specific $A \beta$ monoclonals: evidence that an initially deposited species is A $\beta 42(43)$. Neuron 13:45-53

156. Jack CR Jr, Knopman DS, Jagust WJ, Petersen RC, Weiner MW, Aisen PS et al (2013) Tracking pathophysiological processes in Alzheimer's disease: an updated hypothetical model of dynamic biomarkers. Lancet Neurol 12:207-216. https://doi.org/10.1016/ S1474-4422(12)70291-0

157. Jackson K, Barisone GA, Diaz E, Jin LW, DeCarli C, Despa F (2013) Amylin deposition in the brain: a second amyloid in Alzheimer disease? Ann Neurol 74:517-526. https://doi. org/10.1002/ana.23956
158. Jagust WJ, Landau SM, Shaw LM, Trojanowski JQ, Koeppe RA, Reiman EM et al (2009) Relationships between biomarkers in aging and dementia. Neurology 73:1193-1199. https://doi. org/10.1212/WNL.0b013e3181bc010c

159. James BD, Wilson RS, Boyle PA, Trojanowski JQ, Bennett DA, Schneider JA (2016) TDP-43 stage, mixed pathologies, and clinical Alzheimer's-type dementia. Brain 139:2983-2993. https:// doi.org/10.1093/brain/aww224

160. Janelidze S, Stomrud E, Palmqvist S, Zetterberg H, van Westen D, Jeromin A et al (2016) Plasma $\beta$-amyloid in Alzheimer's disease and vascular disease. Sci Rep 6:26801. https://doi. org/10.1038/srep26801

161. Janelidze S, Zetterberg H, Mattsson N, Palmqvist S, Vanderstichele H, Lindberg O et al (2016) CSF A $\beta 42 / A \beta 40$ and A $\beta 42 /$ A $\beta 38$ ratios: better diagnostic markers of Alzheimer disease. Ann Clin Transl Neurol 3:154-165. https://doi.org/10.1002/acn3.274

162. Jay TR, von Saucken VE, Landreth GE (2017) TREM2 in neurodegenerative diseases. Mol Neurodegener 12:56. https://doi. org/10.1186/s13024-017-0197-5

163. Josephs KA, Whitwell JL, Knopman DS, Hu WT, Stroh DA, Baker M et al (2008) Abnormal TDP-43 immunoreactivity in AD modifies clinicopathologic and radiologic phenotype. Neurology 70:1850-1857. https://doi.org/10.1212/01.wnl.00003 04041.09418.b1

164. Jucker M, Walker LC (2013) Self-propagation of pathogenic protein aggregates in neurodegenerative diseases. Nature 501:45-51. https://doi.org/10.1038/nature12481

165. Junttila A, Kuvaja M, Hartikainen P, Siloaho M, Helisalmi S, Moilanen V et al (2016) Cerebrospinal fluid TDP-43 in frontotemporal lobar degeneration and amyotrophic lateral sclerosis patients with and without the C9ORF72 hexanucleotide expansion. Dement Geriatr Cogn Dis Extra 6:142-149. https://doi. org/10.1159/000444788

166. Kakuda N, Miyasaka T, Iwasaki N, Nirasawa T, Wada-Kakuda S, Takahashi-Fujigasaki J et al (2017) Distinct deposition of amyloid-beta species in brains with Alzheimer's disease pathology visualized with MALDI imaging mass spectrometry. Acta Neuropathol Commun 5:73. https://doi.org/10.1186/s4047 8-017-0477-x

167. Kamat PK, Kalani A, Rai S, Swarnkar S, Tota S, Nath C et al (2016) Mechanism of oxidative stress and synapse dysfunction in the pathogenesis of Alzheimer's disease: understanding the therapeutics strategies. Mol Neurobiol 53:648-661. https://doi. org/10.1007/s12035-014-9053-6

168. Kang JH, Irwin DJ, Chen-Plotkin AS, Siderowf A, Caspell C, Coffey CS et al (2013) Association of cerebrospinal fluid $\beta$-amyloid 1-42, t-tau, p-tau181, and $\alpha$-synuclein levels with clinical features of drug-naive patients with early Parkinson disease. JAMA Neurol 70:1277-1287. https://doi.org/10.1001/ jamaneurol.2013.3861

169. Kang JH, Mollenhauer B, Coffey CS, Toledo JB, Weintraub D, Galasko DR et al (2016) CSF biomarkers associated with disease heterogeneity in early Parkinson's disease: the Parkinson's Progression Markers Initiative study. Acta Neuropathol 131:935949. https://doi.org/10.1007/s00401-016-1552-2

170. Kapaki E, Paraskevas GP, Emmanouilidou E, Vekrellis K (2013) The diagnostic value of CSF $\alpha$-synuclein in the differential diagnosis of dementia with Lewy bodies vs. normal subjects and patients with Alzheimer's disease. PLoS One 8:e81654. https:// doi.org/10.1371/journal.pone.0081654

171. Kasai T, Tokuda T, Ishii R, Ishigami N, Tsuboi Y, Nakagawa $M$ et al (2014) Increased $\alpha$-synuclein levels in the cerebrospinal fluid of patients with Creutzfeldt-Jakob disease. J Neurol 261:1203-1209. https://doi.org/10.1007/s00415-014-7334-7

172. Kasuga K, Tokutake T, Ishikawa A, Uchiyama T, Tokuda T, Onodera $\mathrm{O}$ et al (2010) Differential levels of $\alpha$-synuclein, 
$\beta$-amyloid42 and tau in CSF between patients with dementia with Lewy bodies and Alzheimer's disease. J Neurol Neurosurg Psychiatry 81:608-610. https://doi.org/10.1136/jnnp.2009.19748 3

173. Kennedy ME, Stamford AW, Chen X, Cox K, Cumming JN, Dockendorf MF et al (2016) The BACE1 inhibitor verubecestat (MK-8931) reduces CNS $\beta$-amyloid in animal models and in Alzheimer's disease patients. Sci Transl Med 8:363ra150. https ://doi.org/10.1126/scitranslmed.aad9704

174. Kerchner G, Ayalon G, Blendstrup M, Brunstein F, Chandra P, Datwani A et al (2017) Targeting tau with RO7105705: Phase I results and design of a Phase II study in prodromal-to-mild AD. Abstract presented at the 10th Clinical Trials on Alzheimer's Disease (CTAD). Boston (1-4 November 2017)

175. Kester MI, Teunissen CE, Crimmins DL, Herries EM, Ladenson JH, Scheltens $P$ et al (2015) Neurogranin as a cerebrospinal fluid biomarker for synaptic loss in symptomatic Alzheimer disease. JAMA Neurol 72:1275-1280. https://doi.org/10.1001/jamaneurol .2015 .1867

176. Kester MI, Teunissen CE, Sutphen C, Herries EM, Ladenson JH, Xiong C et al (2015) Cerebrospinal fluid VILIP-1 and YKL-40, candidate biomarkers to diagnose, predict and monitor Alzheimer's disease in a memory clinic cohort. Alzheimers Res Ther 7:59. https://doi.org/10.1186/s13195-015-0142-1

177. Khan SS, Bloom GS (2016) Tau: the center of a signaling nexus in Alzheimer's disease. Front Neurosci 10:31. https://doi. org/10.3389/fnins.2016.00031

178. Kim D, Kim YS, Shin DW, Park CS, Kang JH (2016) Harnessing cerebrospinal fluid biomarkers in clinical trials for treating Alzheimer's and Parkinson's diseases: potential and challenges. J Clin Neurol 12:381-392. https://doi.org/10.3988/ jen.2016.12.4.381

179. Kim HJ, Park KW, Kim TE, Im JY, Shin HS, Kim S et al (2015) Elevation of the plasma $\mathrm{A} \beta 40 / \mathrm{A} \beta 42$ ratio as a diagnostic marker of sporadic early-onset Alzheimer's disease. J Alzheimers Dis 48:1043-1050. https://doi.org/10.3233/JAD-143018

180. Kim J, Onstead L, Randle S, Price R, Smithson L, Zwizinski C et al (2007) A $\beta 40$ inhibits amyloid deposition in vivo. J Neurosci 27:627-633. https://doi.org/10.1523/jneurosci.4849-06.2007

181. Kim WS, Kågedal K, Halliday GM (2014) Alpha-synuclein biology in Lewy body diseases. Alzheimers Res Ther 6:73. https:// doi.org/10.1186/s13195-014-0073-2

182. Komori M, Kosa P, Stein J, Zhao V, Blake A, Cherup J et al (2017) Pharmacodynamic effects of daclizumab in the intrathecal compartment. Ann Clin Transl Neurol 4:478-490. https://doi. org/10.1002/acn3.427

183. Korff A, Liu C, Ginghina C, Shi M, Zhang J, Initiative Alzheimer's Disease Neuroimaging (2013) $\alpha$-Synuclein in cerebrospinal fluid of Alzheimer's disease and mild cognitive impairment. J Alzheimers Dis 36:679-688. https://doi.org/10.3233/jad-13045 8

184. Kuhle J, Nourbakhsh B, Grant D, Morant S, Barro C, Yaldizli O et al (2017) Serum neurofilament is associated with progression of brain atrophy and disability in early MS. Neurology 88:826831. https://doi.org/10.1212/wnl.0000000000003653

185. Kuhlmann J, Andreasson U, Pannee J, Bjerke M, Portelius E, Leinenbach A et al (2017) CSF Abeta1-42-an excellent but complicated Alzheimer's biomarker-a route to standardisation. Clin Chim Acta 467:27-33. https://doi.org/10.1016/j. cca.2016.05.014

186. Kuhn PH, Koroniak K, Hogl S, Colombo A, Zeitschel U, Willem $M$ et al (2012) Secretome protein enrichment identifies physiological BACE1 protease substrates in neurons. EMBO J 31:3157-3168. https://doi.org/10.1038/emboj.2012.173

187. Kuiperij HB, Versleijen AA, Beenes M, Verwey NA, Benussi L, Paterlini A et al (2017) Tau rather than TDP-43 proteins are potential cerebrospinal fluid biomarkers for frontotemporal lobar degeneration subtypes: a pilot study. J Alzheimers Dis 55:585595. https://doi.org/10.3233/jad-160386

188. Kuperstein I, Broersen K, Benilova I, Rozenski J, Jonckheere W, Debulpaep M et al (2010) Neurotoxicity of Alzheimer's disease $A \beta$ peptides is induced by small changes in the $A \beta 42$ to $A \beta 40$ ratio. EMBO J 29:3408-3420. https://doi.org/10.1038/emboj .2010 .211

189. Kvartsberg H, Duits FH, Ingelsson M, Andreasen N, Öhrfelt A, Andersson K et al (2015) Cerebrospinal fluid levels of the synaptic protein neurogranin correlates with cognitive decline in prodromal Alzheimer's disease. Alzheimers Dement 11:1180-1190. https://doi.org/10.1016/j.jalz.2014.10.009

190. Kvartsberg H, Portelius E, Andreasson U, Brinkmalm G, Hellwig $\mathrm{K}$, Lelental $\mathrm{N}$ et al (2015) Characterization of the postsynaptic protein neurogranin in paired cerebrospinal fluid and plasma samples from Alzheimer's disease patients and healthy controls. Alzheimers Res Ther 7:40. https://doi.org/10.1186/s1319 5-015-0124-3

191. Lai KSP, Liu CS, Rau A, Lanctot KL, Kohler CA, Pakosh M et al (2017) Peripheral inflammatory markers in Alzheimer's disease: a systematic review and meta-analysis of 175 studies. J Neurol Neurosurg Psychiatry 88:876-882. https://doi.org/10.1136/jnnp2017-316201

192. Laterza OF, Modur VR, Crimmins DL, Olander JV, Landt Y, Lee JM et al (2006) Identification of novel brain biomarkers. Clin Chem 52:1713-1721. https://doi.org/10.1373/clinc hem.2006.070912

193. Lauridsen C, Sando SB, Moller I, Berge G, Pomary PK, Grontvedt GR et al (2017) Cerebrospinal fluid Abeta43 Is reduced in early-onset compared to late-onset Alzheimer's Disease, but has similar diagnostic accuracy to Abeta42. Front Aging Neurosci 9:210. https://doi.org/10.3389/fnagi.2017.00210

194. Lee JM, Blennow K, Andreasen N, Laterza O, Modur V, Olander $\mathrm{J}$ et al (2008) The brain injury biomarker VLP-1 is increased in the cerebrospinal fluid of Alzheimer disease patients. Clin Chem 54:1617-1623. https://doi.org/10.1373/clinchem.2008.104497

195. Lee PH, Lee G, Park HJ, Bang OY, Joo IS, Huh K (2006) The plasma alpha-synuclein levels in patients with Parkinson's disease and multiple system atrophy. J Neural Transm (Vienna) 113:1435-1439. https://doi.org/10.1007/s00702-005-0427-9

196. Lee VM, Balin BJ, Otvos L Jr, Trojanowski JQ (1991) A68: a major subunit of paired helical filaments and derivatized forms of normal tau. Science 251:675-678

197. Lee VM, Trojanowski JQ (2001) Transgenic mouse models of tauopathies: prospects for animal models of Pick's disease. Neurology 56:S26-S30

198. Leitão MJ, Baldeiras I, Herukka SK, Pikkarainen M, Leinonen V, Simonsen AH et al (2015) Chasing the effects of pre-analytical confounders-a multicenter study on CSF-AD biomarkers. Front Neurol 6:153. https://doi.org/10.3389/fneur.2015.00153

199. Lemstra AW, de Beer MH, Teunissen CE, Schreuder C, Scheltens P, van der Flier WM et al (2017) Concomitant AD pathology affects clinical manifestation and survival in dementia with Lewy bodies. J Neurol Neurosurg Psychiatry 88:113-118. https://doi. org/10.1136/jnnp-2016-313775

200. Leschik J, Welzel A, Weissmann C, Eckert A, Brandt R (2007) Inverse and distinct modulation of tau-dependent neurodegeneration by presenilin 1 and amyloid- $\beta$ in cultured cortical neurons: evidence that tau phosphorylation is the limiting factor in amyloid- $\beta$-induced cell death. J Neurochem 101:1303-1315. https://doi.org/10.1111/j.1471-4159.2006.04435.x

201. Leung YY, Toledo JB, Nefedov A, Polikar R, Raghavan N, Xie SX et al (2015) Identifying amyloid pathology-related cerebrospinal fluid biomarkers for Alzheimer's disease in a multicohort 
study. Alzheimers Dement (Amst) 1:339-348. https://doi. org/10.1016/j.dadm.2015.06.008

202. Leuzy A, Chiotis K, Hasselbalch SG, Rinne JO, de Mendonça A, Otto $\mathrm{M}$ et al (2016) Pittsburgh compound B imaging and cerebrospinal fluid amyloid- $\beta$ in a multicentre European memory clinic study. Brain 139:2540-2553. https://doi.org/10.1093/brain /aww160

203. Leverenz JB, Fishel MA, Peskind ER, Montine TJ, Nochlin D, Steinbart E et al (2006) Lewy body pathology in familial Alzheimer disease: evidence for disease- and mutation-specific pathologic phenotype. Arch Neurol 63:370-376. https://doi. org/10.1001/archneur.63.3.370

204. Lewczuk P, Lelental N, Lachmann I, Holzer M, Flach K, Brandner $S$ et al (2017) Non-phosphorylated tau as a potential biomarker of Alzheimer's disease: analytical and diagnostic characterization. J Alzheimers Dis 55:159-170. https://doi.org/10.3233/ JAD-160448

205. Lewczuk P, Matzen A, Blennow K, Parnetti L, Molinuevo JL, Eusebi $P$ et al (2017) Cerebrospinal fluid A $\beta 42 / 40$ corresponds better than A $\beta 42$ to amyloid PET in Alzheimer's disease. J Alzheimers Dis 55:813-822. https://doi.org/10.3233/jad-160722

206. Lewczuk P, Riederer P, O'Bryant SE, Verbeek MM, Dubois B, Visser PJ et al (2017) Cerebrospinal fluid and blood biomarkers for neurodegenerative dementias: an update of the Consensus of the Task Force on Biological Markers in Psychiatry of the World Federation of Societies of Biological Psychiatry. World J Biol Psychiatry. https://doi.org/10.1080/15622975.2017.1375556

207. Lewis KA, Su Y, Jou O, Ritchie C, Foong C, Hynan LS et al (2010) Abnormal neurites containing C-terminally truncated alpha-synuclein are present in Alzheimer's disease without conventional Lewy body pathology. Am J Pathol 177:3037-3050. https://doi.org/10.2353/ajpath.2010.100552

208. Leyhe T, Andreasen N, Simeoni M, Reich A, von Arnim CA, Tong X et al (2014) Modulation of beta-amyloid by a single dose of GSK933776 in patients with mild Alzheimer's disease: a phase I study. Alzheimers Res Ther 6:19. https://doi.org/10.1186/ alzrt249

209. Li G, Sokal I, Quinn JF, Leverenz JB, Brodey M, Schellenberg GD et al (2007) CSF tau/A 342 ratio for increased risk of mild cognitive impairment: a follow-up study. Neurology 69:631-639. https://doi.org/10.1212/01.wnl.0000267428.62582.aa

210. Li X, Lei P, Tuo Q, Ayton S, Li QX, Moon S et al (2015) Enduring elevations of hippocampal amyloid precursor protein and iron are features of $\beta$-amyloid toxicity and are mediated by tau. Neurotherapeutics 12:862-873. https://doi.org/10.1007/s1331 1-015-0378-2

211. Libreros S, Iragavarapu-Charyulu V (2015) YKL-40/CHI3L1 drives inflammation on the road of tumor progression. J Leukoc Biol 98:931-936. https://doi.org/10.1189/jlb.3VMR0415-142R

212. Lin CH, Yang SY, Horng HE, Yang CC, Chieh JJ, Chen HH et al (2017) Plasma $\alpha$-synuclein predicts cognitive decline in Parkinson's disease. J Neurol Neurosurg Psychiatry 88:818-824. https ://doi.org/10.1136/jnnp-2016-314857

213. Lippa CF, Schmidt ML, Lee VM, Trojanowski JQ (1999) Antibodies to alpha-synuclein detect Lewy bodies in many Down's syndrome brains with Alzheimer's disease. Ann Neurol 45:353-357

214. Lista S, Emanuele E (2011) Role of amyloid beta1-42 and neuroimaging biomarkers in Alzheimer's disease. Biomark Med 5:411-413. https://doi.org/10.2217/bmm.11.50

215. Lista S, Faltraco F, Hampel H (2013) Biological and methodical challenges of blood-based proteomics in the field of neurological research. Prog Neurobiol 101-102:18-34. https://doi. org/10.1016/j.pneurobio.2012.06.006

216. Lista S, Faltraco F, Prvulovic D, Hampel H (2013) Blood and plasma-based proteomic biomarker research in Alzheimer's disease. Prog Neurobiol 101-102:1-17. https://doi.org/10.1016/j. pneurobio.2012.06.007

217. Lista S, Garaci FG, Ewers M, Teipel S, Zetterberg H, Blennow $\mathrm{K}$ et al (2014) CSF Abeta1-42 combined with neuroimaging biomarkers in the early detection, diagnosis and prediction of Alzheimer's disease. Alzheimers Dement 10:381-392. https:// doi.org/10.1016/j.jalz.2013.04.506

218. Lista S, Hampel H (2017) Synaptic degeneration and neurogranin in the pathophysiology of Alzheimer's disease. Expert Rev Neurother 17:47-57. https://doi.org/10.1080/14737175.2016.12042 34

219. Lista S, Khachaturian ZS, Rujescu D, Garaci F, Dubois B, Hampel H (2016) Application of systems theory in longitudinal studies on the origin and progression of Alzheimer's disease. Methods Mol Biol 1303:49-67. https://doi. org/10.1007/978-1-4939-2627-5_2

220. Lista S, Toschi N, Baldacci F, Zetterberg H, Blennow K, Kilimann I et al (2017) Diagnostic accuracy of CSF neurofilament light chain protein in the biomarker-guided classification system for Alzheimer's disease. Neurochem Int 108:355-360. https:// doi.org/10.1016/j.neuint.2017.05.010

221. Lista S, Toschi N, Baldacci F, Zetterberg H, Blennow K, Kilimann I et al (2017) Cerebrospinal fluid neurogranin as a biomarker of neurodegenerative diseases: a cross-sectional study. J Alzheimers Dis 59:1327-1334. https://doi.org/10.3233/jad170368

222. Lista S, Zetterberg H, O’Bryant SE, Blennow K, Hampel H (2017) Evolving relevance of neuroproteomics in Alzheimer's disease. Methods Mol Biol 1598:101-115. https://doi. org/10.1007/978-1-4939-6952-4_5

223. Liu M, Guo S, Hibbert JM, Jain V, Singh N, Wilson NO et al (2011) CXCL10/IP-10 in infectious diseases pathogenesis and potential therapeutic implications. Cytokine Growth Factor Rev 22:121-130. https://doi.org/10.1016/j.cytogfr.2011.06.001

224. Ljungqvist J, Zetterberg H, Mitsis M, Blennow K, Skoglund T (2017) Serum neurofilament light protein as a marker for diffuse axonal injury: results from a case series study. J Neurotrauma 34:1124-1127. https://doi.org/10.1089/neu.2016.4496

225. Llorens F, Kruse N, Karch A, Schmitz M, Zafar S, Gotzmann $\mathrm{N}$ et al (2017) Validation of $\alpha$-synuclein as a CSF biomarker for sporadic Creutzfeldt-Jakob disease. Mol Neurobiol 55:22492257. https://doi.org/10.1007/s12035-017-0479-5

226. Loeffler DA, Connor JR, Juneau PL, Snyder BS, Kanaley L, DeMaggio AJ et al (1995) Transferrin and iron in normal, Alzheimer's disease, and Parkinson's disease brain regions. J Neurochem 65:710-724

227. Lövheim H, Elgh F, Johansson A, Zetterberg H, Blennow K, Hallmans $G$ et al (2017) Plasma concentrations of free amyloid $\beta$ cannot predict the development of Alzheimer's disease. Alzheimers Dement 13:778-782. https://doi.org/10.1016/j. jalz.2016.12.004

228. Lu CH, Macdonald-Wallis C, Gray E, Pearce N, Petzold A, Norgren $\mathrm{N}$ et al (2015) Neurofilament light chain: a prognostic biomarker in amyotrophic lateral sclerosis. Neurology 84:22472257. https://doi.org/10.1212/WNL.0000000000001642

229. Luk KC, Kehm V, Carroll J, Zhang B, O’Brien P, Trojanowski JQ et al (2012) Pathological $\alpha$-synuclein transmission initiates Parkinson-like neurodegeneration in nontransgenic mice. Science 338:949-953. https://doi.org/10.1126/science.1227157

230. Luo X, Hou L, Shi H, Zhong X, Zhang Y, Zheng D et al (2013) CSF levels of the neuronal injury biomarker visinin-like protein-1 in Alzheimer's disease and dementia with Lewy bodies. J Neurochem 127:681-690. https://doi.org/10.1111/jnc.12331

231. Lycke JN, Karlsson JE, Andersen O, Rosengren LE (1998) Neurofilament protein in cerebrospinal fluid: a potential marker 
of activity in multiple sclerosis. J Neurol Neurosurg Psychiatry 64:402-404

232. Majbour NK, Chiasserini D, Vaikath NN, Eusebi P, Tokuda T, van de Berg W et al (2017) Increased levels of CSF total but not oligomeric or phosphorylated forms of alpha-synuclein in patients diagnosed with probable Alzheimer's disease. Sci Rep 7:40263. https://doi.org/10.1038/srep40263

233. Majbour NK, Vaikath NN, van Dijk KD, Ardah MT, Varghese $\mathrm{S}$, Vesterager LB et al (2016) Oligomeric and phosphorylated alpha-synuclein as potential CSF biomarkers for Parkinson's disease. Mol Neurodegener 11:7. https://doi.org/10.1186/s1302 4-016-0072-9

234. Marsh SE, Blurton-Jones M (2012) Examining the mechanisms that link $\beta$-amyloid and $\alpha$-synuclein pathologies. Alzheimers Res Ther 4:11. https://doi.org/10.1186/alzrt109

235. Masliah E, Hansen L, Albright T, Mallory M, Terry RD (1991) Immunoelectron microscopic study of synaptic pathology in Alzheimer's disease. Acta Neuropathol 81:428-433

236. Masliah E, Mallory M, Alford M, DeTeresa R, Hansen LA, McKeel DW Jr et al (2001) Altered expression of synaptic proteins occurs early during progression of Alzheimer's disease. Neurology 56:127-129

237. Masliah E, Terry RD, Alford M, DeTeresa R, Hansen LA (1991) Cortical and subcortical patterns of synaptophysinlike immunoreactivity in Alzheimer's disease. Am J Pathol 138:235-246

238. Masters CL, Bateman R, Blennow K, Rowe CC, Sperling RA, Cummings JL (2015) Alzheimer's disease. Nat Rev Dis Primers 1:15056. https://doi.org/10.1038/nrdp.2015.56

239. Masters CL, Simms G, Weinman NA, Multhaup G, McDonald BL, Beyreuther K (1985) Amyloid plaque core protein in Alzheimer disease and Down syndrome. Proc Natl Acad Sci USA 82:4245-4249

240. Mattsson N, Andreasson U, Zetterberg H, Blennow K, Alzheimer's Disease Neuroimaging Initiative (2017) Association of plasma neurofilament light with neurodegeneration in patients with Alzheimer disease. JAMA Neurol 74:557-566. https://doi. org/10.1001/jamaneurol.2016.6117

241. Mattsson N, Carrillo MC, Dean RA, Devous MD Sr, Nikolcheva T, Pesini P et al (2015) Revolutionizing Alzheimer's disease and clinical trials through biomarkers. Alzheimers Dement (Amst) 1:412-419. https://doi.org/10.1016/j.dadm.2015.09.001

242. Mattsson N, Insel PS, Palmqvist S, Portelius E, Zetterberg H, Weiner $\mathrm{M}$ et al (2016) Cerebrospinal fluid tau, neurogranin, and neurofilament light in Alzheimer's disease. EMBO Mol Med 8:1184-1196. https://doi.org/10.15252/emmm.201606540

243. Mattsson N, Insel PS, Palmqvist S, Stomrud E, van Westen D, Minthon L et al (2016) Increased amyloidogenic APP processing in $\mathrm{APOE} \varepsilon 4$-negative individuals with cerebral $\beta$-amyloidosis. Nat Commun 7:10918. https://doi.org/10.1038/ncomms10918

244. Mattsson N, Tabatabaei S, Johansson P, Hansson O, Andreasson U, Månsson JE et al (2011) Cerebrospinal fluid microglial markers in Alzheimer's disease: elevated chitotriosidase activity but lack of diagnostic utility. Neuromol Med 13:151-159. https://doi. org/10.1007/s12017-011-8147-9

245. Mattsson N, Zetterberg H, Janelidze S, Insel PS, Andreasson U, Stomrud E et al (2016) Plasma tau in Alzheimer disease. Neurology 87:1827-1835. https://doi.org/10.1212/WNL.0000000000 003246

246. McGowan E, Pickford F, Kim J, Onstead L, Eriksen J, Yu C et al (2005) A $\beta 42$ is essential for parenchymal and vascular amyloid deposition in mice. Neuron 47:191-199. https://doi. org/10.1016/j.neuron.2005.06.030

247. McKhann GM, Knopman DS, Chertkow H, Hyman BT, Jack CR Jr, Kawas CH et al (2011) The diagnosis of dementia due to Alzheimer's disease: recommendations from the National
Institute on Aging-Alzheimer's Association workgroups on diagnostic guidelines for Alzheimer's disease. Alzheimers Dement 7:263-269. https://doi.org/10.1016/j.jalz.2011.03.005

248. Mehta PD, Pirttila T, Mehta SP, Sersen EA, Aisen PS, Wisniewski HM (2000) Plasma and cerebrospinal fluid levels of amyloid beta proteins 1-40 and 1-42 in Alzheimer disease. Arch Neurol 57:100-105

249. Mellergård J, Tisell A, Blystad I, Grönqvist A, Blennow K, Olsson B et al (2017) Cerebrospinal fluid levels of neurofilament and tau correlate with brain atrophy in natalizumab-treated multiple sclerosis. Eur J Neurol 24:112-121. https://doi.org/10.1111/ ene. 13162

250. Meredith JE Jr, Sankaranarayanan S, Guss V, Lanzetti AJ, Berisha F, Neely RJ et al (2013) Characterization of novel CSF tau and ptau biomarkers for Alzheimer's disease. PLoS One 8:e76523. https://doi.org/10.1371/journal.pone.0076523

251. Mielke MM, Hagen CE, Wennberg AMV, Airey DC, Savica R, Knopman DS et al (2017) Association of plasma total tau level with cognitive decline and risk of mild cognitive impairment or dementia in the Mayo Clinic Study on Aging. JAMA Neurol 74:1073-1080. https://doi.org/10.1001/jamaneurol.2017.1359

252. Mohorko N, Bresjanac M (2008) Tau protein and human tauopathies: an overview. Zdrav Vestn 77:II-35-41

253. Mollenhauer B, Cullen V, Kahn I, Krastins B, Outeiro TF, Pepivani I et al (2008) Direct quantification of CSF $\alpha$-synuclein by ELISA and first cross-sectional study in patients with neurodegeneration. Exp Neurol 213:315-325. https://doi.org/10.1016/j. expneurol.2008.06.004

254. Mollenhauer B, Steinacker P, Bahn E, Bibl M, Brechlin P, Schlossmacher MG et al (2007) Serum heart-type fatty acidbinding protein and cerebrospinal fluid tau: marker candidates for dementia with Lewy bodies. Neurodegener Dis 4:366-375. https://doi.org/10.1159/000105157

255. Mori Y, Yoshino Y, Ochi S, Yamazaki K, Kawabe K, Abe M et al (2015) TREM2 mRNA expression in leukocytes is increased in Alzheimer's disease and schizophrenia. PLoS One 10:e0136835. https://doi.org/10.1371/journal.pone.0136835

256. Motter R, Vigo-Pelfrey C, Kholodenko D, Barbour R, JohnsonWood K, Galasko D et al (1995) Reduction of beta-amyloid peptide42 in the cerebrospinal fluid of patients with Alzheimer's disease. Ann Neurol 38:643-648. https://doi.org/10.1002/ana.41038 0413

257. Mroczko B, Groblewska M, Zboch M, Muszynski P, Zajkowska A, Borawska R et al (2015) Evaluation of visinin-like protein 1 concentrations in the cerebrospinal fluid of patients with mild cognitive impairment as a dynamic biomarker of Alzheimer's disease. J Alzheimers Dis 43:1031-1037. https://doi. org/10.3233/jad-141050

258. Mulder SD, van der Flier WM, Verheijen JH, Mulder C, Scheltens P, Blankenstein MA et al (2010) BACE1 activity in cerebrospinal fluid and its relation to markers of AD pathology. J Alzheimers Dis 20:253-260. https://doi.org/10.3233/jad-2010-1367

259. Mulugeta E, Londos E, Ballard C, Alves G, Zetterberg H, Blennow $\mathrm{K}$ et al (2011) CSF amyloid $\beta 38$ as a novel diagnostic marker for dementia with Lewy bodies. J Neurol Neurosurg Psychiatry 82:160-164. https://doi.org/10.1136/jnnp.2009.199398

260. Naj AC, Schellenberg GD, Alzheimer's Disease Genetics Consortium (2017) Genomic variants, genes, and pathways of Alzheimer's disease: an overview. Am J Med Genet B Neuropsychiatr Genet 174:5-26. https://doi.org/10.1002/ajmg.b.32499

261. Nakamura A, Kaneko N, Villemagne VL, Kato T, Doecke J, Doré $\mathrm{V}$ et al (2018) High performance plasma amyloid- $\beta$ biomarkers for Alzheimer's disease. Nature 554:249-254. https://doi. org/10.1038/nature25456

262. Nath S, Koziarz A, Badhiwala JH, Alhazzani W, Jaeschke R, Sharma $S$ et al (2017) Atraumatic versus conventional lumbar 
puncture needles: a systematic review and meta-analysis. Lancet 391:1197-1204. https://doi.org/10.1016/S0140-6736(17)32451 $-0$

263. Nelson PT, Alafuzoff I, Bigio EH, Bouras C, Braak H, Cairns NJ et al (2012) Correlation of Alzheimer disease neuropathologic changes with cognitive status: a review of the literature. $\mathrm{J}$ Neuropathol Exp Neurol 71:362-381. https://doi.org/10.1097/ NEN.0b013e31825018f7

264. Neumann K, Farías G, Slachevsky A, Perez P, Maccioni RB (2011) Human platelets tau: a potential peripheral marker for Alzheimer's disease. J Alzheimers Dis 25:103-109. https://doi. org/10.3233/JAD-2011-101641

265. Neumann M, Sampathu DM, Kwong LK, Truax AC, Micsenyi $\mathrm{MC}$, Chou TT et al (2006) Ubiquitinated TDP-43 in frontotemporal lobar degeneration and amyotrophic lateral sclerosis. Science 314:130-133. https://doi.org/10.1126/science.1134108

266. Novakova L, Axelsson M, Khademi M, Zetterberg H, Blennow $\mathrm{K}$, Malmeström C et al (2017) Cerebrospinal fluid biomarkers as a measure of disease activity and treatment efficacy in relapsingremitting multiple sclerosis. J Neurochem 141:296-304. https:// doi.org/10.1111/jnc. 13881

267. Novakova L, Axelsson M, Khademi M, Zetterberg H, Blennow $\mathrm{K}$, Malmeström C et al (2017) Cerebrospinal fluid biomarkers of inflammation and degeneration as measures of fingolimod efficacy in multiple sclerosis. Mult Scler 23:62-71. https://doi. org/10.1177/1352458516639384

268. O'Bryant SE, Gupta V, Henriksen K, Edwards M, Jeromin A, Lista $S$ et al (2015) Guidelines for the standardization of preanalytic variables for blood-based biomarker studies in Alzheimer's disease research. Alzheimers Dement 11:549-560. https://doi. org/10.1016/j.jalz.2014.08.099

269. O’Bryant SE, Mielke MM, Rissman RA, Lista S, Vanderstichele $\mathrm{H}$, Zetterberg $\mathrm{H}$ et al (2017) Blood-based biomarkers in Alzheimer disease: current state of the science and a novel collaborative paradigm for advancing from discovery to clinic. Alzheimers Dement 13:45-58. https://doi.org/10.1016/j.jalz.2016.09.014

270. Öhrfelt A, Brinkmalm A, Dumurgier J, Brinkmalm G, Hansson $\mathrm{O}$, Zetterberg $\mathrm{H}$ et al (2016) The pre-synaptic vesicle protein synaptotagmin is a novel biomarker for Alzheimer's disease. Alzheimers Res Ther 8:41. https://doi.org/10.1186/s13195-016-0208-8

271. Olsson B, Lautner R, Andreasson U, Öhrfelt A, Portelius E, Bjerke $\mathrm{M}$ et al (2016) CSF and blood biomarkers for the diagnosis of Alzheimer's disease: a systematic review and meta-analysis. Lancet Neurol 15:673-684. https://doi.org/10.1016/s1474 -4422(16)00070-3

272. Olsson F, Schmidt S, Althoff V, Munter LM, Jin S, Rosqvist S et al (2014) Characterization of intermediate steps in amyloid beta $(\mathrm{A} \beta)$ production under near-native conditions. J Biol Chem 289:1540-1550. https://doi.org/10.1074/jbc.M113.498246

273. Ovod V, Ramsey KN, Mawuenyega KG, Bollinger JG, Hicks T, Schneider T et al (2017) Amyloid $\beta$ concentrations and stable isotope labeling kinetics of human plasma specific to central nervous system amyloidosis. Alzheimers Dement 13:841-849. https://doi.org/10.1016/j.jalz.2017.06.2266

274. Palmqvist S, Janelidze S, Stromrud E, Zetterberg H, Karl J, Mattsson N et al (2018) Detecting brain amyloid status using fully automated plasma $\mathrm{A} \beta$ biomarker assays. Abstract presented at the Alzheimer's Association International Conference (AAIC) 2018. Chicago (22-26 July 2018)

275. Palmqvist S, Zetterberg H, Mattsson N, Johansson P, Alzheimer's Disease Neuroimaging Initiative, Minthon L et al (2015) Detailed comparison of amyloid PET and CSF biomarkers for identifying early Alzheimer disease. Neurology 85:1240-1249. https://doi. org/10.1212/wnl.0000000000001991

276. Pannee J, Portelius E, Minthon L, Gobom J, Andreasson U, Zetterberg $\mathrm{H}$ et al (2016) Reference measurement procedure for CSF amyloid beta (A $\beta) 1-42$ and the CSF A $\beta 1-42 / A \beta 1-40$ ratio- a cross-validation study against amyloid PET. J Neurochem 139:651-658. https://doi.org/10.1111/jnc.13838

277. Pannee J, Törnqvist U, Westerlund A, Ingelsson M, Lannfelt $\mathrm{L}$, Brinkmalm $\mathrm{G}$ et al (2014) The amyloid- $\beta$ degradation pattern in plasma-a possible tool for clinical trials in Alzheimer's disease. Neurosci Lett 573:7-12. https://doi.org/10.1016/j.neule t.2014.04.041

278. Park JC, Han SH, Cho HJ, Byun MS, Yi D, Choe YM et al (2017) Chemically treated plasma $A \beta$ is a potential blood-based biomarker for screening cerebral amyloid deposition. Alzheimers Res Ther 9:20. https://doi.org/10.1186/s13195-017-0248-8

279. Parnetti L, Eusebi P, Lleó A (2016) Cerebrospinal fluid biomarkers for target engagement and efficacy in clinical trials for Alzheimer's and Parkinson's diseases. Front Neurol Neurosci 39:117-123. https://doi.org/10.1159/000445452

280. Pascoal TA, Mathotaarachchi S, Shin M, Benedet AL, Mohades S, Wang S et al (2017) Synergistic interaction between amyloid and tau predicts the progression to dementia. Alzheimers Dement 13:644-653. https://doi.org/10.1016/j.jalz.2016.11.005

281. Pereira JB, Strandberg TO, Palmqvist S, Volpe G, van Westen D, Westman E et al (2018) Amyloid network topology characterizes the progression of Alzheimer's disease during the predementia stages. Cereb Cortex 28:340-349. https://doi.org/10.1093/cerco $\mathrm{r} / \mathrm{bhx} 294$

282. Pereira JB, Westman E, Hansson O, Alzheimer's Disease Neuroimaging Initiative (2017) Association between cerebrospinal fluid and plasma neurodegeneration biomarkers with brain atrophy in Alzheimer's disease. Neurobiol Aging 58:14-29. https:// doi.org/10.1016/j.neurobiolaging.2017.06.002

283. Perneczky R, Alexopoulos P, Alzheimer's Disease Neuroimaging Initiative (2014) Cerebrospinal fluid BACE1 activity and markers of amyloid precursor protein metabolism and axonal degeneration in Alzheimer's disease. Alzheimers Dement 10:S425-S429 e421. https://doi.org/10.1016/j.jalz.2013.09.006

284. Perret-Liaudet A, Pelpel M, Tholance Y, Dumont B, Vanderstichele H, Zorzi W et al (2012) Risk of Alzheimer's disease biological misdiagnosis linked to cerebrospinal collection tubes. J Alzheimers Dis 31:13-20. https://doi.org/10.3233/ JAD-2012-120361

285. Petersen RC, Aisen P, Boeve BF, Geda YE, Ivnik RJ, Knopman DS et al (2013) Mild cognitive impairment due to Alzheimer disease in the community. Ann Neurol 74:199-208. https://doi. org/10.1002/ana.23931

286. Petzold A, Keir G, Warren J, Fox N, Rossor MN (2007) A systematic review and meta-analysis of CSF neurofilament protein levels as biomarkers in dementia. Neurodegener Dis 4:185-194. https://doi.org/10.1159/000101843

287. Piccio L, Deming Y, Del-Águila JL, Ghezzi L, Holtzman DM, Fagan AM et al (2016) Cerebrospinal fluid soluble TREM2 is higher in Alzheimer disease and associated with mutation status. Acta Neuropathol 131:925-933. https://doi.org/10.1007/ s00401-016-1533-5

288. Pijnenburg YA, Janssen JC, Schoonenboom NS, Petzold A, Mulder C, Stigbrand T et al (2007) CSF neurofilaments in frontotemporal dementia compared with early onset Alzheimer's disease and controls. Dement Geriatr Cogn Disord 23:225-230. https://doi.org/10.1159/000099473

289. Portelius E, Price E, Brinkmalm G, Stiteler M, Olsson M, Persson $\mathrm{R}$ et al (2011) A novel pathway for amyloid precursor protein processing. Neurobiol Aging 32:1090-1098. https://doi. org/10.1016/j.neurobiolaging.2009.06.002

290. Portelius E, Westman-Brinkmalm A, Zetterberg H, Blennow K (2006) Determination of $\beta$-amyloid peptide signatures in cerebrospinal fluid using immunoprecipitation-mass spectrometry. J Proteome Res 5:1010-1016. https://doi.org/10.1021/pr050475v 
291. Portelius E, Zetterberg H, Skillback T, Tornqvist U, Andreasson U, Trojanowski JQ et al (2015) Cerebrospinal fluid neurogranin: relation to cognition and neurodegeneration in Alzheimer's disease. Brain 138:3373-3385. https://doi.org/10.1093/brain/awv26 7

292. Pottiez G, Yang L, Stewart T, Song N, Aro P, Galasko DR et al (2017) Mass-spectrometry-based method to quantify in parallel tau and amyloid beta 1-42 in CSF for the diagnosis of Alzheimer's disease. J Proteome Res 16:1228-1238. https://doi. org/10.1021/acs.jproteome.6b00829

293. Querol-Vilaseca M, Colom-Cadena M, Pegueroles J, San MartínPaniello C, Clarimon J, Belbin O et al (2017) YKL-40 (Chitinase 3-like I) is expressed in a subset of astrocytes in Alzheimer's disease and other tauopathies. J Neuroinflammation 14:118. https ://doi.org/10.1186/s12974-017-0893-7

294. Racine AM, Koscik RL, Nicholas CR, Clark LR, Okonkwo OC, Oh JM et al (2016) Cerebrospinal fluid ratios with A $\beta 42$ predict preclinical brain $\beta$-amyloid accumulation. Alzheimers Dement (Amst) 2:27-38. https://doi.org/10.1016/j.dadm.2015.11.006

295. Reiman EM (2017) Alzheimer disease in 2016: putting AD treatments and biomarkers to the test. Nat Rev Neurol 13:74-76. https ://doi.org/10.1038/nrneurol.2017.1

296. Rhodin JA, Thomas T (2001) A vascular connection to Alzheimer's disease. Microcirculation 8:207-220. https://doi. org $/ 10.1038 / \mathrm{sj} / \mathrm{mn} / 7800086$

297. Riemenschneider M, Wagenpfeil S, Vanderstichele H, Otto M, Wiltfang J, Kretzschmar H et al (2003) Phospho-tau/total tau ratio in cerebrospinal fluid discriminates Creutzfeldt-Jakob disease from other dementias. Mol Psychiatry 8:343-347. https:// doi.org/10.1038/sj.mp.4001220

298. Ritter A, Cummings J (2015) Fluid biomarkers in clinical trials of Alzheimer's disease therapeutics. Front Neurol 6:186. https:// doi.org/10.3389/fneur.2015.00186

299. Rivero-Santana A, Ferreira D, Perestelo-Pérez L, Westman E, Wahlund LO, Sarría A et al (2017) Cerebrospinal fluid biomarkers for the differential diagnosis between Alzheimer's disease and frontotemporal lobar degeneration: systematic review, HSROC analysis, and confounding factors. J Alzheimers Dis 55:625-644. https://doi.org/10.3233/JAD-160366

300. Robinson J, Lee E, Xie S, Rennert L, Suh E, Bredenberg C et al (2018) Neurodegenerative disease concomitant proteinopathies are prevalent, age-related and APOE4-associated. Brain 141:2181-2193. https://doi.org/10.1093/brain/awy146

301. Roe CM, Fagan AM, Grant EA, Hassenstab J, Moulder KL, Maue Dreyfus D et al (2013) Amyloid imaging and CSF biomarkers in predicting cognitive impairment up to 7.5 years later. Neurology 80:1784-1791. https://doi.org/10.1212/WNL.0b013 e3182918ca6

302. Rojas JC, Karydas A, Bang J, Tsai RM, Blennow K, Liman V et al (2016) Plasma neurofilament light chain predicts progression in progressive supranuclear palsy. Ann Clin Transl Neurol 3:216-225. https://doi.org/10.1002/acn3.290

303. Rosén C, Andersson CH, Andreasson U, Molinuevo JL, Bjerke M, Rami L et al (2014) Increased levels of chitotriosidase and YKL-40 in cerebrospinal fluid from patients with Alzheimer's disease. Dement Geriatr Cogn Dis Extra 4:297-304. https://doi. org/10.1159/000362164

304. Roussos P, Katsel P, Fam P, Tan W, Purohit DP, Haroutunian $\mathrm{V}$ (2015) The triggering receptor expressed on myeloid cells 2 (TREM2) is associated with enhanced inflammation, neuropathological lesions and increased risk for Alzheimer's dementia. Alzheimers Dement 11:1163-1170. https://doi.org/10.1016/j. jalz.2014.10.013

305. Rowe CC, Bourgeat P, Ellis KA, Brown B, Lim YY, Mulligan $\mathrm{R}$ et al (2013) Predicting Alzheimer disease with $\beta$-amyloid imaging: results from the Australian Imaging, Biomarkers, and
Lifestyle Study of Ageing. Ann Neurol 74:905-913. https://doi. org/10.1002/ana.24040

306. Russell CL, Mitra V, Hansson K, Blennow K, Gobom J, Zetterberg $\mathrm{H}$ et al (2017) Comprehensive quantitative profiling of tau and phosphorylated tau peptides in cerebrospinal fluid by mass spectrometry provides new biomarker candidates. J Alzheimers Dis 55:303-313. https://doi.org/10.3233/JAD-160633

307. Salminen A, Kauppinen A, Kaarniranta K (2017) Hypoxia/ ischemia activate processing of amyloid precursor protein: impact of vascular dysfunction in the pathogenesis of Alzheimer's disease. J Neurochem 140:536-549. https://doi. org/10.1111/jnc. 13932

308. Salvadores N, Shahnawaz M, Scarpini E, Tagliavini F, Soto C (2014) Detection of misfolded A $\beta$ oligomers for sensitive biochemical diagnosis of Alzheimer's disease. Cell Rep 7:261-268. https://doi.org/10.1016/j.celrep.2014.02.031

309. Sanabria-Castro A, Alvarado-Echeverría I, Monge-Bonilla C (2017) Molecular pathogenesis of Alzheimer's disease: an update. Ann Neurosci 24:46-54. https://doi.org/10.1159/00046 4422

310. Sanfilippo C, Forlenza O, Zetterberg H, Blennow K (2016) Increased neurogranin concentrations in cerebrospinal fluid of Alzheimer's disease and in mild cognitive impairment due to AD. J Neural Transm (Vienna) 123:1443-1447. https://doi. org/10.1007/s00702-016-1597-3

311. Savage MJ, Holder DJ, Wu G, Kaplow J, Siuciak JA, Potter WZ (2015) Soluble BACE- 1 activity and $\mathrm{sA} \beta \mathrm{PP} \beta$ concentrations in Alzheimer's disease and age-matched healthy control cerebrospinal fluid from the Alzheimer's Disease Neuroimaging Initiative-1 baseline cohort. J Alzheimers Dis 46:431-440. https://doi. org/10.3233/jad-142778

312. Savage MJ, Kalinina J, Wolfe A, Tugusheva K, Korn R, Cash-Mason $\mathrm{T}$ et al (2014) A sensitive a $\beta$ oligomer assay discriminates Alzheimer's and aged control cerebrospinal fluid. J Neurosci 34:2884-2897. https://doi.org/10.1523/JNEUR OSCI.1675-13.2014

313. Scheff SW, Price DA, Schmitt FA, Mufson EJ (2006) Hippocampal synaptic loss in early Alzheimer's disease and mild cognitive impairment. Neurobiol Aging 27:1372-1384. https://doi. org/10.1016/j.neurobiolaging.2005.09.012

314. Scheltens P, Blennow K, Breteler MM, de Strooper B, Frisoni GB, Salloway S et al (2016) Alzheimer's disease. Lancet 388:505-517. https://doi.org/10.1016/s0140-6736(15)01124-1

315. Scheuner D, Eckman C, Jensen M, Song X, Citron M, Suzuki $\mathrm{N}$ et al (1996) Secreted amyloid beta-protein similar to that in the senile plaques of Alzheimer's disease is increased in vivo by the presenilin 1 and 2 and APP mutations linked to familial Alzheimer's disease. Nat Med 2:864-870

316. Schmidt ML, Murray J, Lee VM, Hill WD, Wertkin A, Trojanowski JQ (1991) Epitope map of neurofilament protein domains in cortical and peripheral nervous system Lewy bodies. Am J Pathol 139:53-65

317. Schneider LS, Mangialasche F, Andreasen N, Feldman H, Giacobini E, Jones R et al (2014) Clinical trials and late-stage drug development for Alzheimer's disease: an appraisal from 1984 to 2014. J Intern Med 275:251-283. https://doi.org/10.1111/ joim. 12191

318. Schuster J, Funke SA (2016) Methods for the specific detection and quantitation of amyloid- $\beta$ oligomers in cerebrospinal fluid. J Alzheimers Dis 53:53-67. https://doi.org/10.3233/JAD-15102 9

319. Seeburger JL, Holder DJ, Combrinck M, Joachim C, Laterza O, Tanen M et al (2015) Cerebrospinal fluid biomarkers distinguish postmortem-confirmed Alzheimer's disease from other dementias and healthy controls in the OPTIMA cohort. J Alzheimers Dis 44:525-539. https://doi.org/10.3233/JAD-141725 
320. Selkoe DJ, Hardy J (2016) The amyloid hypothesis of Alzheimer's disease at 25 years. EMBO Mol Med 8:595-608. https:// doi.org/10.15252/emmm.201606210

321. Sengupta U, Nilson AN, Kayed R (2016) The role of amyloid- $\beta$ oligomers in toxicity, propagation, and immunotherapy. EBioMedicine 6:42-49. https://doi.org/10.1016/j.ebiom.2016.03.035

322. Seubert P, Vigo-Pelfrey C, Esch F, Lee M, Dovey H, Davis D et al (1992) Isolation and quantification of soluble Alzheimer's $\beta$-peptide from biological fluids. Nature 359:325-327. https:// doi.org/10.1038/359325a0

323. Sevigny J, Chiao P, Bussiere T, Weinreb PH, Williams L, Maier M et al (2016) The antibody aducanumab reduces Abeta plaques in Alzheimer's disease. Nature 537:50-56. https://doi. org/10.1038/nature 19323

324. Shahim P, Zetterberg H, Tegner Y, Blennow K (2017) Serum neurofilament light as a biomarker for mild traumatic brain injury in contact sports. Neurology 88:1788-1794. https://doi. org/10.1212/wnl.0000000000003912

325. Shahnawaz M, Tokuda T, Waragai M, Mendez N, Ishii R, Trenkwalder C et al (2017) Development of a biochemical diagnosis of Parkinson disease by detection of $\alpha$-synuclein misfolded aggregates in cerebrospinal fluid. JAMA Neurol 74:163-172. https://doi.org/10.1001/jamaneurol.2016.4547

326. Shaw LM, Vanderstichele H, Knapik-Czajka M, Clark CM, Aisen PS, Petersen RC et al (2009) Cerebrospinal fluid biomarker signature in Alzheimer's Disease neuroimaging initiative subjects. Ann Neurol 65:403-413. https://doi.org/10.1002/ ana. 21610

327. Shaw LM, Vanderstichele H, Knapik-Czajka M, Figurski M, Coart E, Blennow K et al (2011) Qualification of the analytical and clinical performance of CSF biomarker analyses in ADNI. Acta Neuropathol 121:597-609. https://doi.org/10.1007/s0040 1-011-0808-0

328. Sheinerman KS, Toledo JB, Tsivinsky VG, Irwin D, Grossman M, Weintraub D et al (2017) Circulating brain-enriched microRNAs as novel biomarkers for detection and differentiation of neurodegenerative diseases. Alzheimers Res Ther 9:89. https:// doi.org/10.1186/s13195-017-0316-0

329. Shekhar S, Kumar R, Rai N, Kumar V, Singh K, Upadhyay AD et al (2016) Estimation of tau and phosphorylated tau181 in serum of Alzheimer's disease and mild cognitive impairment patients. PLoS One 11:e0159099. https://doi.org/10.1371/journ al.pone.0159099

330. Shen Y, Wang H, Sun Q, Yao H, Keegan AP, Mullan M et al (2018) Increased plasma beta-secretase 1 may predict conversion to Alzheimer's disease dementia in individuals with mild cognitive impairment. Biol Psychiatry 83:447-455. https://doi. org/10.1016/j.biopsych.2017.02.007

331. Shi M, Zabetian CP, Hancock AM, Ginghina C, Hong Z, Yearout D et al (2010) Significance and confounders of peripheral DJ-1 and alpha-synuclein in Parkinson's disease. Neurosci Lett 480:78-82. https://doi.org/10.1016/j.neulet.2010.06.009

332. Sims R, van der Lee SJ, Naj AC, Bellenguez C, Badarinarayan $\mathrm{N}$, Jakobsdottir J et al (2017) Rare coding variants in PLCG2, $A B I 3$, and TREM2 implicate microglial-mediated innate immunity in Alzheimer's disease. Nat Genet 49:1373-1384. https:// doi.org/10.1038/ng.3916

333. Singh N, Haldar S, Tripathi AK, Horback K, Wong J, Sharma D et al (2014) Brain iron homeostasis: from molecular mechanisms to clinical significance and therapeutic opportunities. Antioxid Redox Signal 20:1324-1363. https://doi.org/10.1089/ ars.2012.4931

334. Sjögren M, Blomberg M, Jonsson M, Wahlund LO, Edman A, Lind $\mathrm{K}$ et al (2001) Neurofilament protein in cerebrospinal fluid: a marker of white matter changes. J Neurosci Res 66:510-516. https://doi.org/10.1002/jnr.1242
335. Skillbäck T, Farahmand B, Bartlett JW, Rosén C, Mattsson N, Nägga K et al (2014) CSF neurofilament light differs in neurodegenerative diseases and predicts severity and survival. Neurology 83:1945-1953. https://doi.org/10.1212/wnl.0000000000001015

336. Skillbäck T, Rosén C, Asztely F, Mattsson N, Blennow K, Zetterberg H (2014) Diagnostic performance of cerebrospinal fluid total tau and phosphorylated tau in Creutzfeldt-Jakob disease: results from the Swedish Mortality Registry. JAMA Neurol 71:476-483. https://doi.org/10.1001/jamaneurol.2013.6455

337. Slachevsky A, Guzmán-Martínez L, Delgado C, Reyes P, Farías GA, Muñoz-Neira C et al (2017) Tau platelets correlate with regional brain atrophy in patients with Alzheimer's disease. J Alzheimers Dis 55:1595-1603. https://doi.org/10.3233/JAD160652

338. Slaets S, Le Bastard N, Martin JJ, Sleegers K, Van Broeckhoven C, De Deyn PP et al (2013) Cerebrospinal fluid A $\beta 1-40$ improves differential dementia diagnosis in patients with intermediate p-tau181 levels. J Alzheimers Dis 36:759-767. https:// doi.org/10.3233/jad-130107

339. Slaets S, Vanmechelen E, Le Bastard N, Decraemer H, Vandijck M, Martin JJ et al (2014) Increased CSF $\alpha$-synuclein levels in Alzheimer's disease: correlation with tau levels. Alzheimers Dement 10:S290-S298. https://doi.org/10.1016/j. jalz.2013.10.004

340. Snyder HM, Corriveau RA, Craft S, Faber JE, Greenberg SM, Knopman D et al (2015) Vascular contributions to cognitive impairment and dementia including Alzheimer's disease. Alzheimers Dement 11:710-717. https://doi.org/10.1016/j. jalz.2014.10.008

341. Soares HD, Gasior M, Toyn JH, Wang JS, Hong Q, Berisha F et al (2016) The $\gamma$-secretase modulator, BMS-932481, modulates $\mathrm{A} \beta$ peptides in the plasma and cerebrospinal fluid of healthy volunteers. J Pharmacol Exp Ther 358:138-150. https://doi. org/10.1124/jpet.116.232256

342. Steardo L Jr, Bronzuoli MR, Iacomino A, Esposito G, Steardo L, Scuderi C (2015) Does neuroinflammation turn on the flame in Alzheimer's disease? Focus on astrocytes. Front Neurosci 9:259. https://doi.org/10.3389/fnins.2015.00259

343. Strozyk D, Blennow K, White LR, Launer LJ (2003) CSF A 42 levels correlate with amyloid-neuropathology in a populationbased autopsy study. Neurology 60:652-656

344. Suárez-Calvet M, Araque Caballero MÁ, Kleinberger G, Bateman RJ, Fagan AM, Morris JC et al (2016) Early changes in CSF sTREM2 in dominantly inherited Alzheimer's disease occur after amyloid deposition and neuronal injury. Sci Transl Med 8:369ra178. https://doi.org/10.1126/scitranslmed.aag1767

345. Suárez-Calvet M, Dols-Icardo O, Lladó A, Sánchez-Valle R, Hernández I, Amer G et al (2014) Plasma phosphorylated TDP43 levels are elevated in patients with frontotemporal dementia carrying a C9orf72 repeat expansion or a GRN mutation. J Neurol Neurosurg Psychiatry 85:684-691. https://doi.org/10.1136/ jnnp-2013-305972

346. Suárez-Calvet M, Kleinberger G, Araque Caballero MÁ, Brendel M, Rominger A, Alcolea D et al (2016) sTREM2 cerebrospinal fluid levels are a potential biomarker for microglia activity in early-stage Alzheimer's disease and associate with neuronal injury markers. EMBO Mol Med 8:466-476. https://doi. org/10.15252/emmm.201506123

347. Sutphen CL, McCue L, Herries EM, Xiong C, Ladenson JH, Holtzman DM et al (2018) Longitudinal decreases in multiple cerebrospinal fluid biomarkers of neuronal injury in symptomatic late onset Alzheimer's disease. Alzheimers Dement 14:869-879. https://doi.org/10.1016/j.jalz.2018.01.012

348. Suzuki N, Cheung TT, Cai XD, Odaka A, Otvos L Jr, Eckman C et al (1994) An increased percentage of long amyloid beta 
protein secreted by familial amyloid beta protein precursor (beta APP717) mutants. Science 264:1336-1340

349. Suzuki N, Iwatsubo T, Odaka A, Ishibashi Y, Kitada C, Ihara Y (1994) High tissue content of soluble beta 1-40 is linked to cerebral amyloid angiopathy. Am J Pathol 145:452-460

350. Swardfager W, Lanctôt K, Rothenburg L, Wong A, Cappell J, Herrmann N (2010) A meta-analysis of cytokines in Alzheimer's disease. Biol Psychiatry 68:930-941. https://doi.org/10.1016/j. biopsych.2010.06.012

351. Sze CI, Bi H, Kleinschmidt-DeMasters BK, Filley CM, Martin LJ (2000) Selective regional loss of exocytotic presynaptic vesicle proteins in Alzheimer's disease brains. J Neurol Sci 175:81-90

352. Tan YJ, Ng ASL, Vipin A, Lim JKW, Chander RJ, Ji F et al (2017) Higher peripheral TREM2 mRNA levels relate to cognitive deficits and hippocampal atrophy in Alzheimer's disease and amnestic mild cognitive impairment. J Alzheimers Dis 58:413423. https://doi.org/10.3233/JAD-161277

353. Tapiola T, Alafuzoff I, Herukka SK, Parkkinen L, Hartikainen P, Soininen $\mathrm{H}$ et al (2009) Cerebrospinal fluid $\beta$-amyloid 42 and tau proteins as biomarkers of Alzheimer-type pathologic changes in the brain. Arch Neurol 66:382-389. https://doi.org/10.1001/ archneurol.2008.596

354. Tarawneh R, D'Angelo G, Crimmins D, Herries E, Griest T, Fagan AM et al (2016) Diagnostic and prognostic utility of the synaptic marker neurogranin in Alzheimer disease. JAMA Neurol 73:561-571. https://doi.org/10.1001/jamaneurol.2016.0086

355. Tarawneh R, D’Angelo G, Macy E, Xiong C, Carter D, Cairns NJ et al (2011) Visinin-like protein-1: diagnostic and prognostic biomarker in Alzheimer disease. Ann Neurol 70:274-285. https ://doi.org/10.1002/ana.22448

356. Tarawneh R, Head D, Allison S, Buckles V, Fagan AM, Ladenson $\mathrm{JH}$ (2015) Cerebrospinal fluid markers of neurodegeneration and rates of brain atrophy in early Alzheimer disease. JAMA Neurol 72:656-665. https://doi.org/10.1001/jamaneurol.2015.0202

357. Tarawneh R, Lee JM, Ladenson JH, Morris JC, Holtzman DM (2012) CSF VILIP-1 predicts rates of cognitive decline in early Alzheimer disease. Neurology 78:709-719. https://doi. org/10.1212/WNL.0b013e318248e568

358. Tatebe H, Kasai T, Ohmichi T, Kishi Y, Kakeya T, Waragai M et al (2017) Quantification of plasma phosphorylated tau to use as a biomarker for brain Alzheimer pathology: pilot case-control studies including patients with Alzheimer's disease and down syndrome. Mol Neurodegener 12:63. https://doi.org/10.1186/ s13024-017-0206-8

359. Terry RD, Masliah E, Salmon DP, Butters N, DeTeresa R, Hill $R$ et al (1991) Physical basis of cognitive alterations in Alzheimer's disease: synapse loss is the major correlate of cognitive impairment. Ann Neurol 30:572-580. https://doi.org/10.1002/ ana.410300410

360. The Ronald and Nancy Reagan Research Institute of the Alzheimer's Association and the National Institute on Aging Working Group (1998) Consensus report of the working group on: "Molecular and biochemical markers of Alzheimer's disease". Neurobiol Aging 19:109-116

361. Thorsell A, Bjerke M, Gobom J, Brunhage E, Vanmechelen E, Andreasen $\mathrm{N}$ et al (2010) Neurogranin in cerebrospinal fluid as a marker of synaptic degeneration in Alzheimer's disease. Brain Res 1362:13-22. https://doi.org/10.1016/j.brainres.2010.09.073

362. Timmers M, Barão S, Van Broeck B, Tesseur I, Slemmon J, De Waepenaert $\mathrm{K}$ et al (2017) BACE1 dynamics upon inhibition with a BACE inhibitor and correlation to downstream Alzheimer's disease markers in elderly healthy participants. J Alzheimers Dis 56:1437-1449. https://doi.org/10.3233/JAD-160829

363. Tirucherai G, Ahlijanian M, Crowell J, Kolaitis G, Skudalski S, Medlock M (2016) A single ascending dose study of the taudirected monoclonal antibody BMS-986168. Abstract presented at the 20th International Congress of Parkinson's Disease and Movement Disorders. Berlin (19-23 June 2016)

364. Tokuda T, Qureshi MM, Ardah MT, Varghese S, Shehab SA, Kasai $T$ et al (2010) Detection of elevated levels of $\alpha$-synuclein oligomers in CSF from patients with Parkinson disease. Neurology 75:1766-1772. https://doi.org/10.1212/WNL.0b013e3181 fd613b

365. Toledo JB, Arnold SE, Raible K, Brettschneider J, Xie SX, Grossman M et al (2013) Contribution of cerebrovascular disease in autopsy confirmed neurodegenerative disease cases in the National Alzheimer's Coordinating Centre. Brain 136:26972706. https://doi.org/10.1093/brain/awt188

366. Toledo JB, Korff A, Shaw LM, Trojanowski JQ, Zhang J (2013) CSF alpha-synuclein improves diagnostic and prognostic performance of CSF tau and Abeta in Alzheimer's disease. Acta Neuropathol 126:683-697. https://doi.org/10.1007/s00401-013-1148-z

367. Toledo JB, Xie SX, Trojanowski JQ, Shaw LM (2013) Longitudinal change in CSF tau and A $\beta$ biomarkers for up to 48 months in ADNI. Acta Neuropathol 126:659-670. https://doi.org/10.1007/ s00401-013-1151-4

368. Toombs J, Paterson RW, Lunn MP, Nicholas JM, Fox NC, Chapman MD et al (2013) Identification of an important potential confound in CSF AD studies: aliquot volume. Clin Chem Lab Med 51:2311-2317. https://doi.org/10.1515/cclm-2013-0293

369. Tu S, Okamoto S, Lipton SA, Xu H (2014) Oligomeric A $\beta$-induced synaptic dysfunction in Alzheimer's disease. Mol Neurodegener 9:48. https://doi.org/10.1186/1750-1326-9-48

370. Tyson T, Steiner JA, Brundin P (2016) Sorting out release, uptake and processing of alpha-synuclein during prion-like spread of pathology. J Neurochem 139(Suppl 1):275-289. https://doi. org/10.1111/jnc.13449

371. Tzen KY, Yang SY, Chen TF, Cheng TW, Horng HE, Wen HP et al (2014) Plasma A $\beta$ but not tau is related to brain PiB retention in early Alzheimer's disease. ACS Chem Neurosci 5:830 836. https://doi.org/10.1021/cn500101j

372. van Bergen JM, Li X, Hua J, Schreiner SJ, Steininger SC, Quevenco FC et al (2016) Colocalization of cerebral iron with amyloid beta in mild cognitive impairment. Sci Rep 6:35514. https://doi.org/10.1038/srep35514

373. van Oijen M, Hofman A, Soares HD, Koudstaal PJ, Breteler MM (2006) Plasma $A \beta(1-40)$ and $A \beta(1-42)$ and the risk of dementia: a prospective case-cohort study. Lancet Neurol 5:655-660. https ://doi.org/10.1016/S1474-4422(06)70501-4

374. van Rossum IA, Vos S, Handels R, Visser PJ (2010) Biomarkers as predictors for conversion from mild cognitive impairment to Alzheimer-type dementia: implications for trial design. J Alzheimers Dis 20:881-891. https://doi.org/10.3233/JAD-2010-09160 6

375. Vanderstichele H, Bibl M, Engelborghs S, Le Bastard N, Lewczuk P, Molinuevo JL et al (2012) Standardization of preanalytical aspects of cerebrospinal fluid biomarker testing for Alzheimer's disease diagnosis: a consensus paper from the Alzheimer's Biomarkers Standardization Initiative. Alzheimers Dement 8:65-73. https://doi.org/10.1016/j.jalz.2011.07.004

376. Vassar R, Kuhn PH, Haass C, Kennedy ME, Rajendran L, Wong $P C$ et al (2014) Function, therapeutic potential and cell biology of BACE proteases: current status and future prospects. J Neurochem 130:4-28. https://doi.org/10.1111/jnc.12715

377. Verberk IMW, Slot RE, Verfaillie SCJ, Heijst H, Prins ND, van Berckel BNM et al (2018) Plasma amyloid as prescreener for the earliest Alzheimer pathological changes. Ann Neurol. https ://doi.org/10.1002/ana.25334

378. Vickers JC, Riederer BM, Marugg RA, Buee-Scherrer V, Buee L, Delacourte A et al (1994) Alterations in neurofilament protein immunoreactivity in human hippocampal neurons 
related to normal aging and Alzheimer's disease. Neuroscience 62:1-13

379. Villemagne VL, Burnham S, Bourgeat P, Brown B, Ellis KA, Salvado $O$ et al (2013) Amyloid $\beta$ deposition, neurodegeneration, and cognitive decline in sporadic Alzheimer's disease: a prospective cohort study. Lancet Neurol 12:357-367. https://doi. org/10.1016/S1474-4422(13)70044-9

380. Vivacqua G, Latorre A, Suppa A, Nardi M, Pietracupa S, Mancinelli R et al (2016) Abnormal salivary total and oligomeric alpha-synuclein in Parkinson's disease. PLoS One 11:e0151156. https://doi.org/10.1371/journal.pone.0151156

381. Wang MJ, Yi S, Han JY, Park SY, Jang JW, Chun IK et al (2017) Oligomeric forms of amyloid- $\beta$ protein in plasma as a potential blood-based biomarker for Alzheimer's disease. Alzheimers Res Ther 9:98. https://doi.org/10.1186/s13195-017-0324-0

382. Wang Y, Shi M, Chung KA, Zabetian CP, Leverenz JB, Berg D et al (2012) Phosphorylated $\alpha$-synuclein in Parkinson's disease. Sci Transl Med 4:121ra120. https://doi.org/10.1126/scitranslm ed.3002566

383. Waragai M, Yoshida M, Mizoi M, Saiki R, Kashiwagi K, Takagi $\mathrm{K}$ et al (2012) Increased protein-conjugated acrolein and amyloid- $\beta 40 / 42$ ratio in plasma of patients with mild cognitive impairment and Alzheimer's disease. J Alzheimers Dis 32:33-41. https://doi.org/10.3233/JAD-2012-120253

384. Wennström M, Surova Y, Hall S, Nilsson C, Minthon L, Hansson $\mathrm{O}$ et al (2015) The inflammatory marker YKL-40 is elevated in cerebrospinal fluid from patients with Alzheimer's but not Parkinson's disease or dementia with Lewy bodies. PLoS One 10:e0135458. https://doi.org/10.1371/journal.pone.0135458

385. Weston PSJ, Poole T, Ryan NS, Nair A, Liang Y, Macpherson $\mathrm{K}$ et al (2017) Serum neurofilament light in familial Alzheimer disease: a marker of early neurodegeneration. Neurology 89(21):2167-2175

386. Willemse E, van Uffelen K, Brix B, Engelborghs S, Vanderstichele H, Teunissen C (2017) How to handle adsorption of cerebrospinal fluid amyloid $\beta$ (1-42) in laboratory practice? Identifying problematic handlings and resolving the issue by use of the A $\beta 42 / \mathrm{A} \beta 40$ ratio. Alzheimers Dement 13:885-892. https:// doi.org/10.1016/j.jalz.2017.01.010

387. Williams SM, Schulz P, Rosenberry TL, Caselli RJ, Sierks MR (2017) Blood-based oligomeric and other protein variant biomarkers to facilitate pre-symptomatic diagnosis and staging of Alzheimer's disease. J Alzheimers Dis 58:23-35. https://doi. org/10.3233/jad-161116

388. Wiltfang J, Esselmann H, Bibl M, Hüll M, Hampel H, Kessler $\mathrm{H}$ et al (2007) Amyloid $\beta$ peptide ratio $42 / 40$ but not $\mathrm{A} \beta 42$ correlates with phospho-tau in patients with low- and high-CSF Aß40 load. J Neurochem 101:1053-1059. https://doi.org/10.11 11/j.1471-4159.2006.04404.x

389. Winston CN, Goetzl EJ, Akers JC, Carter BS, Rockenstein EM, Galasko D et al (2016) Prediction of conversion from mild cognitive impairment to dementia with neuronally derived blood exosome protein profile. Alzheimers Dement (Amst) 3:63-72. https://doi.org/10.1016/j.dadm.2016.04.001

390. Wiseman FK, Al-Janabi T, Hardy J, Karmiloff-Smith A, Nizetic D, Tybulewicz VL et al (2015) A genetic cause of Alzheimer disease: mechanistic insights from Down syndrome. Nat Rev Neurosci 16:564-574. https://doi.org/10.1038/nrn3983

391. World Health Organization (2017) Dementia factsheet. http:// www.who.int/mediacentre/factsheets/fs362/en/. Accessed August 2017

392. Wu G, Sankaranarayanan S, Tugusheva K, Kahana J, Seabrook G, Shi XP et al (2008) Decrease in age-adjusted cerebrospinal fluid $\beta$-secretase activity in Alzheimer's subjects. Clin Biochem 41:986-996. https://doi.org/10.1016/j.clinbiochem.2008.04.022
393. Wu G, Sankaranarayanan S, Wong J, Tugusheva K, Michener MS, Shi X et al (2012) Characterization of plasma $\beta$-secretase (BACE1) activity and soluble amyloid precursor proteins as potential biomarkers for Alzheimer's disease. J Neurosci Res 90:2247-2258. https://doi.org/10.1002/jnr.23122

394. Yan R (2017) Physiological functions of the $\beta$-site amyloid precursor protein cleaving enzyme 1 and 2. Front Mol Neurosci 10:97. https://doi.org/10.3389/fnmol.2017.00097

395. Yang CC, Chiu MJ, Chen TF, Chang HL, Liu BH, Yang SY (2018) Assay of plasma phosphorylated tau protein (threonine 181) and total tau protein in early-stage Alzheimer's disease. J Alzheimers Dis 61:1323-1332. https://doi.org/10.3233/JAD-170810

396. Yang T, O’Malley TT, Kanmert D, Jerecic J, Zieske LR, Zetterberg $\mathrm{H}$ et al (2015) A highly sensitive novel immunoassay specifically detects low levels of soluble Abeta oligomers in human cerebrospinal fluid. Alzheimers Res Ther 7:14. https:// doi.org/10.1186/s13195-015-0100-y

397. Yoshiyama Y, Higuchi M, Zhang B, Huang SM, Iwata N, Saido TC et al (2007) Synapse loss and microglial activation precede tangles in a P301S tauopathy mouse model. Neuron 53:337-351. https://doi.org/10.1016/j.neuron.2007.01.010

398. Yuan A, Rao MV, Veeranna Nixon RA (2012) Neurofilaments at a glance. J Cell Sci 125:3257-3263. https://doi.org/10.1242/ jcs.104729

399. Yuan A, Rao MV, Veeranna Nixon RA (2017) Neurofilaments and neurofilament proteins in health and disease. Cold Spring Harb Perspect Biol 9:a018309. https://doi.org/10.1101/cshpe rspect.a018309

400. Yuan P, Condello C, Keene CD, Wang Y, Bird TD, Paul SM et al (2016) TREM2 haplodeficiency in mice and humans impairs the microglia barrier function leading to decreased amyloid compaction and severe axonal dystrophy. Neuron 92:252-264. https:// doi.org/10.1016/j.neuron.2016.09.016

401. Zetterberg H, Andreasson U, Hansson O, Wu G, Sankaranarayanan S, Andersson ME et al (2008) Elevated cerebrospinal fluid BACE1 activity in incipient Alzheimer disease. Arch Neurol 65:1102-1107. https://doi.org/10.1001/archneur.65.8.1102

402. Zetterberg H, Pedersen M, Lind K, Svensson M, Rolstad S, Eckerström C et al (2007) Intra-individual stability of CSF biomarkers for Alzheimer's disease over two years. J Alzheimers Dis 12:255-260

403. Zetterberg H, Skillbäck T, Mattsson N, Trojanowski JQ, Portelius E, Shaw LM et al (2016) Association of cerebrospinal fluid neurofilament light concentration with Alzheimer disease progression. JAMA Neurol 73:60-67. https://doi.org/10.1001/jaman eurol.2015.3037

404. Zetterberg H, Wilson D, Andreasson U, Minthon L, Blennow K, Randall J et al (2013) Plasma tau levels in Alzheimer's disease. Alzheimers Res Ther 5:9. https://doi.org/10.1186/alzrt163

405. Zhang B, Carroll J, Trojanowski JQ, Yao Y, Iba M, Potuzak JS et al (2012) The microtubule-stabilizing agent, epothilone D, reduces axonal dysfunction, neurotoxicity, cognitive deficits, and Alzheimer-like pathology in an interventional study with aged tau transgenic mice. J Neurosci 32:3601-3611. https://doi. org/10.1523/jneurosci.4922-11.2012

406. Zhang QS, Heng Y, Yuan YH, Chen NH (2017) Pathological $\alpha$-synuclein exacerbates the progression of Parkinson's disease through microglial activation. Toxicol Lett 265:30-37. https:// doi.org/10.1016/j.toxlet.2016.11.002

407. Zhong Z, Ewers M, Teipel S, Bürger K, Wallin A, Blennow K et al (2007) Levels of $\beta$-secretase (BACE1) in cerebrospinal fluid as a predictor of risk in mild cognitive impairment. Arch Gen Psychiatry 64:718-726. https://doi.org/10.1001/archpsyc.64.6.718

408. Zhou W, Zhang J, Ye F, Xu G, Su H, Su Y et al (2017) Plasma neurofilament light chain levels in Alzheimer's disease. Neurosci Lett 650:60-64. https://doi.org/10.1016/j.neulet.2017.04.027 


\section{Affiliations}

José Luis Molinuevo ${ }^{1,2} \cdot$ Scott Ayton $^{3} \cdot$ Richard Batrla $^{4} \cdot$ Martin M. Bednar $^{5} \cdot$ Tobias Bittner $^{6} \cdot$ Jeffrey Cummings $^{7}$. Anne M. Fagan ${ }^{8} \cdot$ Harald Hampel $^{9,10,11,12} \cdot$ Michelle M. Mielke $^{13} \cdot$ Alvydas Mikulskis $^{14} \cdot$ Sid O$^{\prime}$ Bryant $^{15}$. Philip Scheltens ${ }^{16}$. Jeffrey Sevigny ${ }^{17}$. Leslie M. Shaw ${ }^{18} \cdot$ Holly D. Soares ${ }^{19} \cdot$ Gary Tong $^{20} \cdot$ John Q. Trojanowski $^{21}$. Henrik Zetterberg $22,23,24,25 \cdot$ Kaj Blennow ${ }^{22,23}$

1 BarcelonaBeta Brain Research Center, Fundació Pasqual Maragall, Universitat Pompeu Fabra, Barcelona, Spain

2 Unidad de Alzheimer y otros trastornos cognitivos, Hospital Clinic-IDIBAPS, Barcelona, Spain

3 Melbourne Dementia Research Centre, Florey Institute of Neuroscience and Mental Health, University of Melbourne, Parkville, VIC, Australia

4 Roche Centralised and Point of Care Solutions, Roche Diagnostics International, Rotkreuz, Switzerland

5 Neuroscience Therapeutic Area Unit, Takeda Development Centre Americas Ltd, Cambridge, MA, USA

6 Genentech, A Member of the Roche Group, Basel, Switzerland

7 Cleveland Clinic Lou Ruvo Center for Brain Health, Las Vegas, NV, USA

8 Department of Neurology, Washington University in St. Louis, St. Louis, MO, USA

9 AXA Research Fund and Sorbonne University Chair, Paris, France

10 Sorbonne University, GRC No 21, Alzheimer Precision Medicine (APM), AP-HP, Pitié-Salpêtrière Hospital, Paris, France

11 Brain and Spine Institute (ICM), INSERM U 1127, CNRS UMR 7225, Paris, France

12 Department of Neurology, Institute of Memory and Alzheimer's Disease (IM2A), Pitié-Salpêtrière Hospital, AP-HP, Paris, France

13 Departments of Epidemiology and Neurology, Mayo Clinic, Rochester, MN, USA

14 Biomarkers, Biogen, Cambridge, MA, USA
15 Department of Pharmacology and Neuroscience; Institute for Healthy Aging, University of North Texas Health Science Center, Fort Worth, TX, USA

16 Department of Neurology and Alzheimer Center, VU University Medical Center, Amsterdam, The Netherlands

17 Roche Innovation Center Basel, F. Hoffmann-La Roche, Basel, Switzerland

18 Department of Pathology and Laboratory Medicine, and Center for Neurodegenerative Disease Research, University of Pennsylvania, Philadelphia, PA, USA

19 Clinical Development Neurology, AbbVie, North Chicago, IL, USA

20 Lundbeck, Deerfield, IL, USA

21 Department of Pathology and Laboratory Medicine, Center for Neurodegenerative Disease Research, Perelman School of Medicine at the University of Pennsylvania, Philadelphia, PA, USA

22 Department of Psychiatry and Neurochemistry, The Sahlgrenska Academy at the University of Gothenburg, Mölndal, Sweden

23 Clinical Neurochemistry Laboratory, Institute of Neuroscience and Physiology, The Sahlgrenska Academy at University of Gothenburg, Mölndal Campus, Sahlgrenska University Hospital, 43180 Mölndal, Sweden

24 Department of Molecular Neuroscience, UCL Institute of Neurology, Queen Square, London, UK

25 UK Dementia Research Institute at UCL, London, UK 